\title{
من المقاربة الفقهية إلى المقاربة الأخلاقية: الاجتهاد المعاصر والجينوم نموذجًا
}

\author{
معتز الخطيب

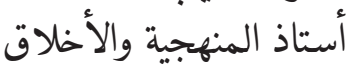 \\ كلية الدراسات الإسلامية، ومركز دراسات التشريع الإسلامي والأخلاق \\ جامعة حمد بن خليفة \\ malkhatib@hbku.edu.qa
}

\section{الخلاصة}

تثير العلاقة يين الفقه والأخلاق_-بوصفهما حقلين مستقلينسالكثير من التساؤلات

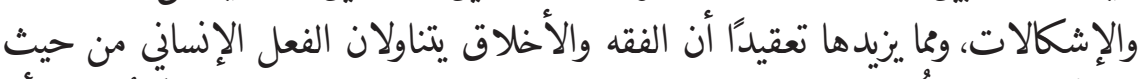

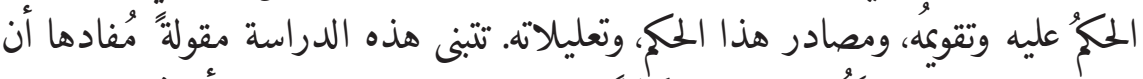

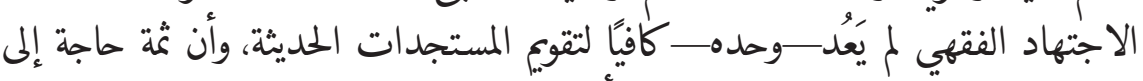

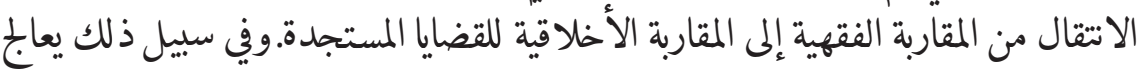

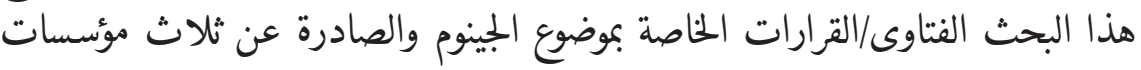

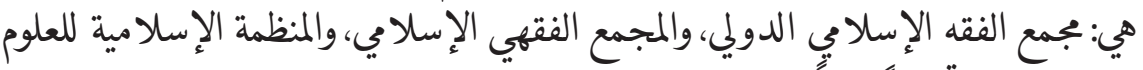

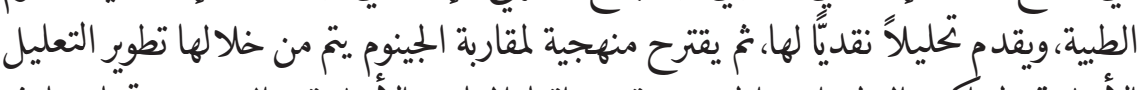

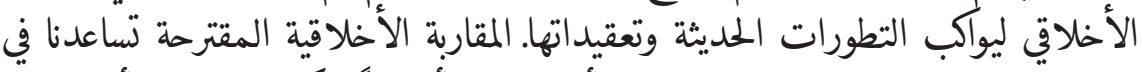

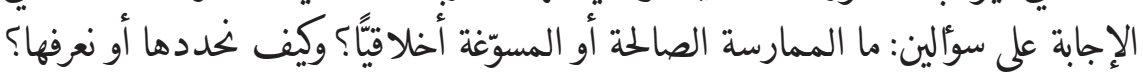

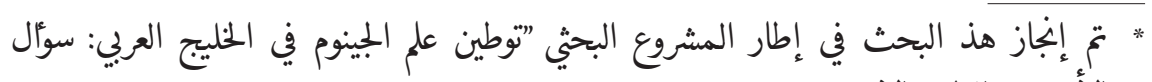
الأخلاق الطبية الإسلامية (Indigenizing Genomics in the Gulf Region (IGGR): The Missing) (Islamic Bioethical Discourse

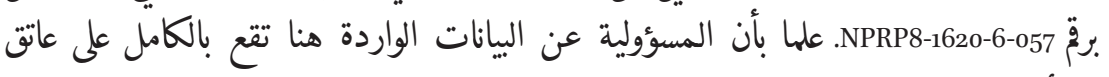


وهي مقاربة أوسع من فكرة البحث عن "حكم الله، بالمنطق الفقهي، وهي مقاربة متعددة

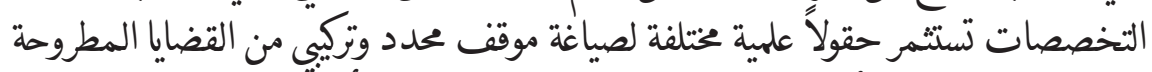

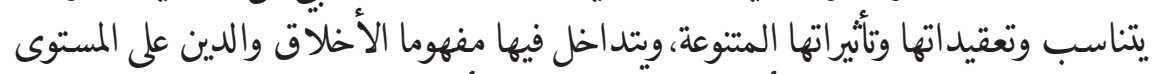

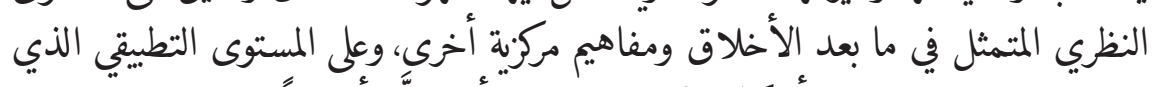

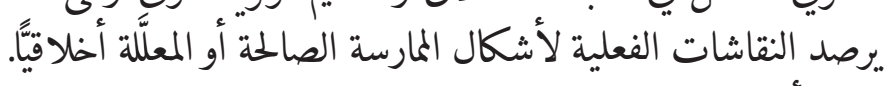

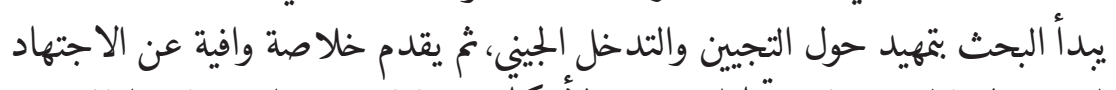

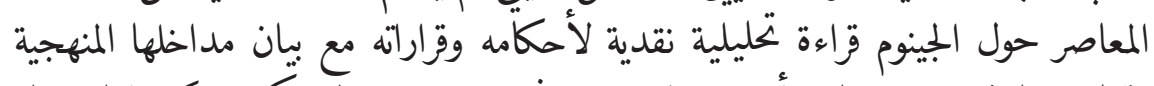

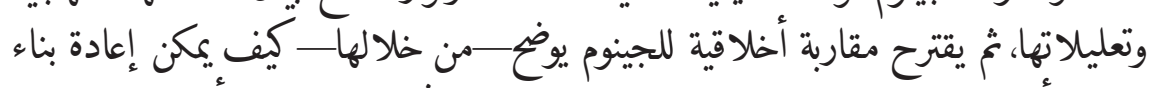

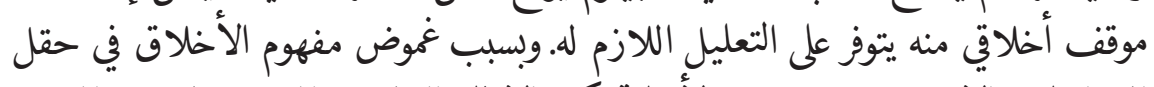

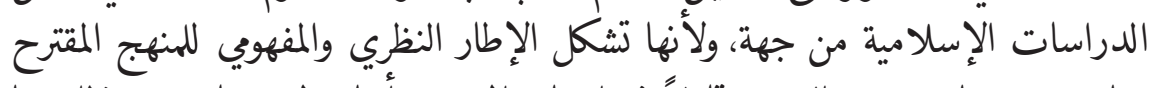

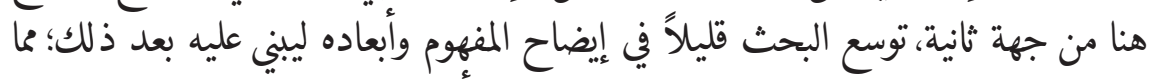
يساعد على إدراك بعض جوانب الفرق بين الفقه والأخلاق.

\section{الكملمات المفتاحية}

الإنسانية - المصاد - الأخلاق الإسلامية - الجينوم - التعليل الأخلاقي - التدخل الجيني - الطبيعة

مقدمة

تثير العلاقة بين الفقه والأخلاق_-بوصفهما حقلين مستقلين -الكثير من

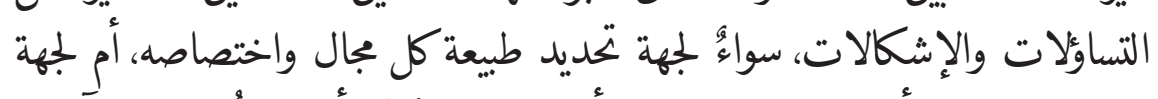

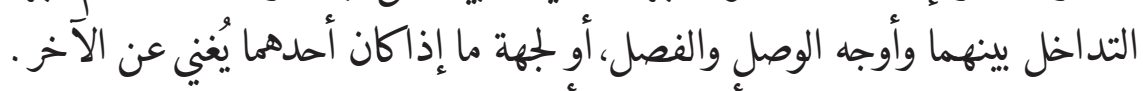

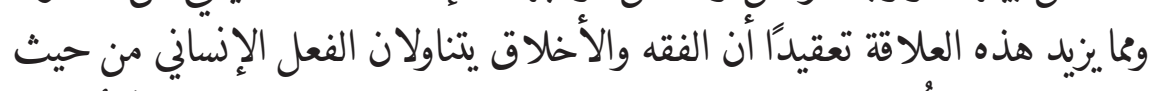

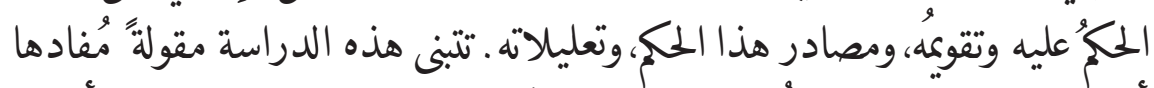

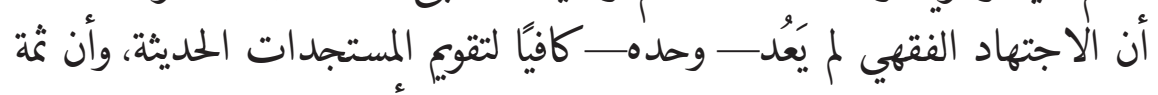

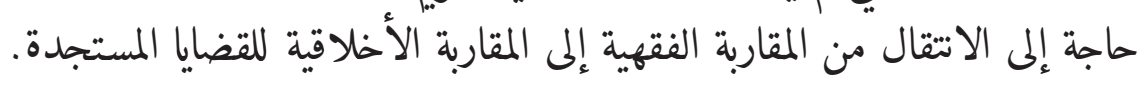

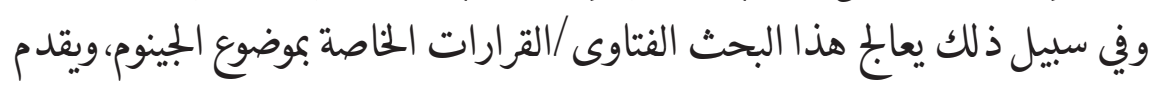

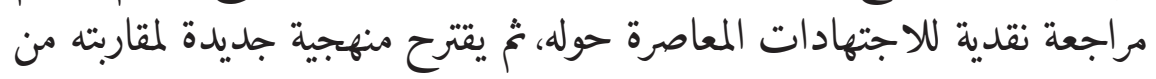


أجل إعادة بناء موقف أخلاقي منه، ويتم من خلال هذه المنهجية تطوير التعليل

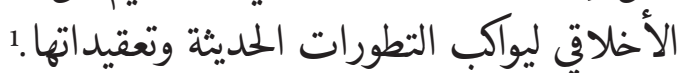
وفي المقاربة الأخلاقية المقترحة يتداخل مفهوما الأخلاق والدين على ولمئل مستوينين:

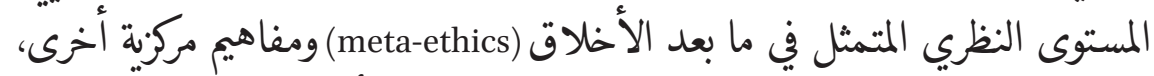

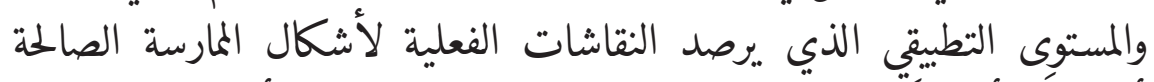

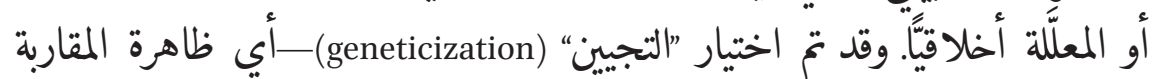

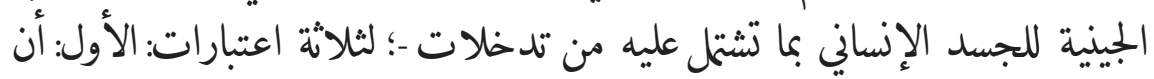

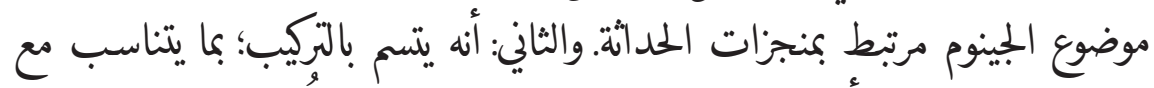

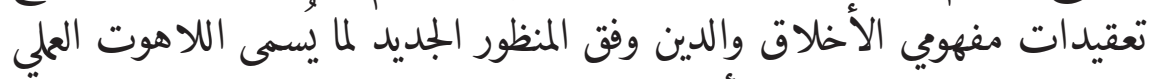

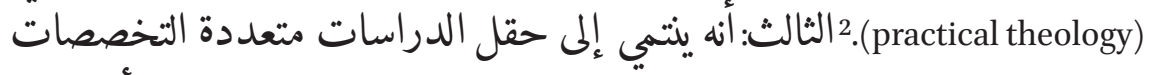
(interdisciplinary) والأخلاقيات الطية، والبيولوجيا، واجتاعيات الطب، والفقه الإسلامي وغيرها.

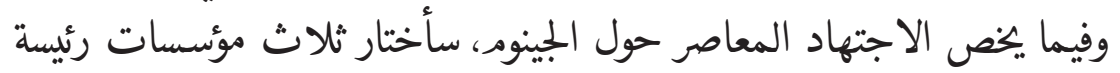
تصدت لهذا الموضوع هي: ممع الفقه الإسلائ الدولي في جدة الذي يضمد فقهاء

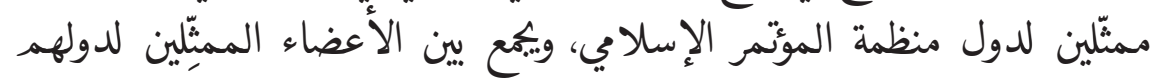

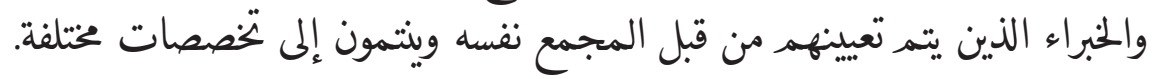

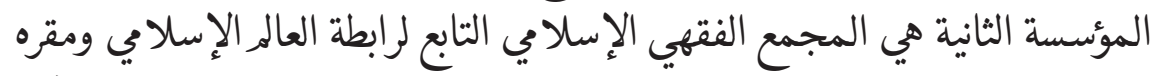

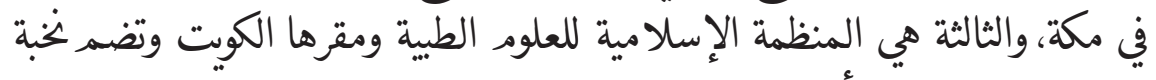

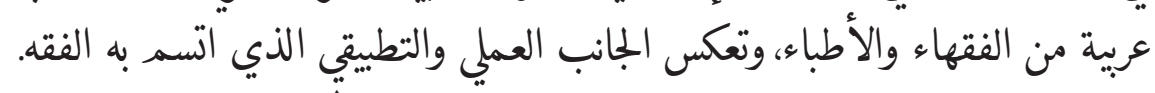

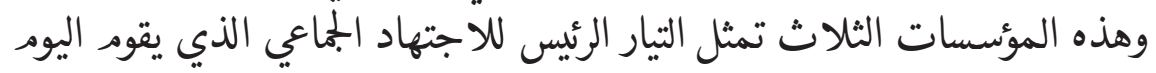
مقام المذاهب الفقهية في القضايا المستجدة.

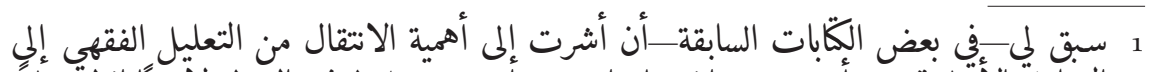

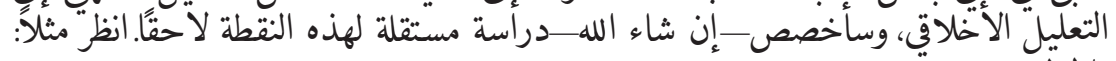

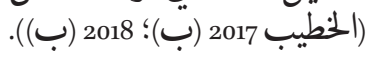

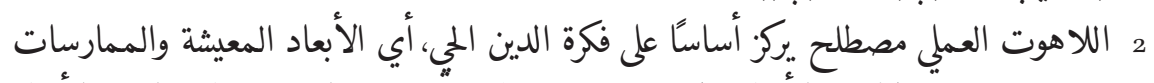

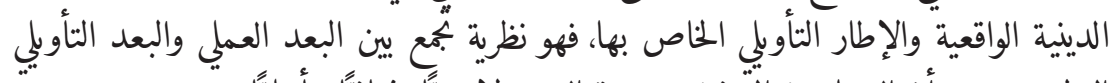

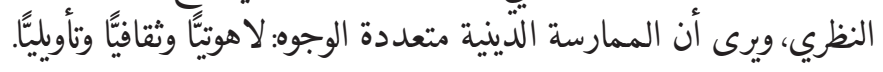




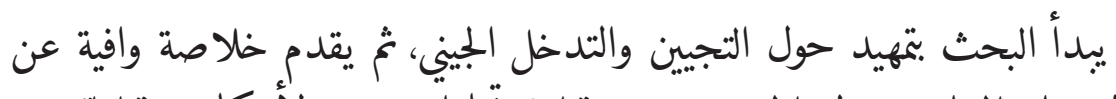

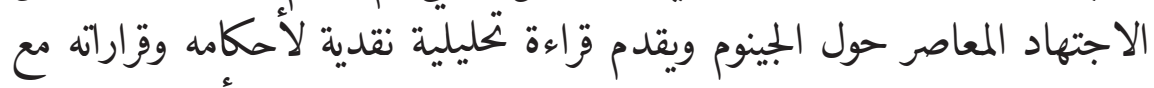

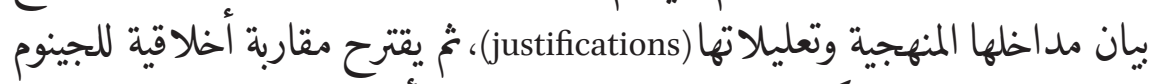
يوضح-من خلالها- كيف يمكن إعادة بناء موقف أخلاقي منه يتوفز على التعليل

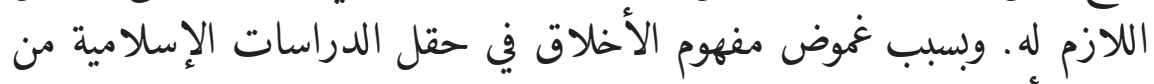

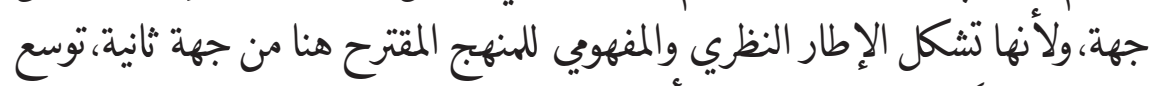

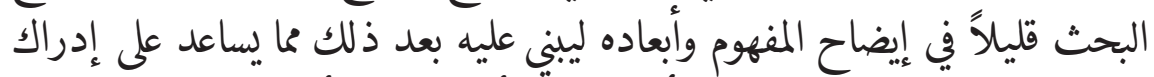

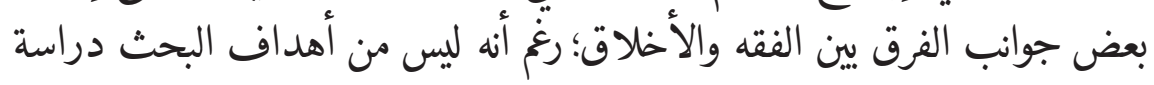
هذه العلاقة نفسها واستيفاء إشكانلاتها.

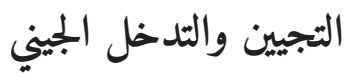

1

الجينوم هو بجموع المادة الوراثية في الخلية الجسمية الواحدة لجسم الإنسان، وهو

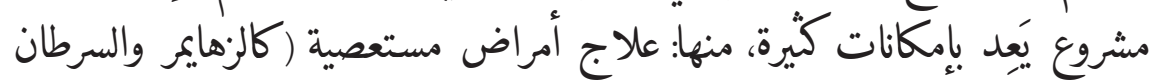

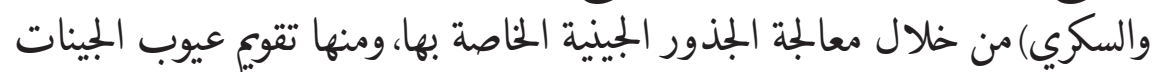

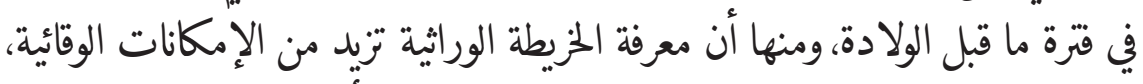

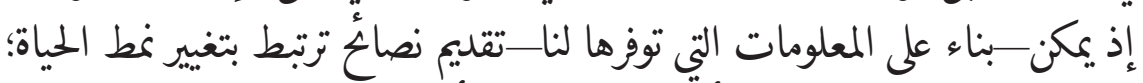

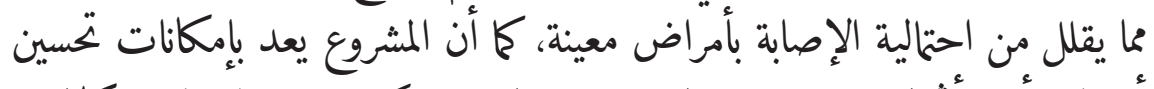

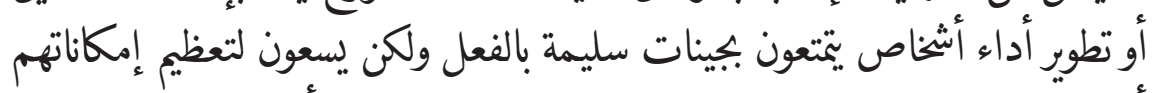

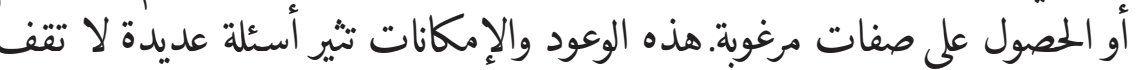

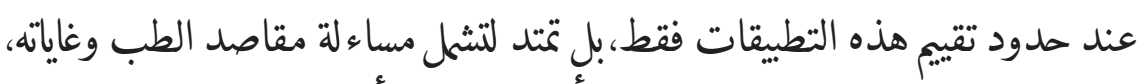
ومقاصد مشروع الجينوم نفسه (علاج أو تطوير؟)، وتأثير كل ذلك فئ على ألى المسؤولية

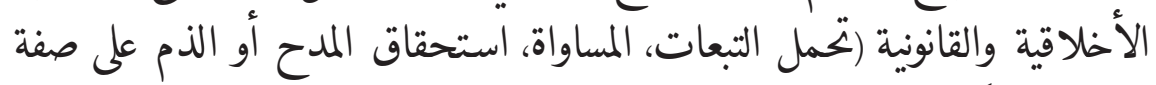

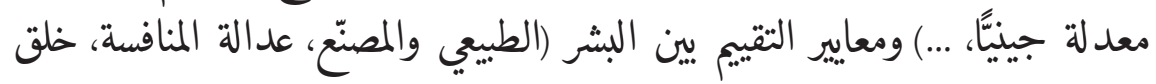

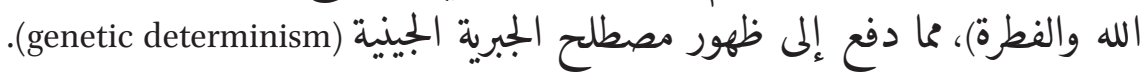

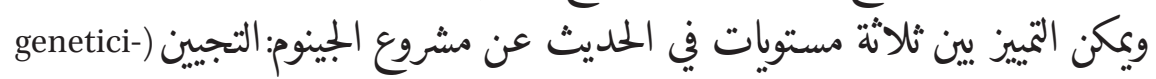
(zation والتدخل الجيني (genetic intervention) والتحسين الجيني (enhancement). 
فبالتجيين" هو المفهوم الأشمل والمركزي بين الثلاثة، وينضوي تحته أنواع محتلفة من

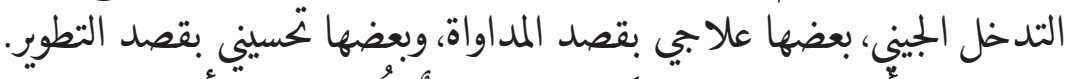

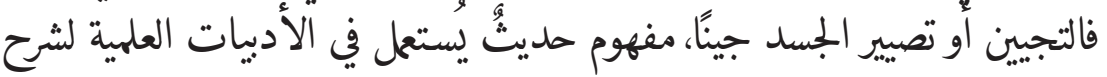

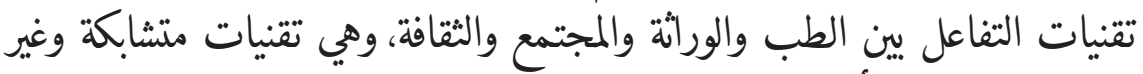

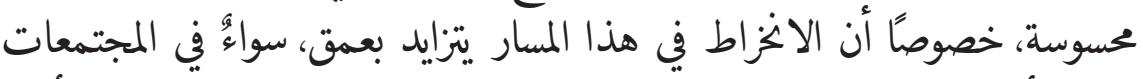

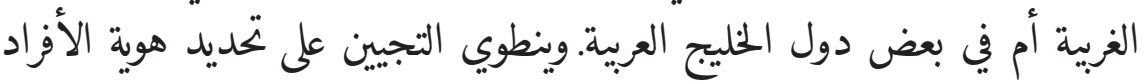

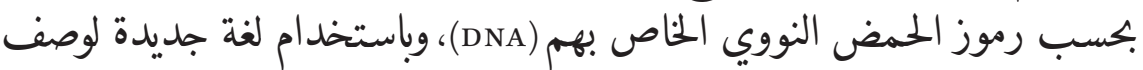
حاة الإنسان وسلوك بواسطة مفردات جينية هي عبارة عن رموز ومخططات

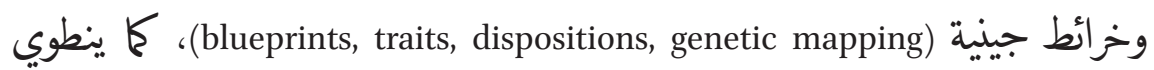

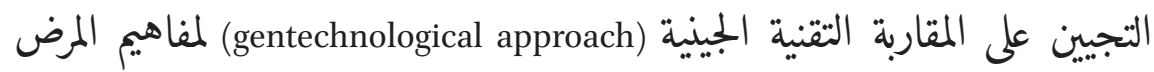

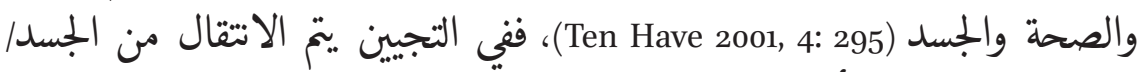
العضو إلى الجينات، أي من الظاهر إلى الباطن الذي صار ظاهرًا.

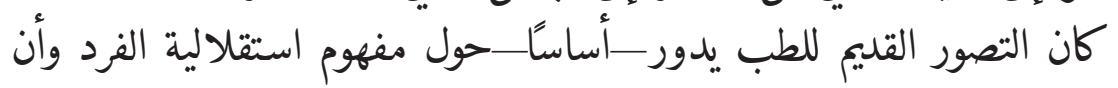

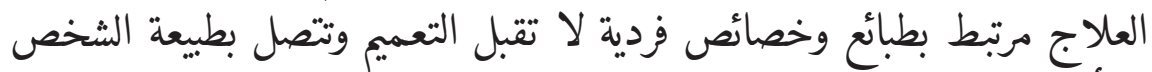

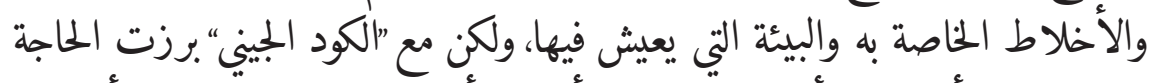

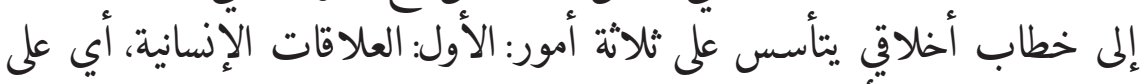

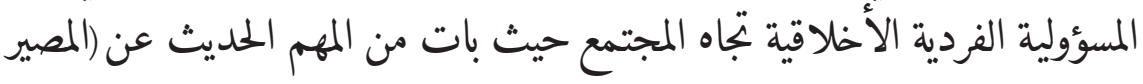
الجماعي) للبشر، والثاني: سلطة الطب وحدودها، والثالث: السيات الثقافي الذي الثي

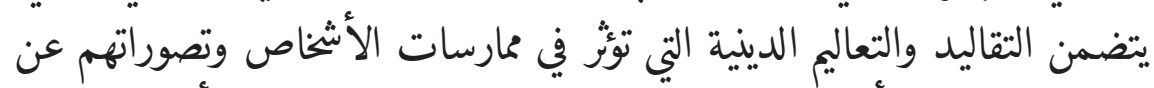

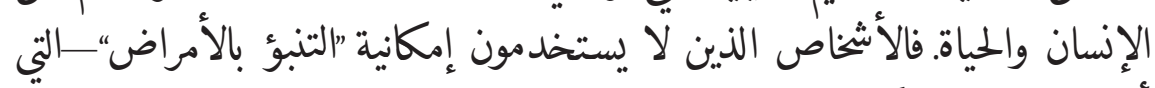

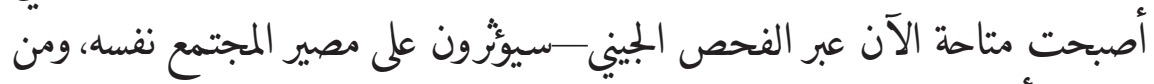

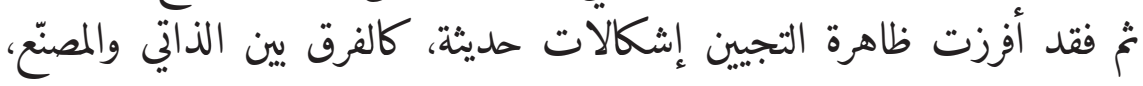
والطييجي وغير الطيبي،،وغير ذلك.3وقد تمت مناقشة هذه الظاهرة في السياق الغربي

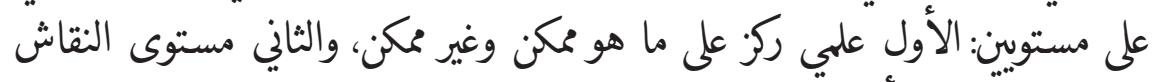

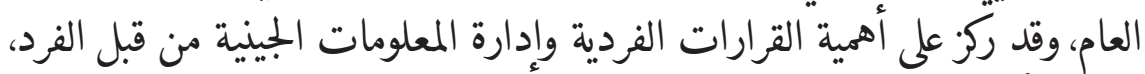

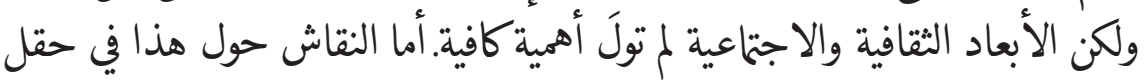

3 المريد حول الإشكالات الأخلاقية والفلسفية التي يثيرها الجينوم انظر: (الخطيب 2019، 51-57). 
الأخلاق فإنه يأخذنا إلى نقاط إضافية من قييل أنه في السيات العليي ثمة رغبة سريعة

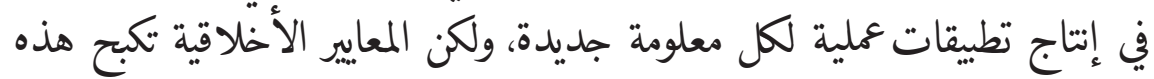

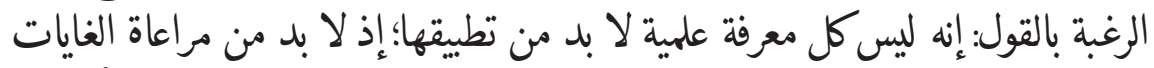

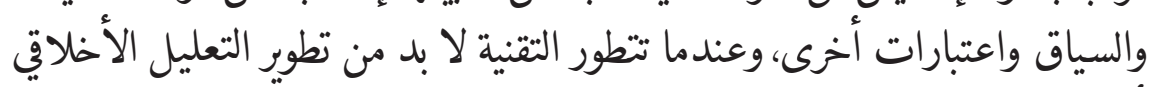
أيضًا حتى تتمن من الحكم على هذه التطارات التطورات وتقيمها.

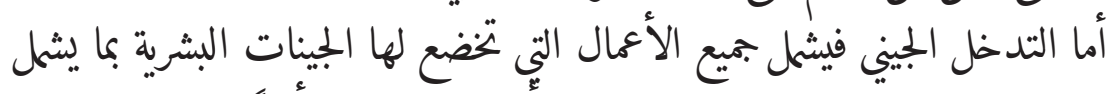

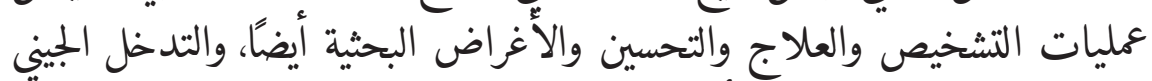

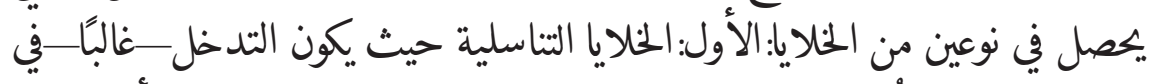

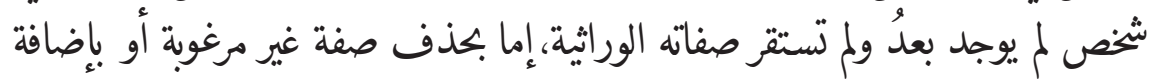

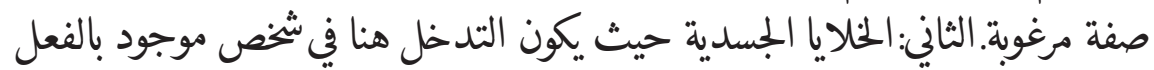
وقد استقرت صفاته، كالمولود حديثًا.

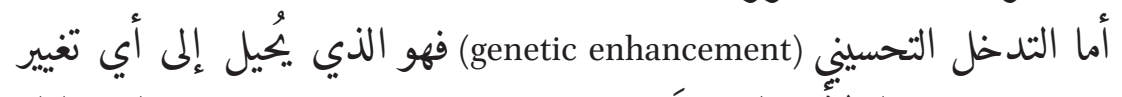

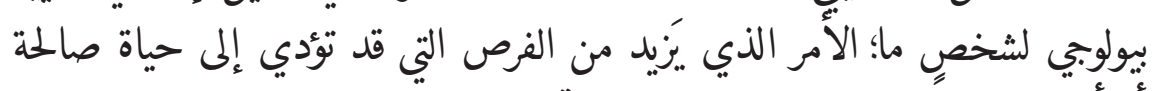

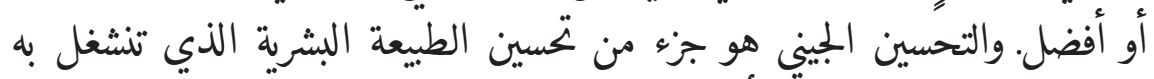
مجالات معرفية متعددة كأخلاق المعالجة الجينينة (ethics of gene therapy)،

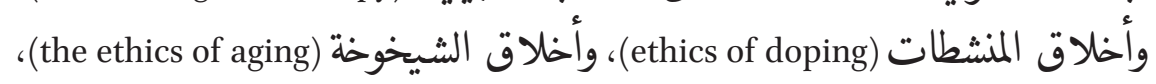

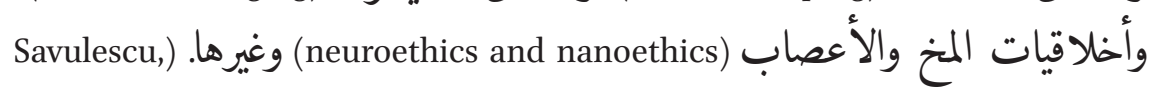
.(Sandberg, and Kahane 2011, 7

\section{الاجتهاد الفقهي وموضوع الجينوم}

يقف الفقيه أمام تحدِ حقيتي في ممارسة عملية الاجتهاد في الزمن الحديث؛ بتعقيداته

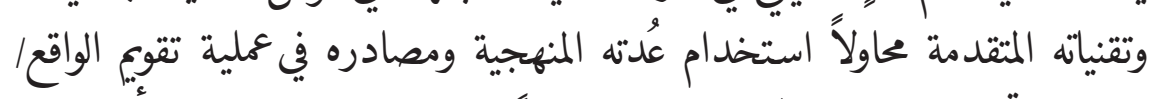

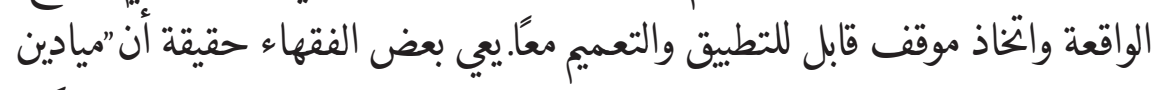

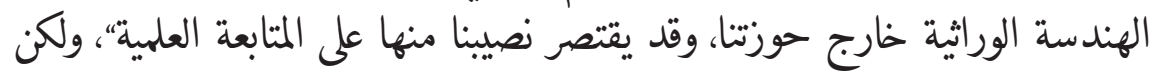

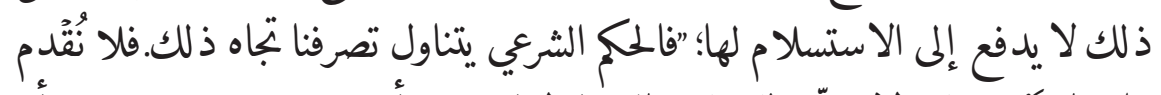

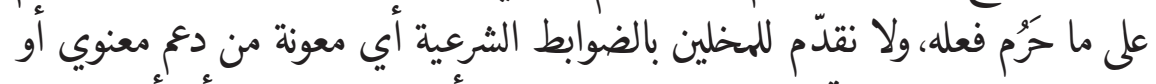

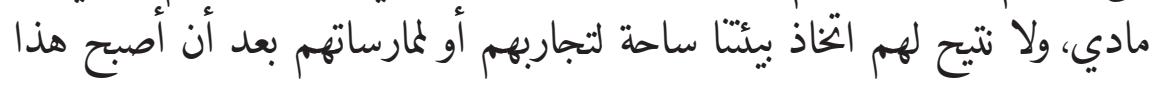


ميسورًا في عصر العلمنة والهيمنة" (أبو غدة 2000، 577). فكيف نوقش موضوع الجينات

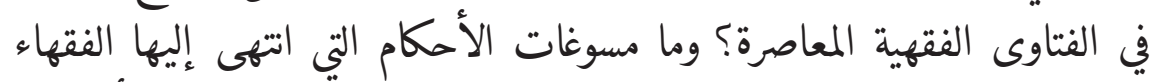

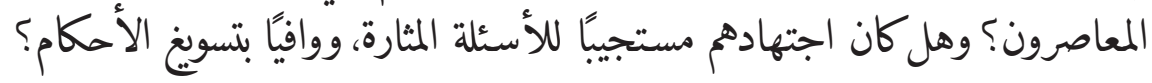
وما المنهجية التي اتبعوها في ذلك اصنك

\section{الا هتمام بالجينوم وسياقه}

لقي هذا الموضوع اهتمامًا واضحًا من الجهات الثمات الثلاث الرئيسة التي اخترناها موضوعًا

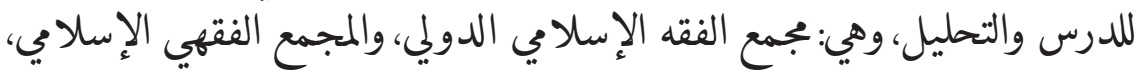

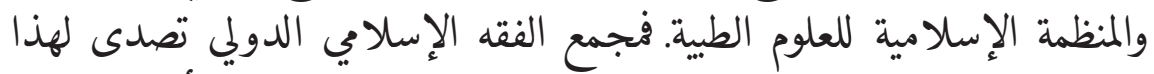

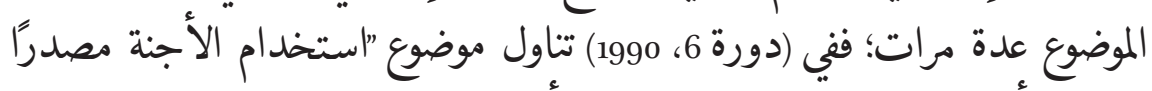

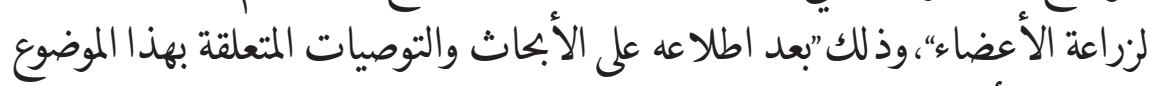

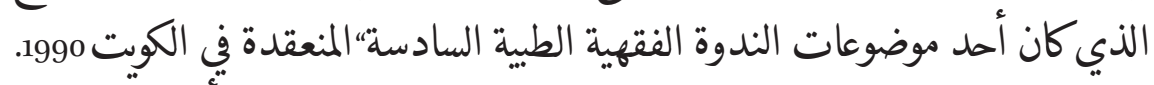

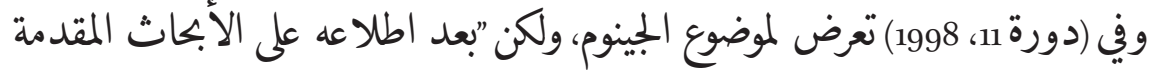

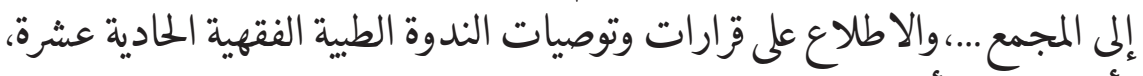

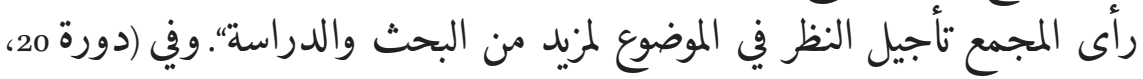

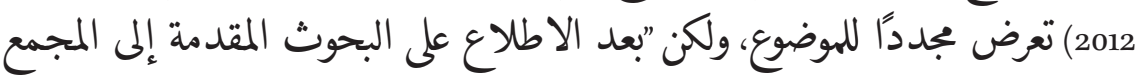

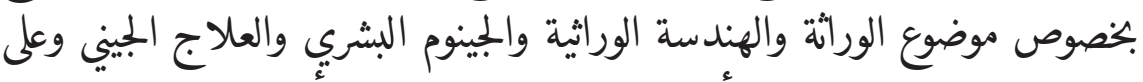

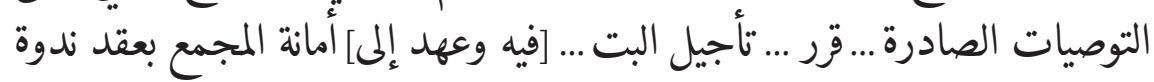
متخصعة للإعداد لدراسة الموضوع دراسة وافية ورفع ما تخرج به من توصيات

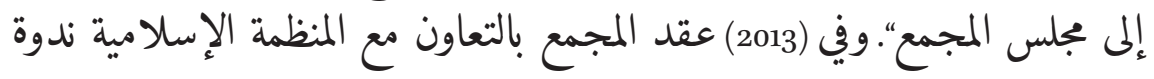

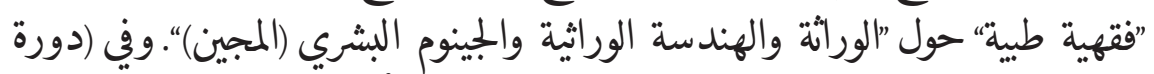

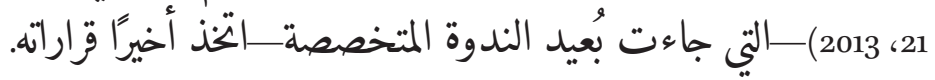
وتتاول المجمع الفقهي الإسلامي بمكة المكرمة هذا الموضوع في دورتين أيضًا:

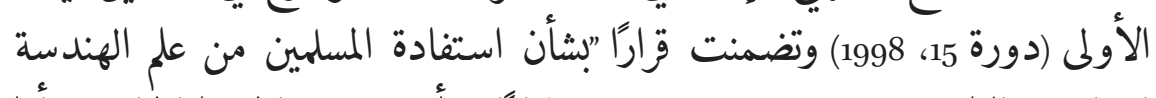

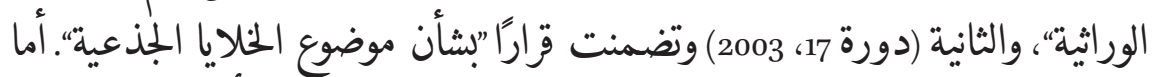
المنظمة الإسلامية للعلوم الطبية فقد عقدت ندوة فورة في (الكويت أكتوبر 1998) تحت

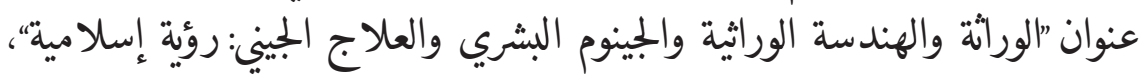

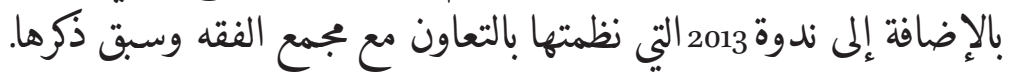


وقد أوضح عبد الستار أبو غدة-ـفي بحثه الذي قدمه لندوة المنظمة سنة 1998-

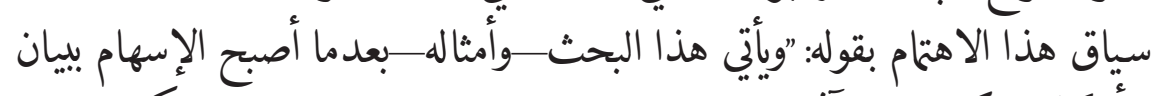

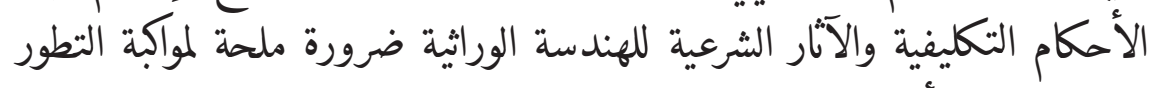

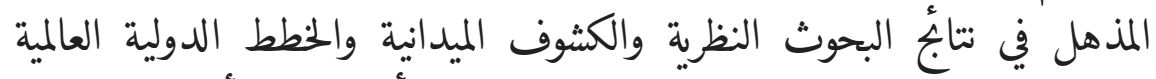

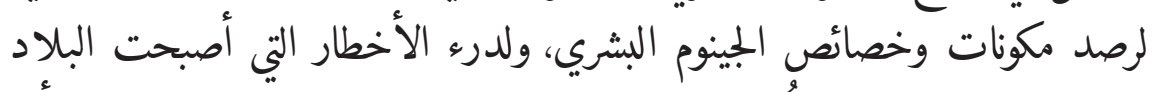

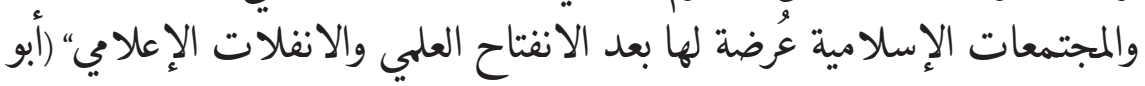
غدة 2000، 574-575).

$$
\text { القرارات البممعية حول الجينوم }
$$

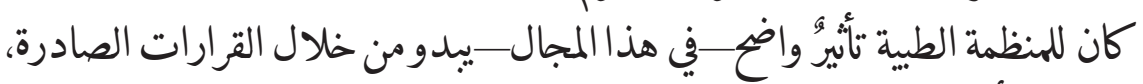

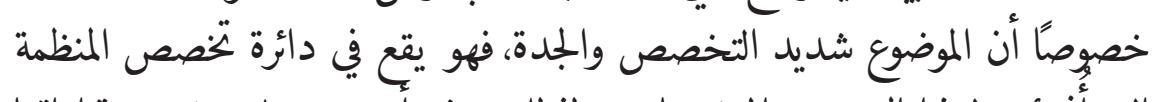

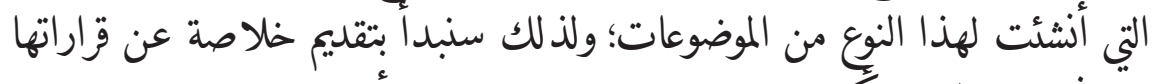

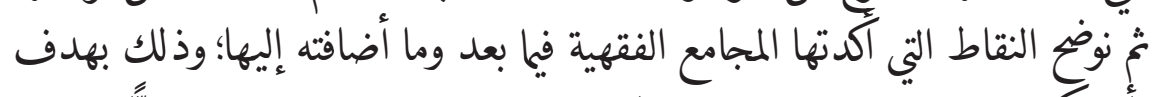

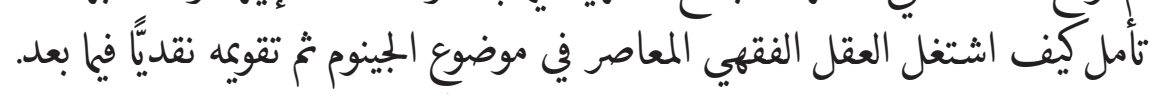

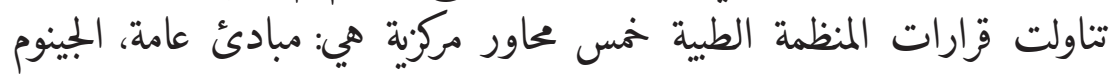

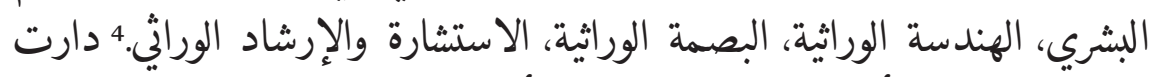

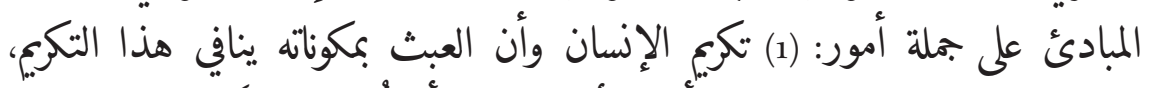

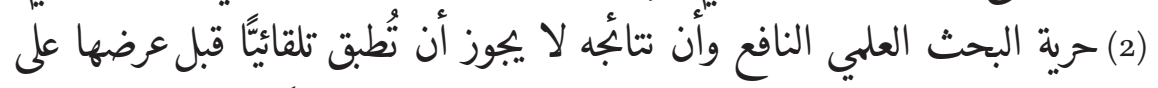

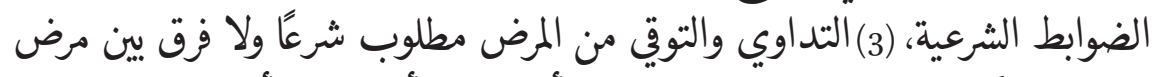

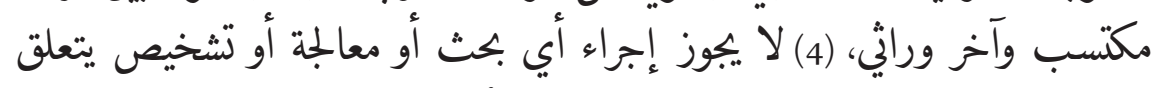

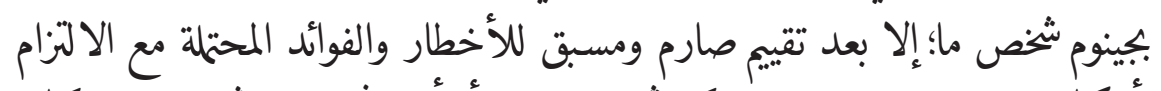

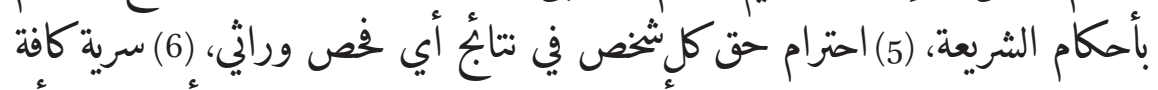

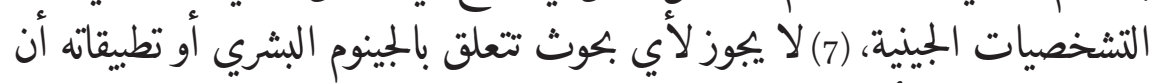

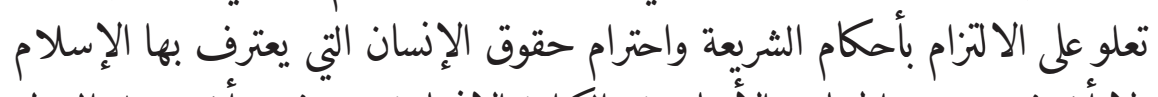

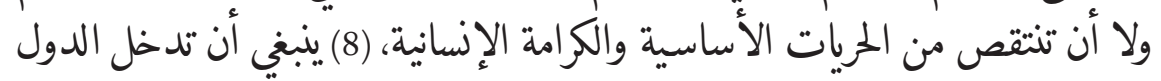

4 عقدت هذه الندوة تحت عنوان "الورائة والهندسة الوراثية والجينوه البشري" في الكويت 13-1998/10/15 (الجندي 2000، 1045-1049). 


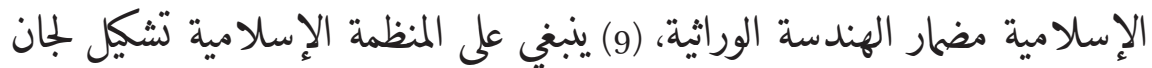

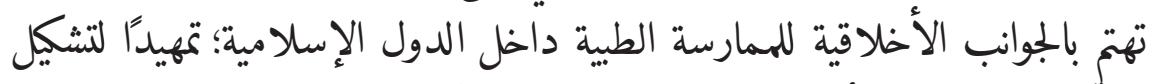

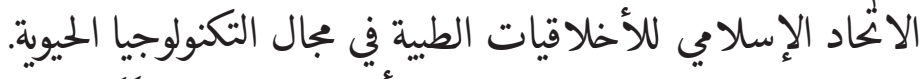

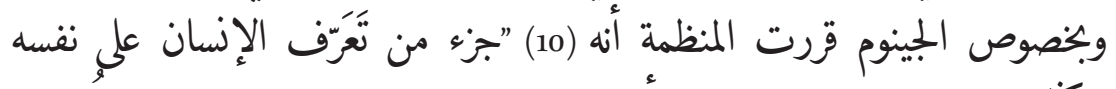

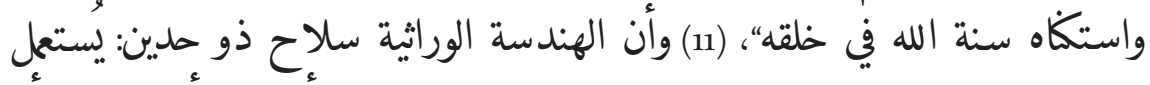

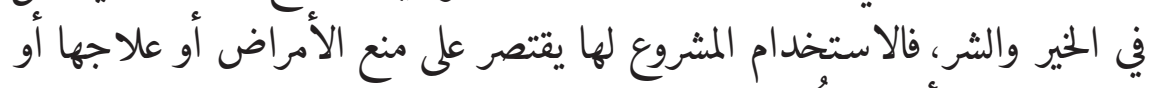

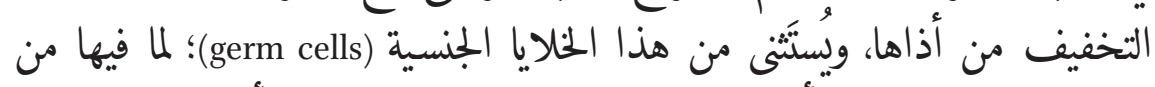

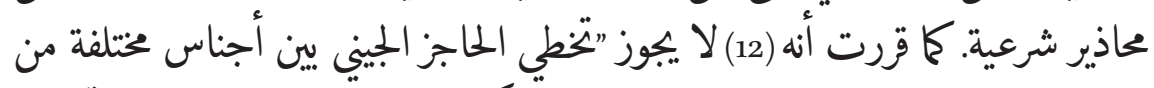

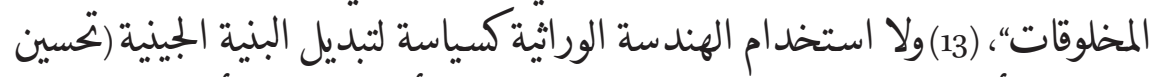

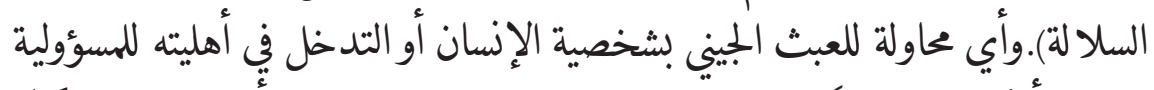

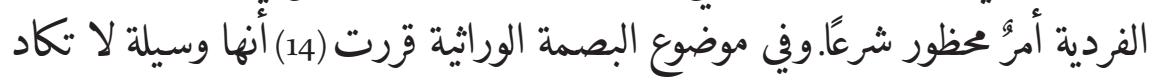

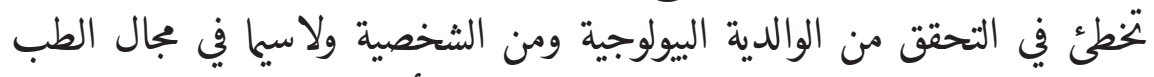

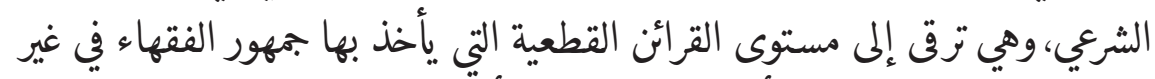

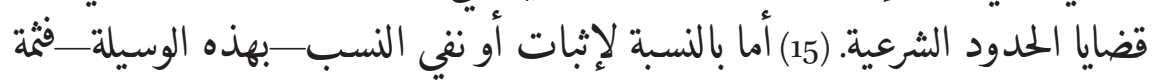

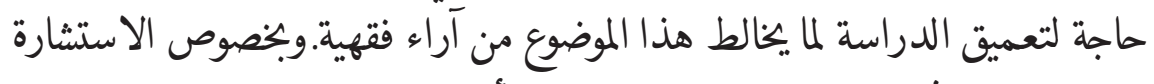

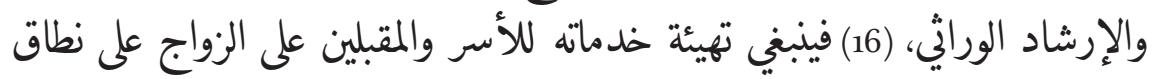

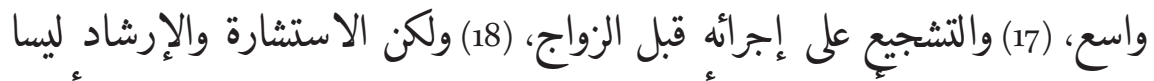

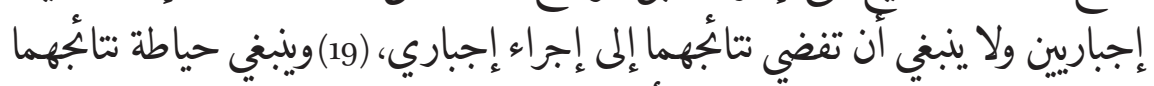

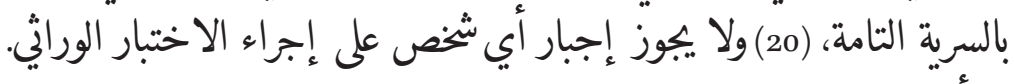

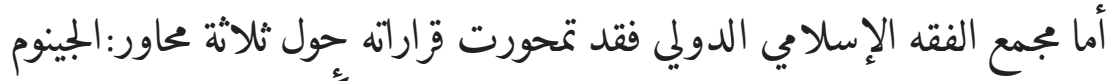

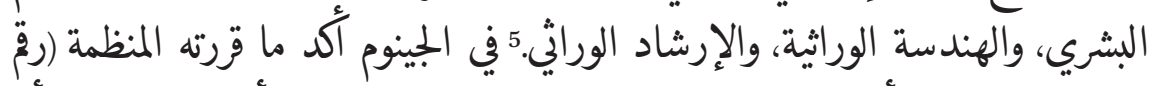

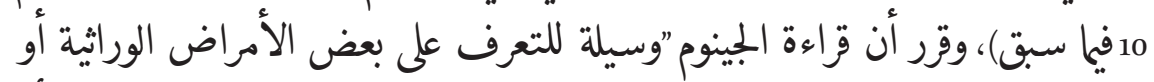

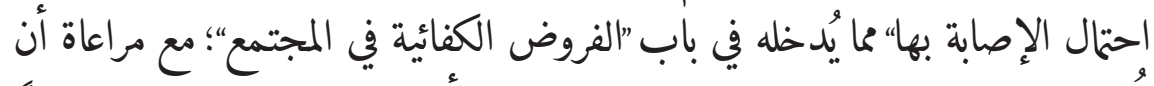

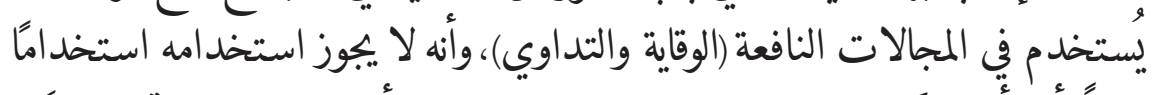

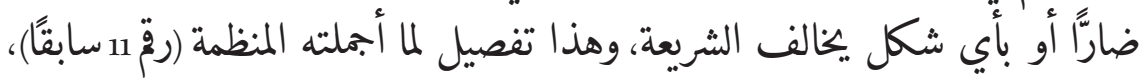

5 كمع الفقه الإسلاي الدولي، الدورة الحادية والعشرون، الرياض، 18-2013/11/22. 


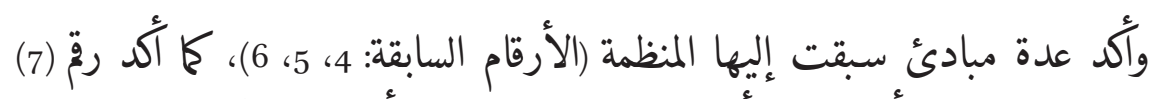

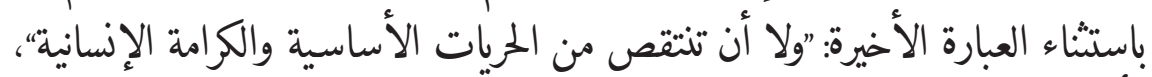

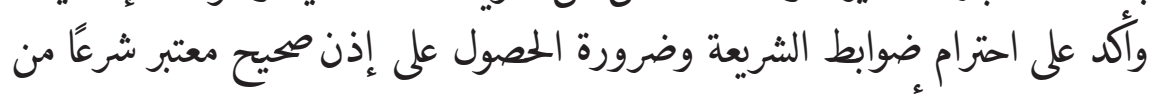

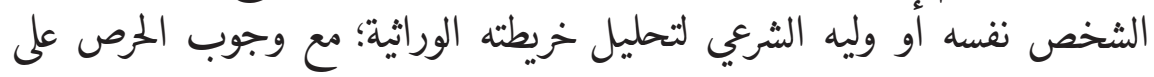
مصلحة الشخص المعني. وفيا يخص العلاج الجيني فقد قسمه إلى نوعين: الأول: علاج الحلايا الجسدية الماية

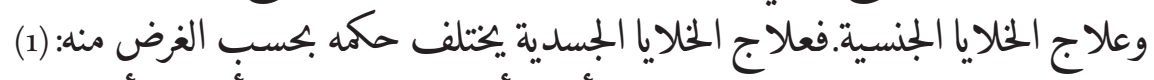

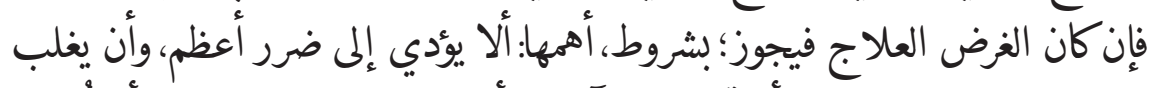

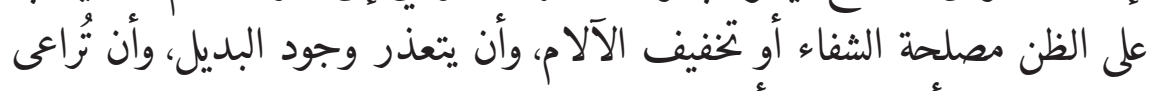

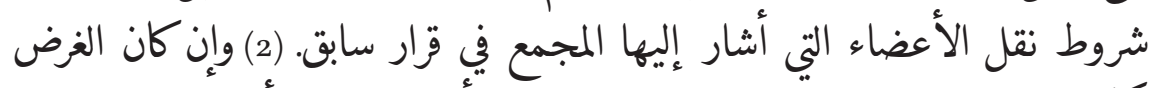

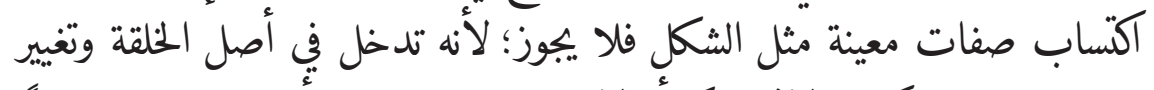

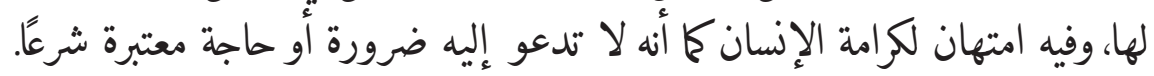

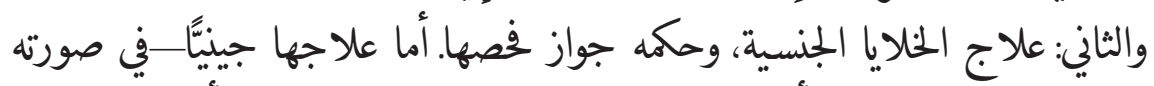

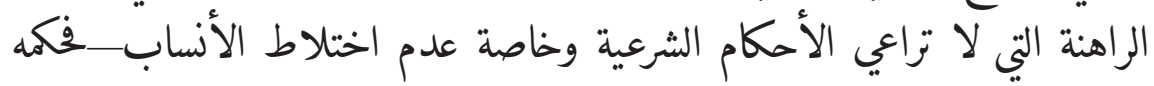

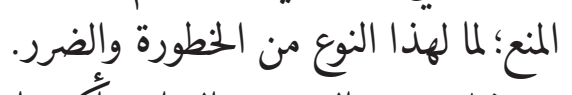

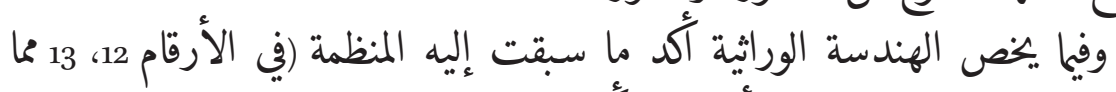

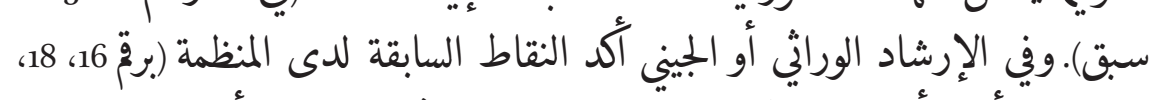

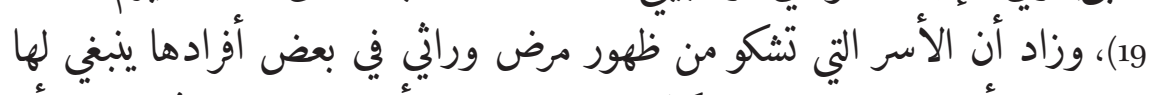

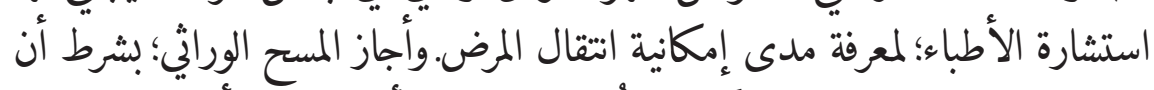

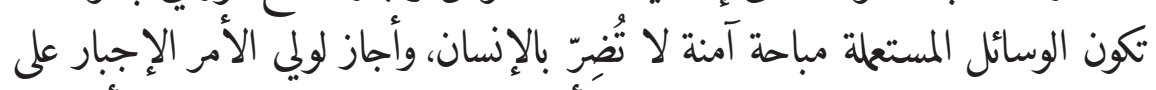

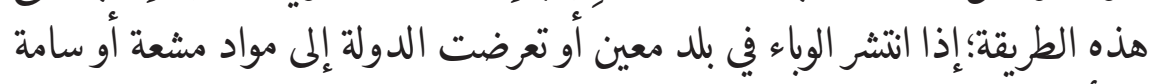

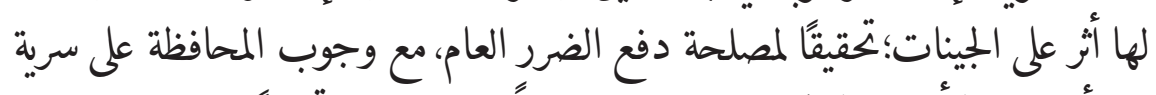

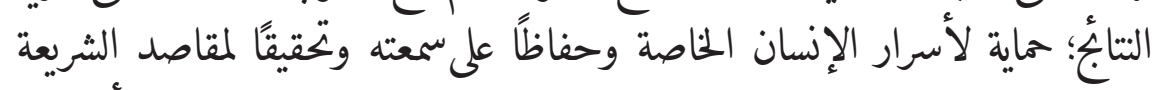

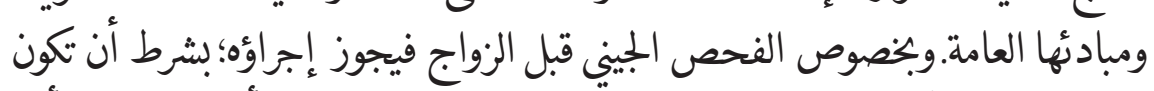

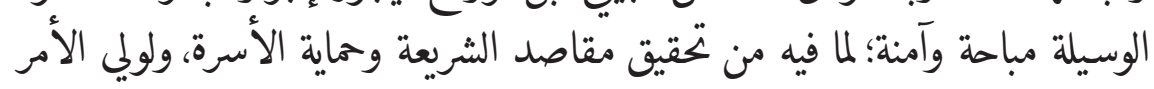

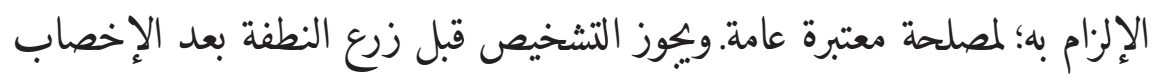

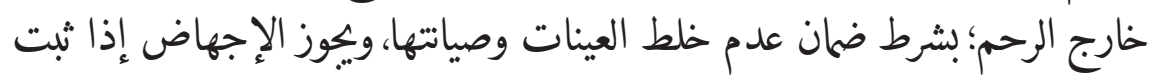




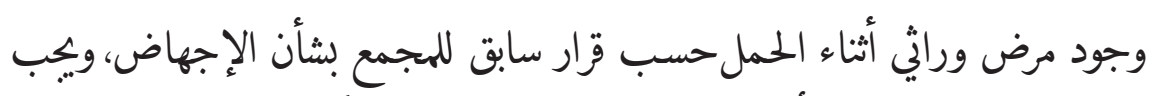
إجراء الفحص الجيني للأطفال حديثي الولادة للتدخل المبكر في الحالات التي ظهر

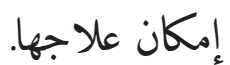

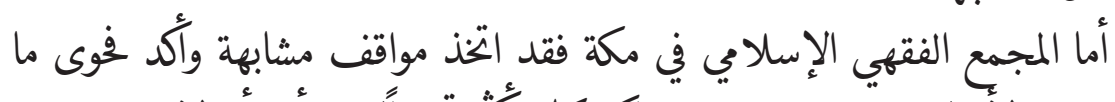

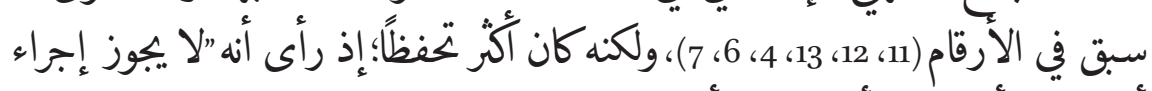

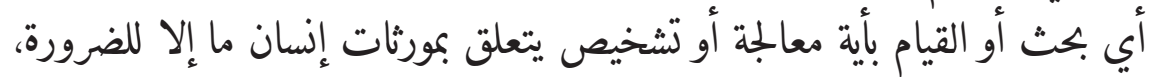

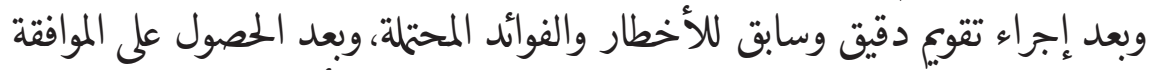

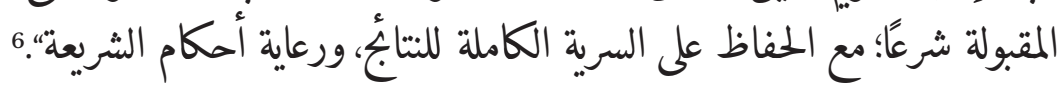

\section{الاجتهاد المعاصر حول الجينوم: تقويم نقدي}

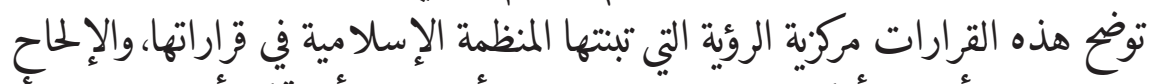

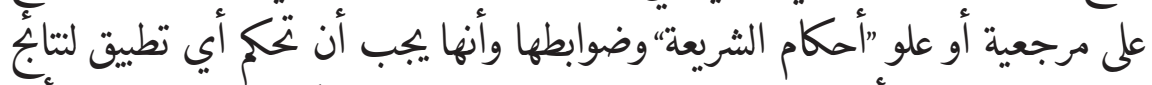

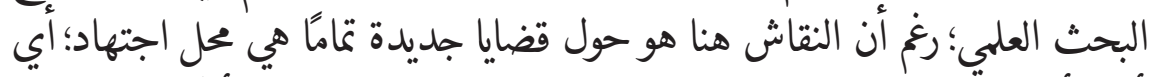

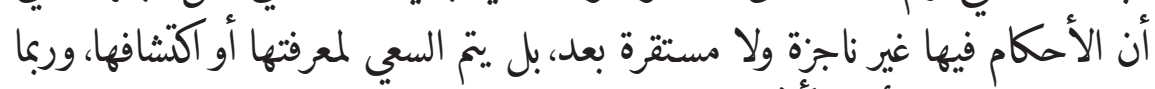

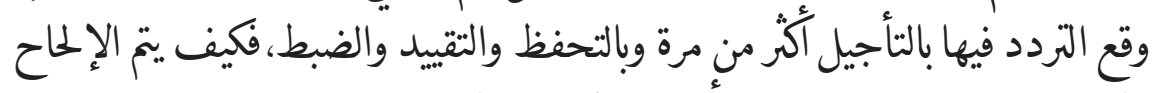

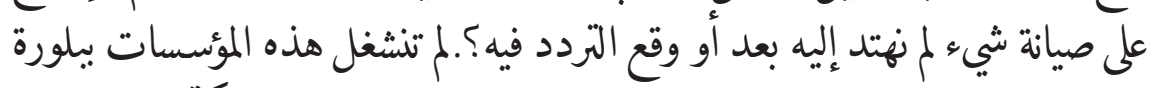

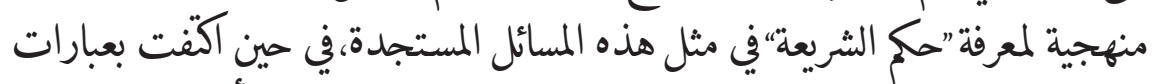

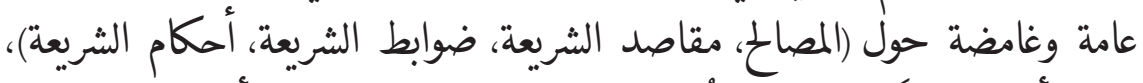

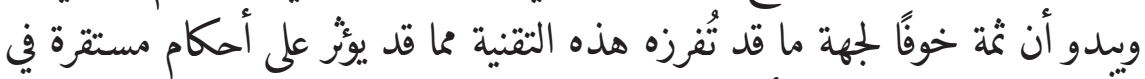

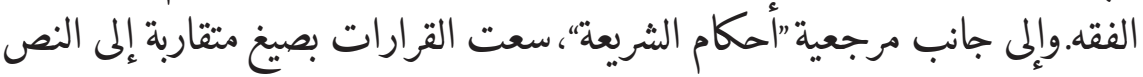

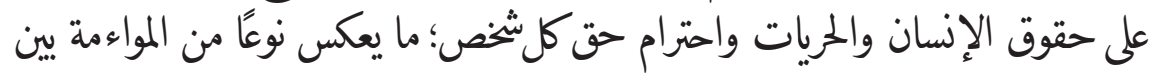

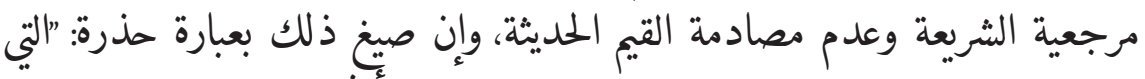

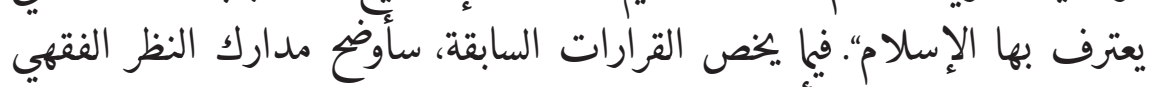

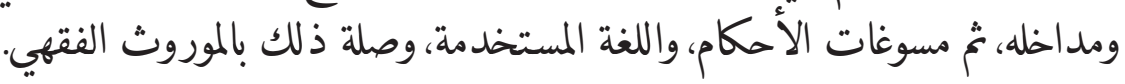

6 المجمع الفقهي الإسلامي التابع لرابطة العاله الإسلاي، الدورة الخامسة عشرة المنعقدة في

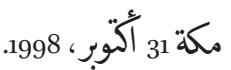


يتوجه نظر الفقيه إلى معالجة استخدامات التقنية الجينية بناءً على تصور محدد

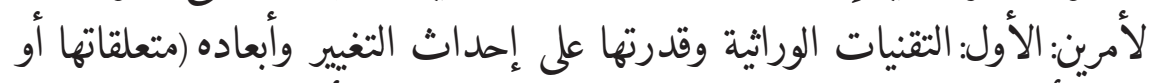

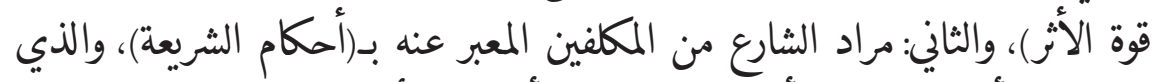

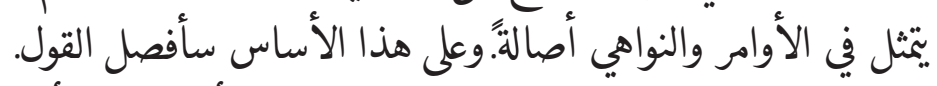

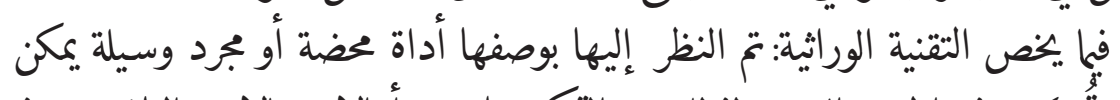

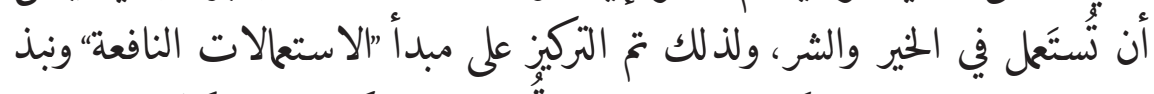

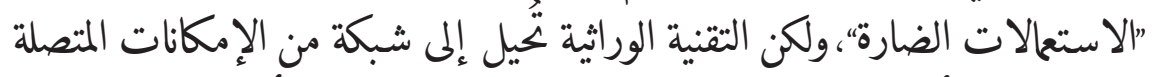

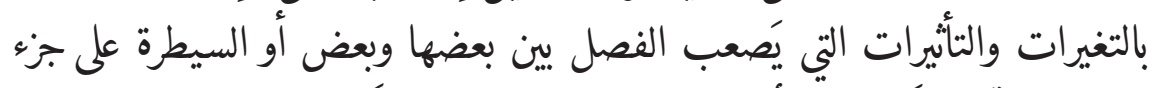

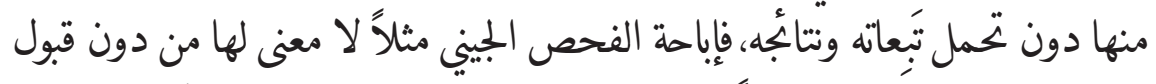

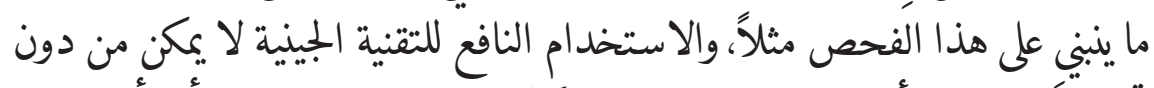

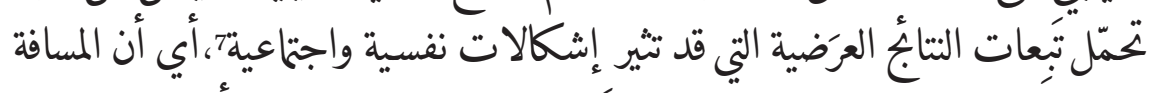

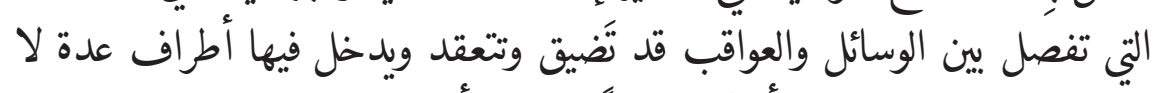

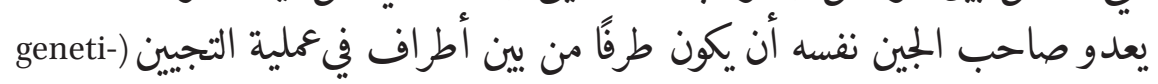

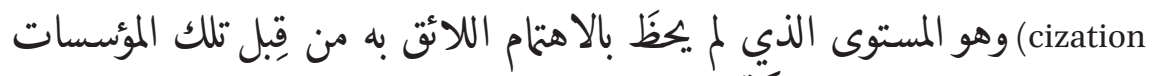

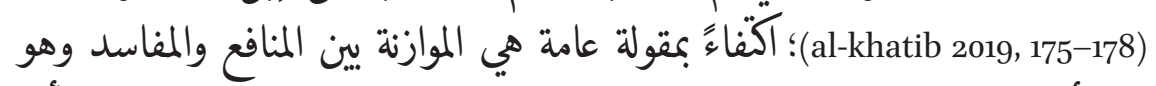
ما سأناقشه لاحقًا. فهذه التقنية تم إدراجها في باب "تعرف الإنسان على نفسه، وأنها

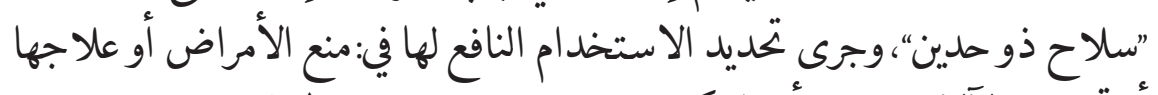

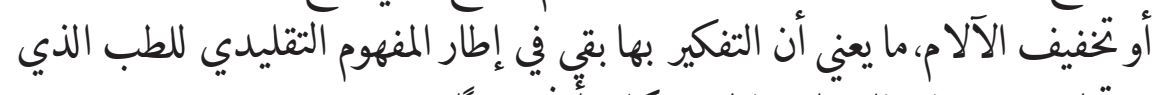

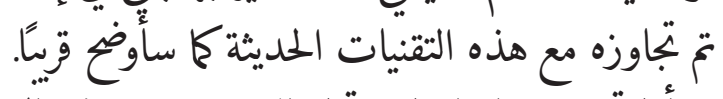

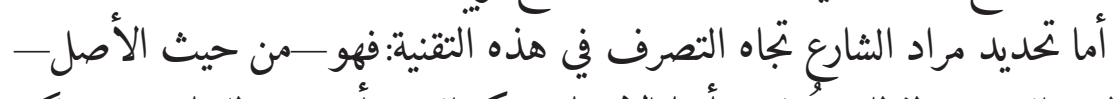

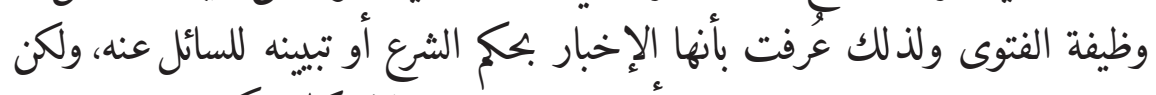

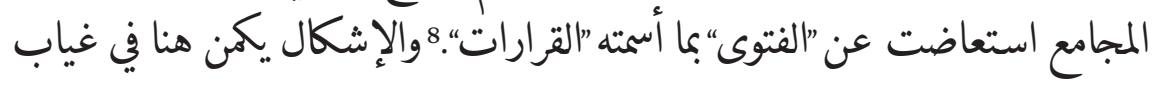

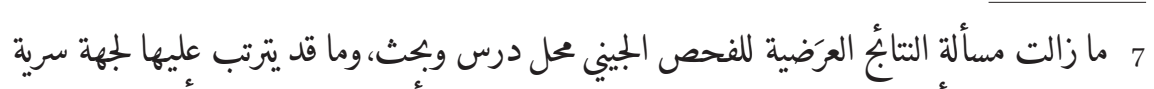

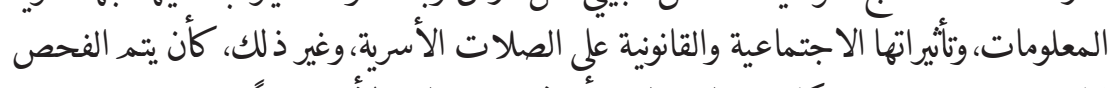

$$
\text { الجيني بهدف علاجي ويكتشف بالمصادفة أن نسبه غير ثابت لألأبويه مثلاً. }
$$

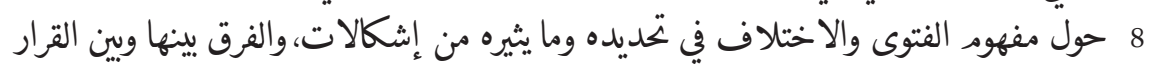

انظر: (الخطيب 2019، 4-5، 10). 
نصرِ من الشارع يكشف عن إرادته، ما يعني أن على المفتي أن يجتهد في تحديد "مراد

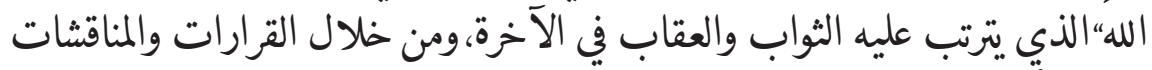

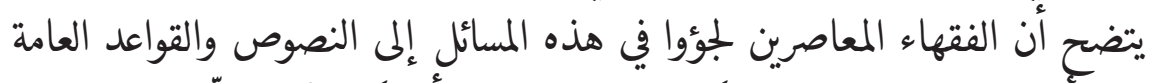

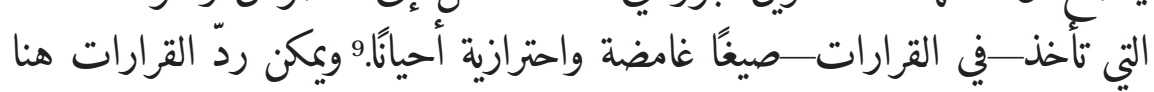

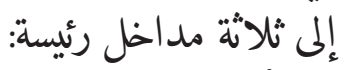

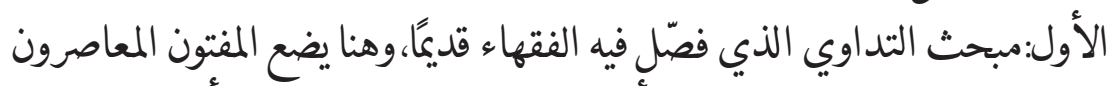

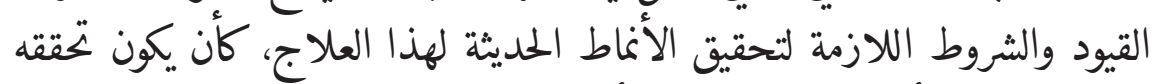

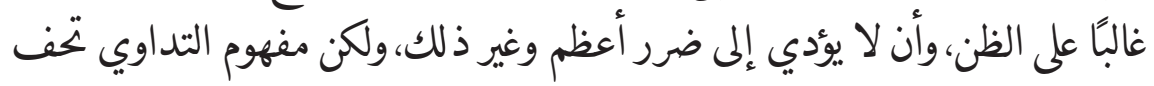

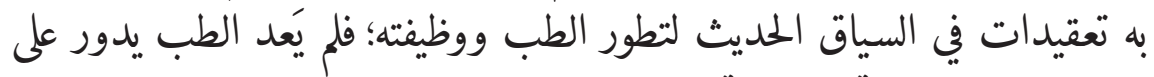

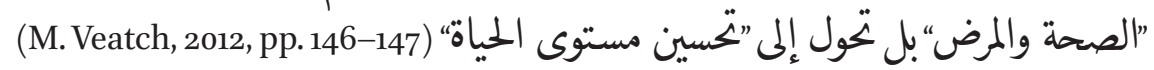

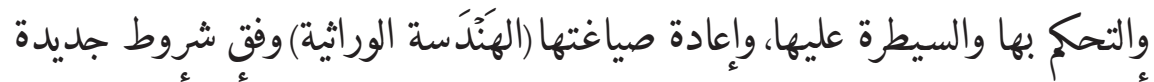

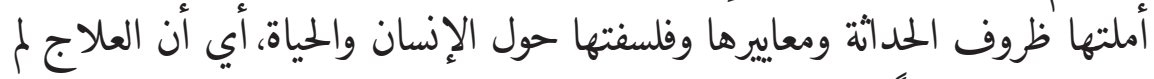

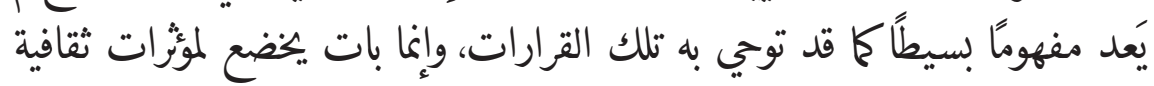
واجتاعية خصوصًا مع ظاهرة التجيين.

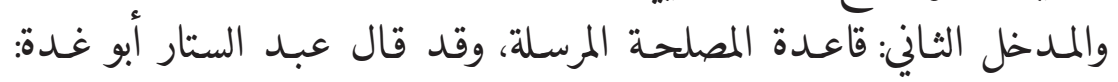

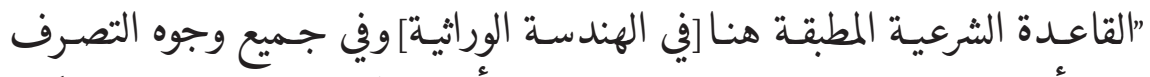

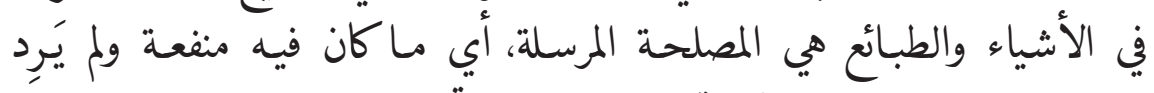

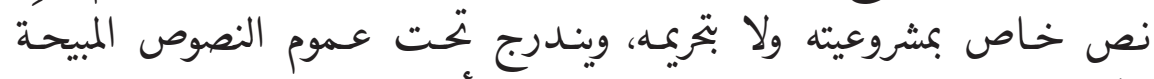

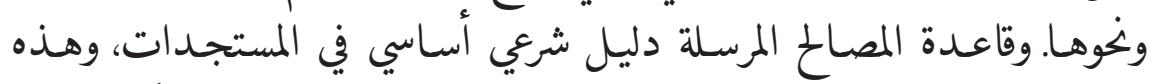

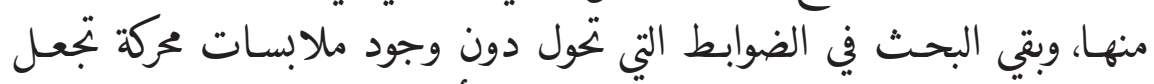

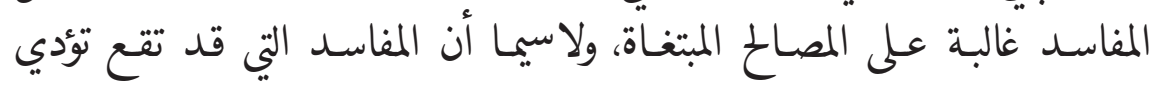

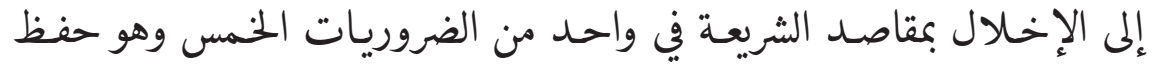

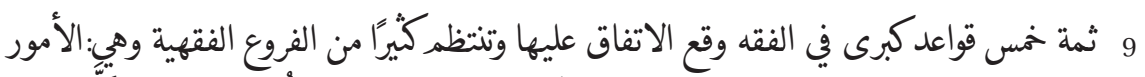

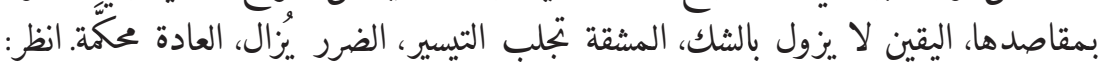

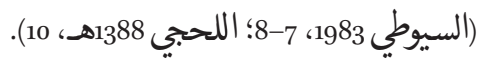




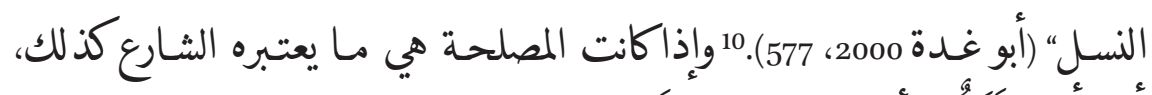

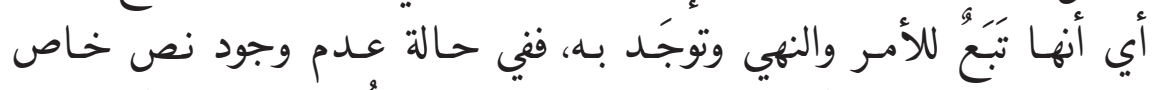

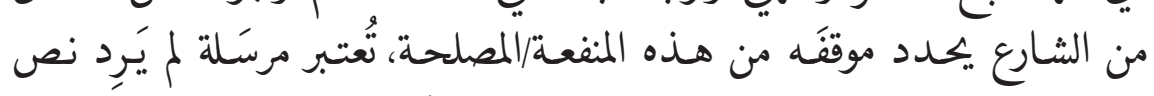

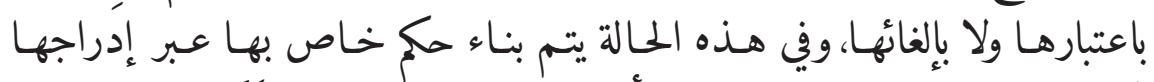

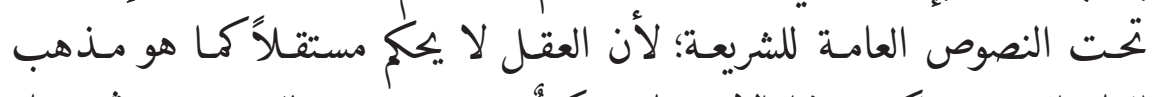

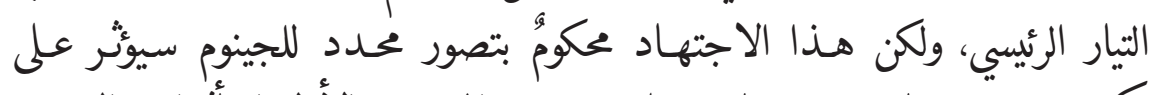

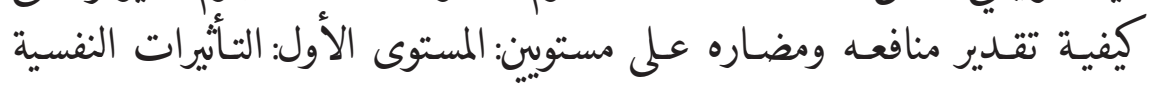

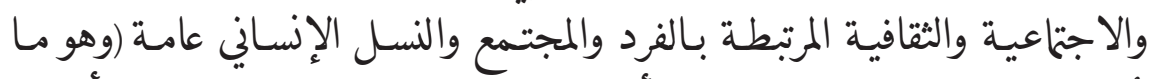

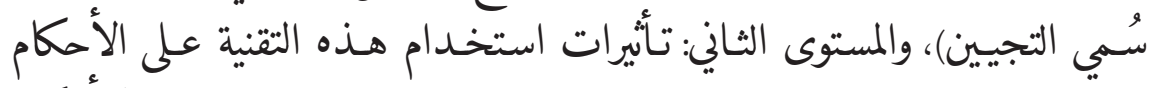

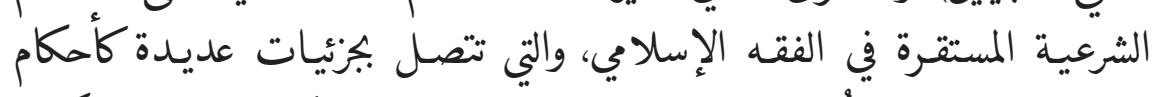

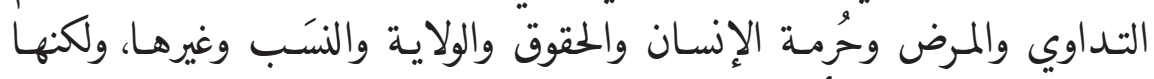

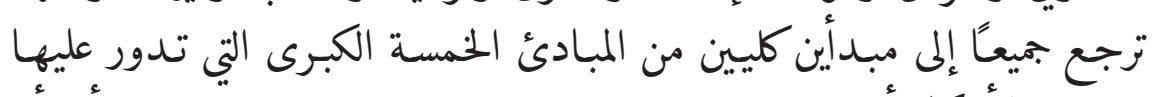

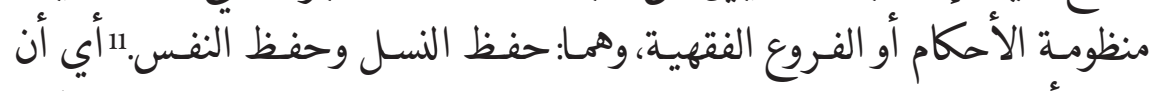

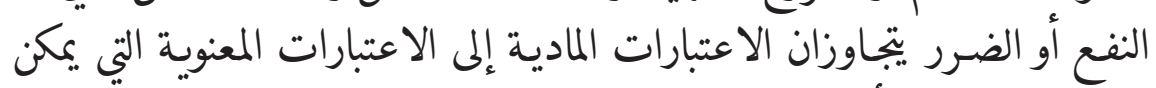

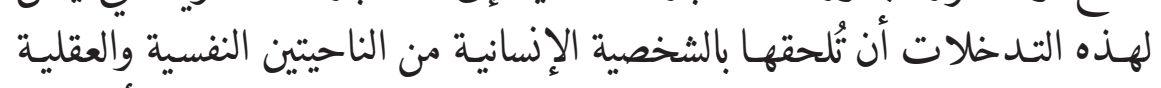

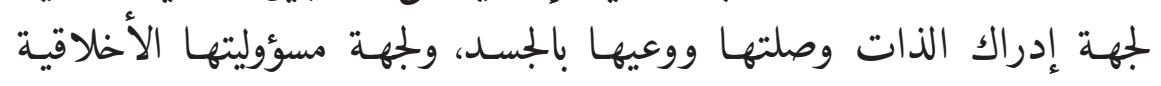
الفردية والاجتاعية المترتبة على التدخل التهات التحسيني.

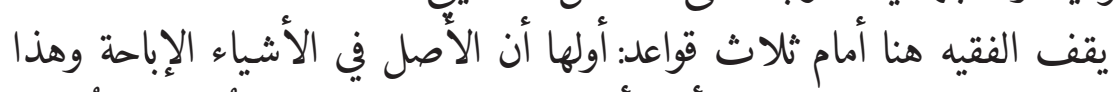

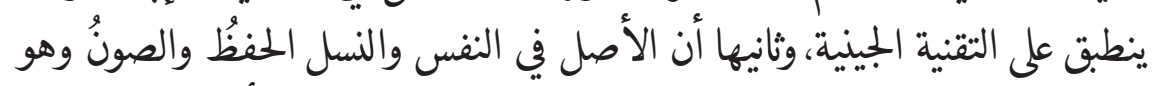

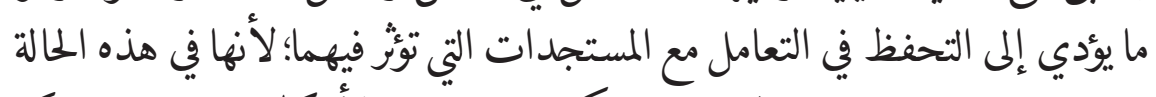

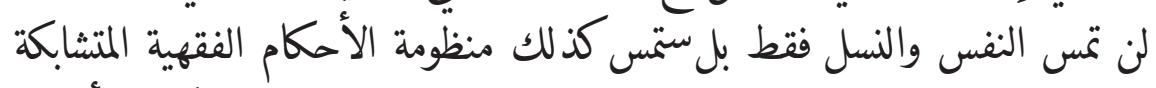

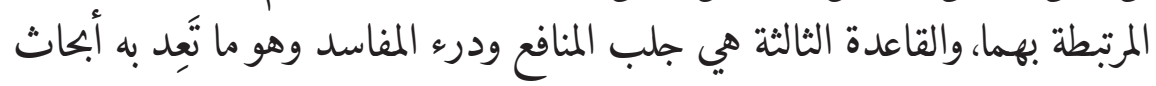

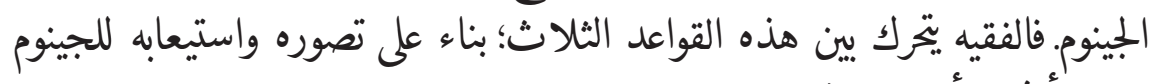

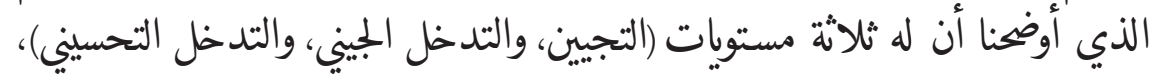
10

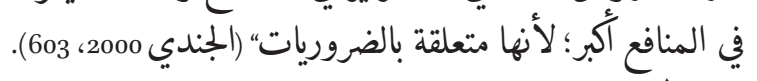

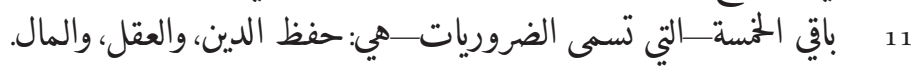


وبناء على معرفته بالتراث الفقهي وتقديره للمنافع والمفاسد؛ لأنه يبحث-ــفي محصلة

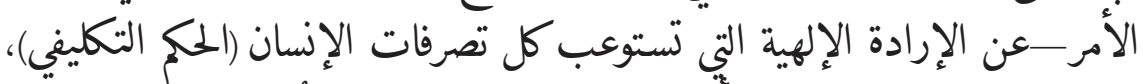

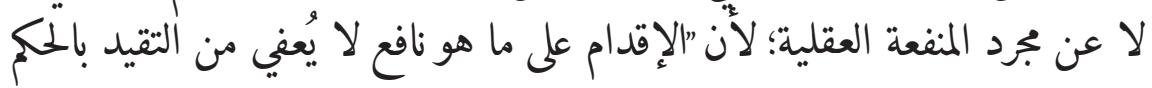

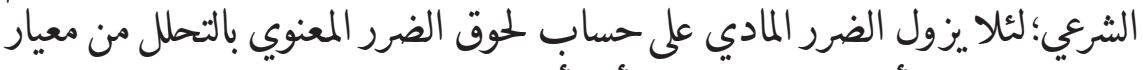

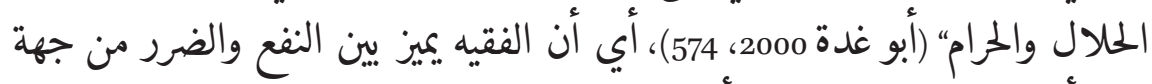
وبين أحكام الشريعة من جهة أخىى وقد يتقاطعان وقد ينفصلان ألمان.

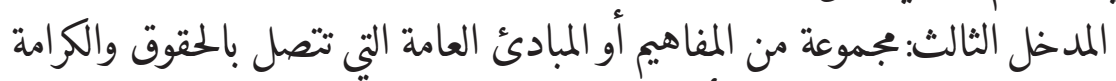

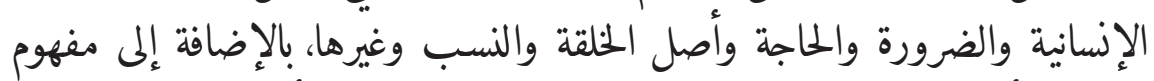

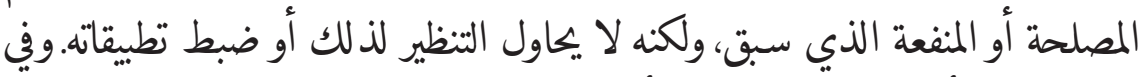

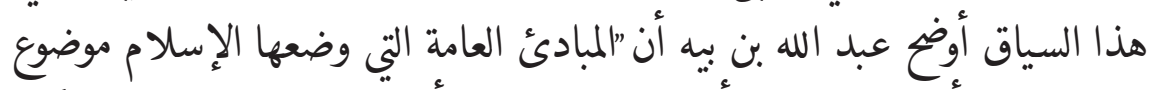

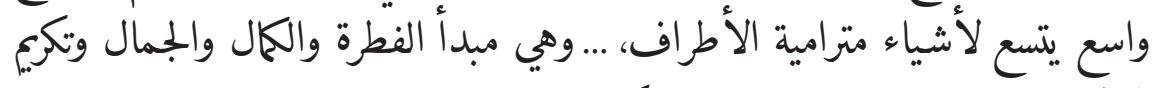

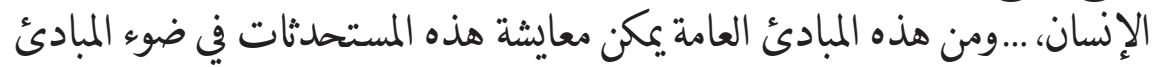

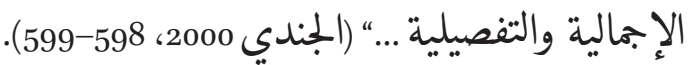
أما بخصوص اللغة المستعلة في هذه القرارات، فالمنظمة مزجت بئين المينة اللغة الفقهية

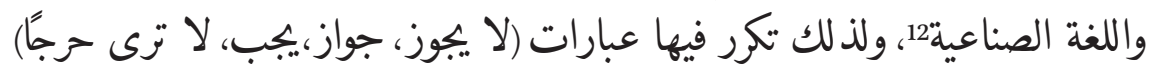

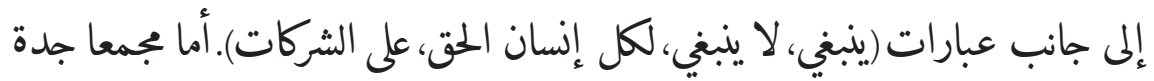

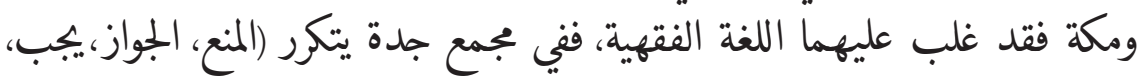

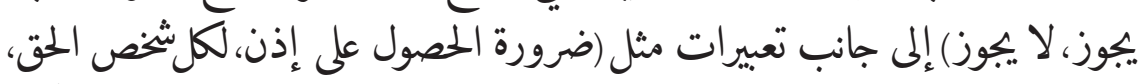

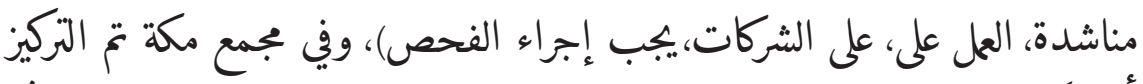

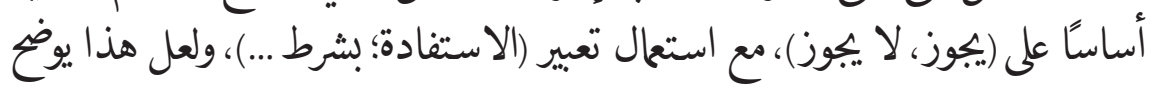

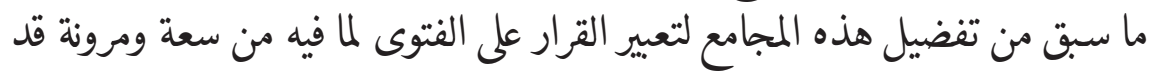

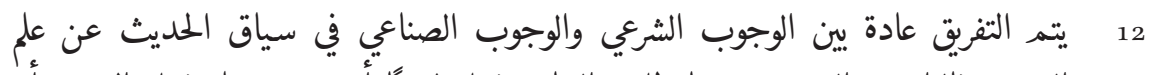

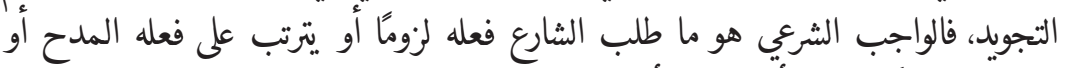

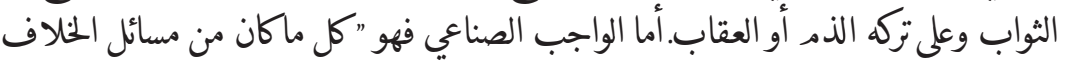

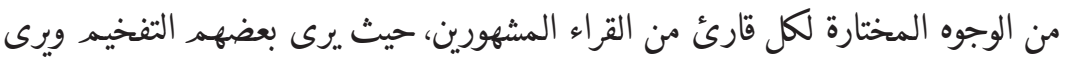

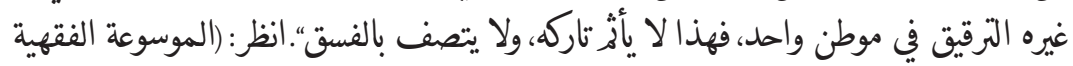


تُّجره من صرامة تعبير "الفتوى" التي تدل فقط على "حكم الله" من جهة، ولما فيه من

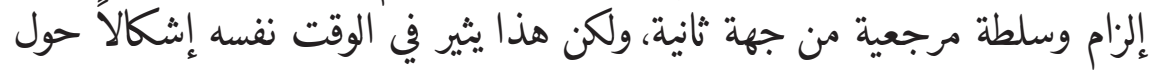

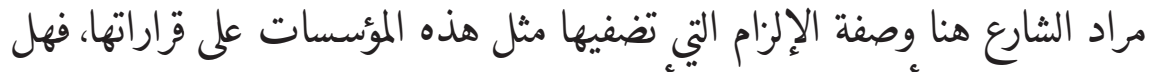

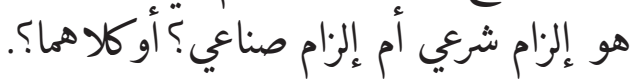

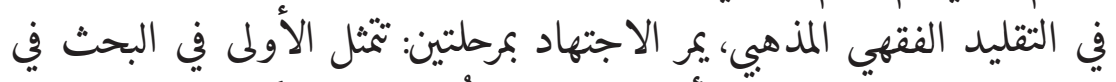

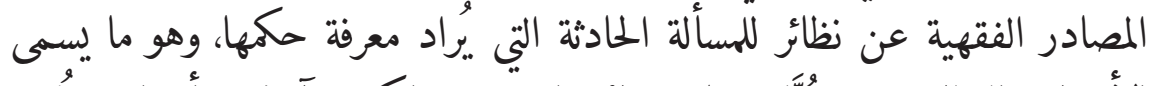
الأشباه والنظائر، و“به يُطَّع على حقائق الفقه ومداركه ومآخذه وأسراره، ويتّهر

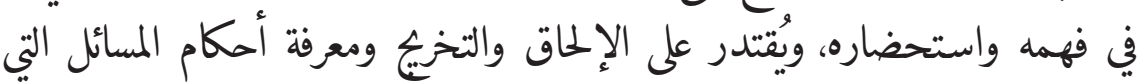

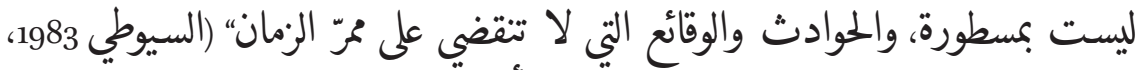

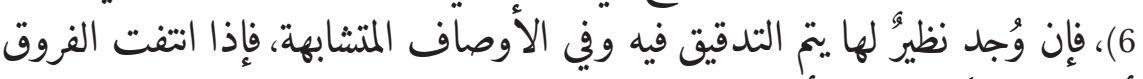

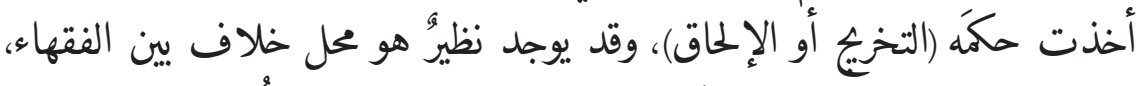

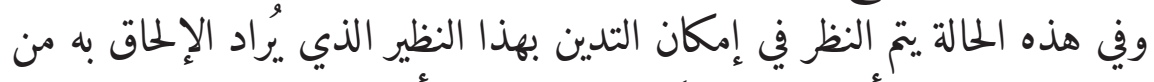

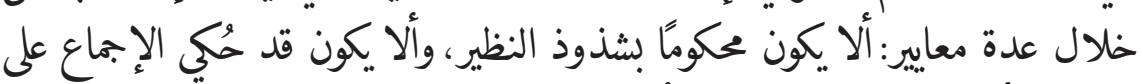

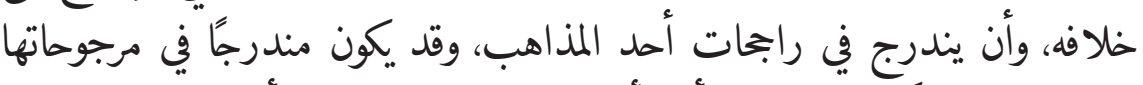

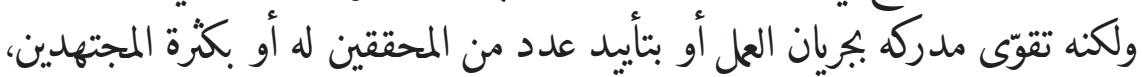

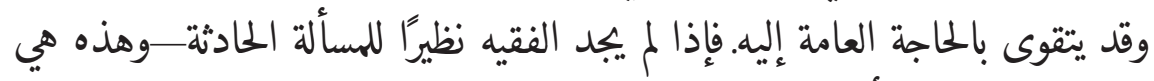

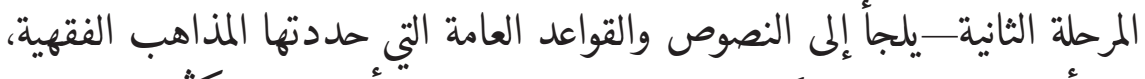

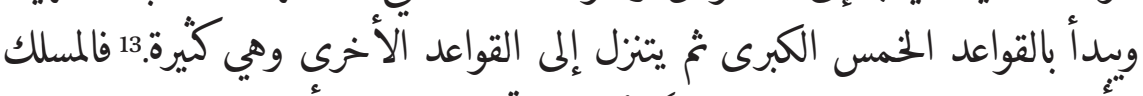

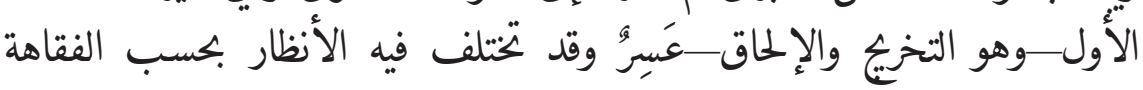

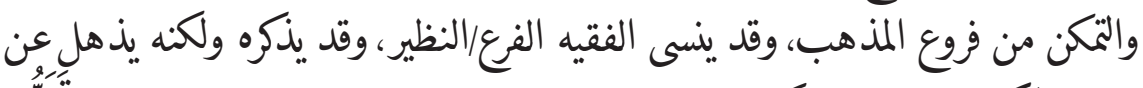

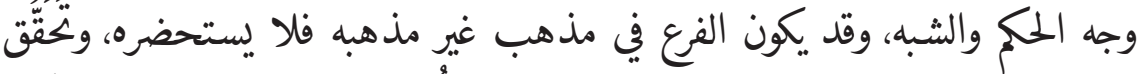

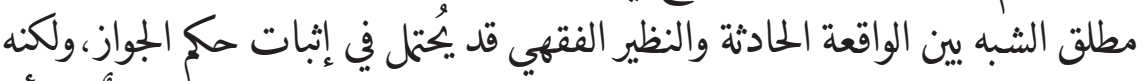

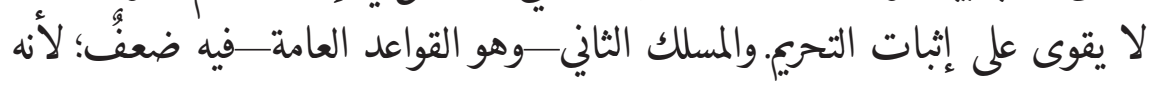

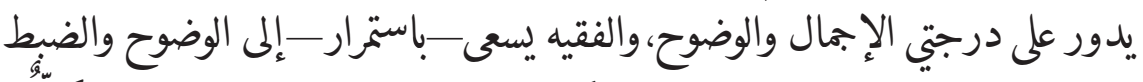
في إدراك مراد الشارع ومقصده، وإدخال كل فروع الفقه في القواعد الخمس فيه تخكلّف

13 أوصلها بعضهم إلى خمسين، وآخرون إلى مئين. انظر: (السيوطي 1983، 7). 


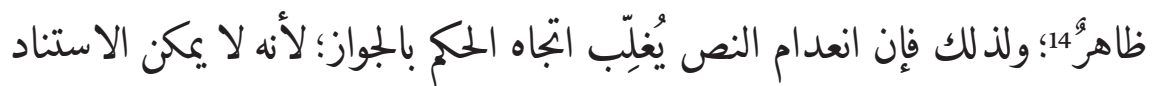

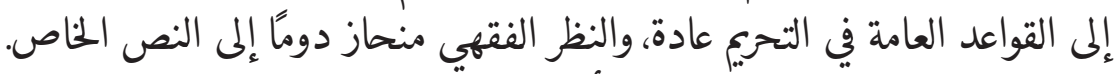

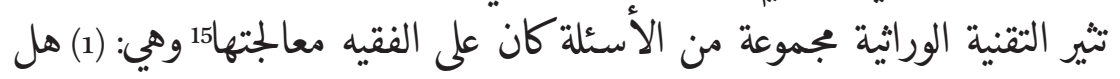

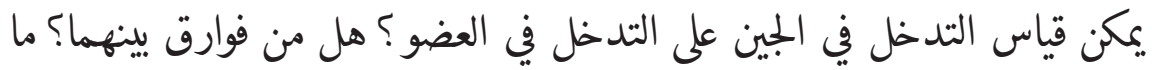

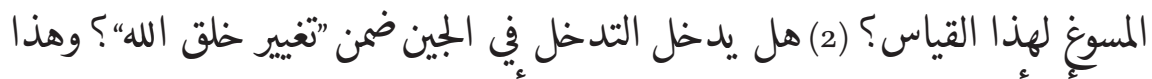

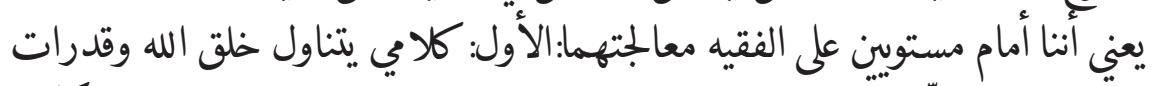

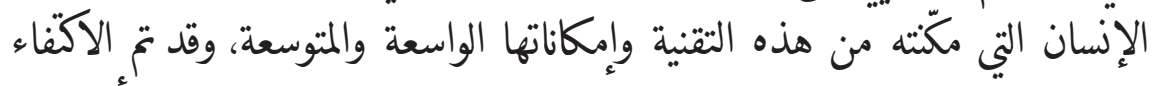

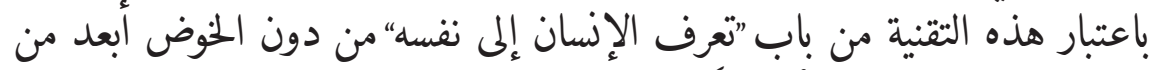

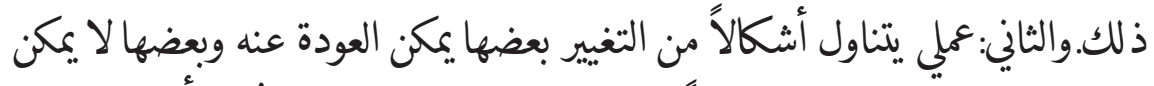

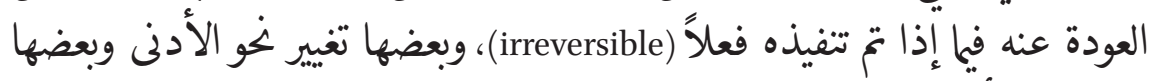

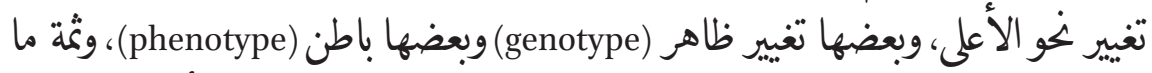

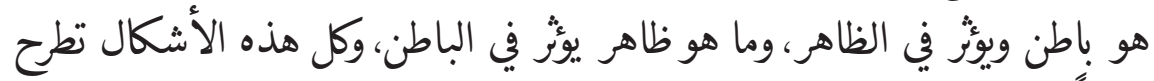

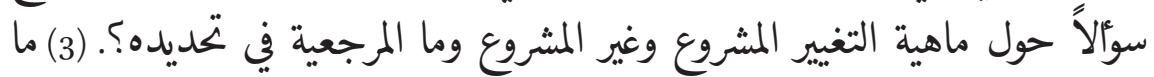

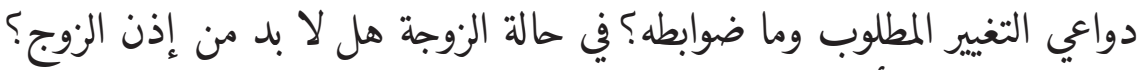

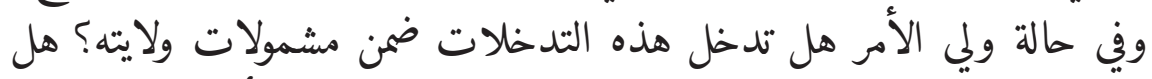

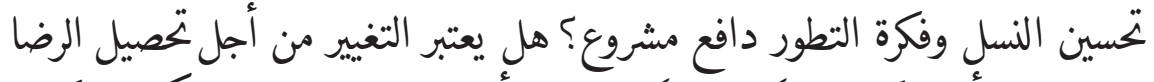

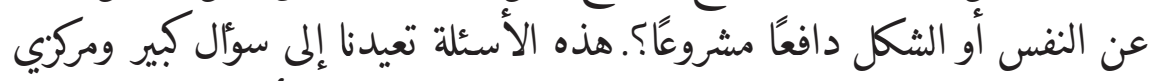

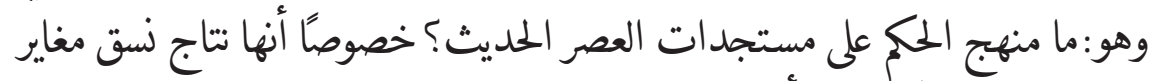

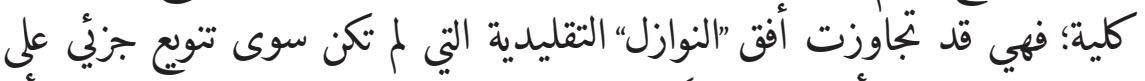

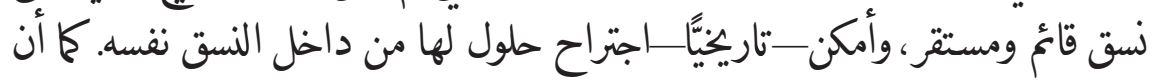

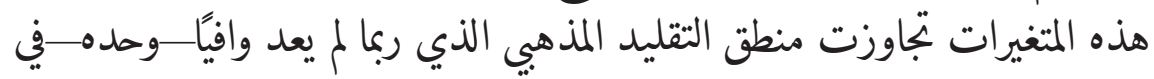
التفاعل معها.

14 15

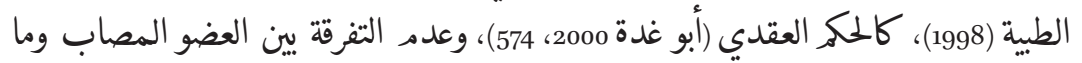

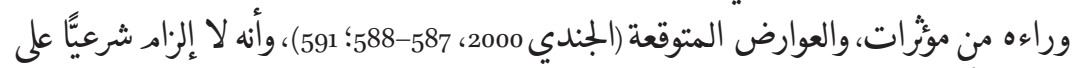

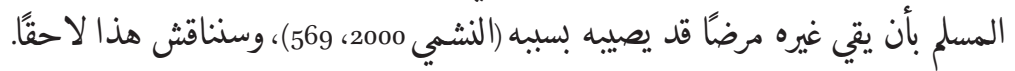


وفي ختام هذا المبحث من المفيد ملاحظة أنه غاب عن هذه القرارات البعد البد البح

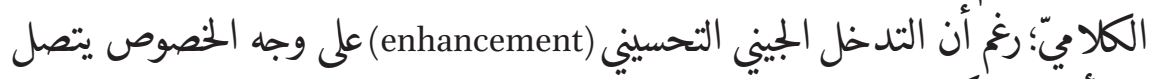

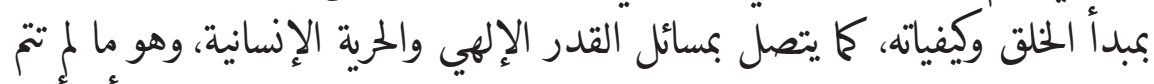
مناقشته، فالتدخل التحسيني يخضع لاختيارات تفضيلية من البشر، ما يعني أنتا أمام

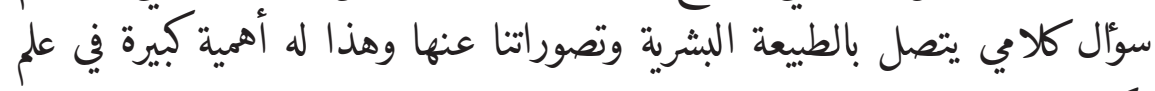
الكلام والفلسفة.

\section{الجينوم: نخو مقاربة أخلاقية}

من خلال الملحوظات النقدية السابقة حول الاجتهاد المعاصر، والأسئلة التي يثيرها

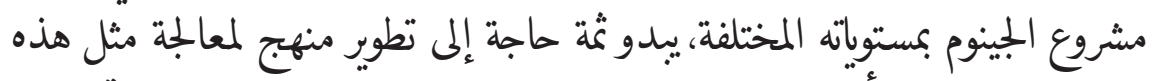

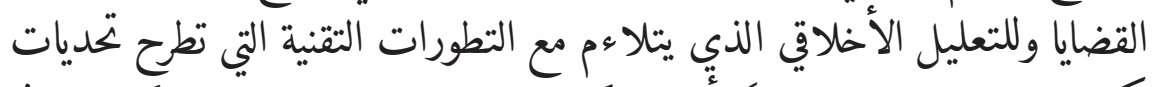

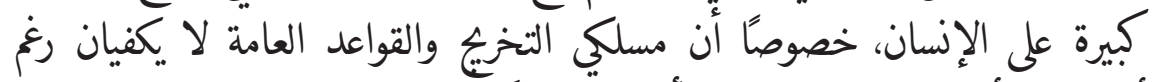

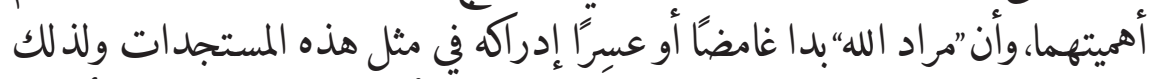

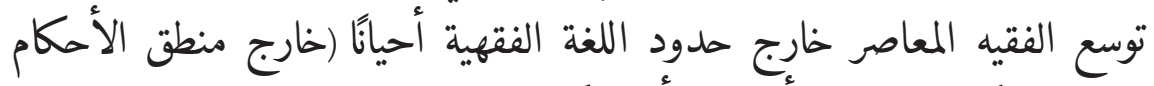

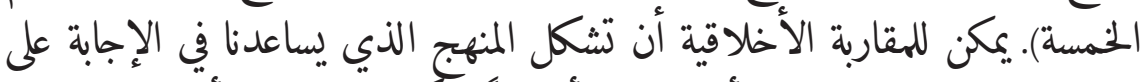

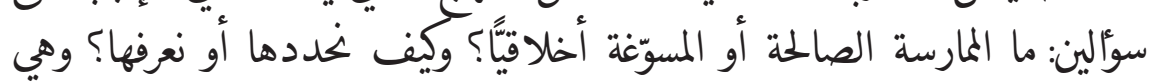

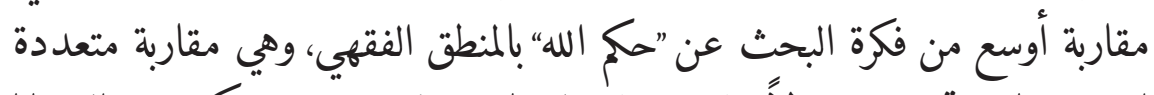

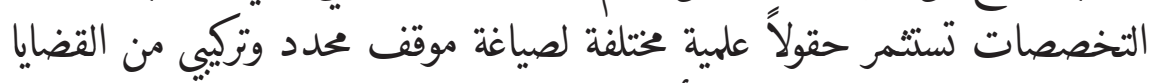

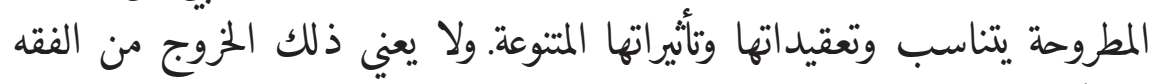

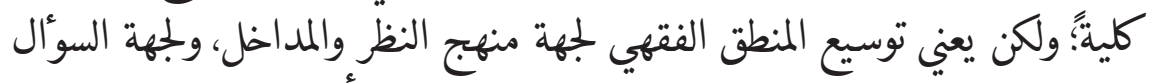

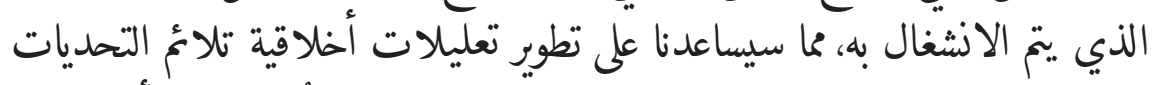

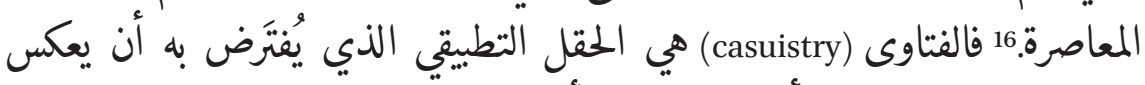
التصورات اللاهوتية والأخلاقية بصيغة أحكام معيارية تخاطب الميني السلوك والضمير.

16 سبق أن كتبت دراسات عدة في هذا الاتجاه يشكل هذا البحث متابعة لها، من ذلك: "آيات

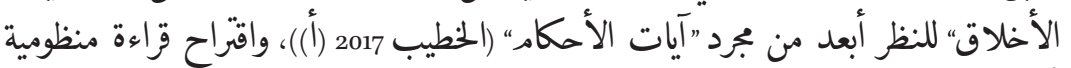

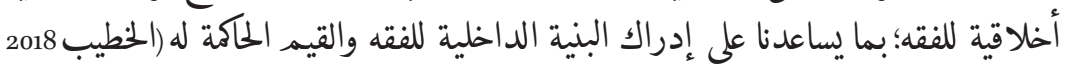


ولكن كيف يمكن لنا أن نعيد صياغة الموقف من الجينوم وفق مقاربة أخلاقية؟ سيكون ذلك من خلال تركيب أربعة مكونات هي الكلام والفلسفة والفقه وأصول

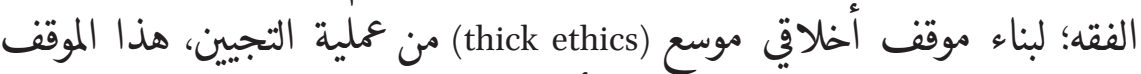

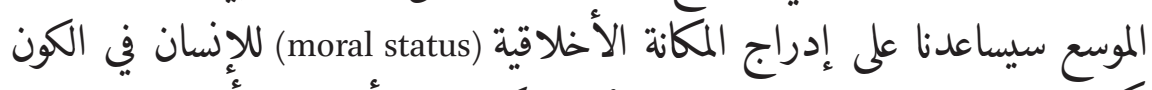

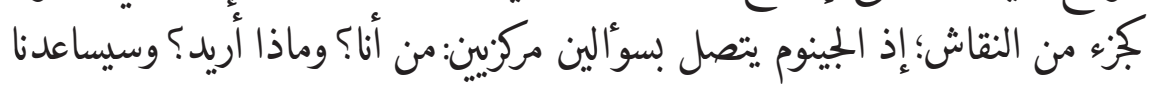

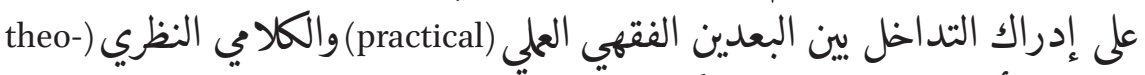

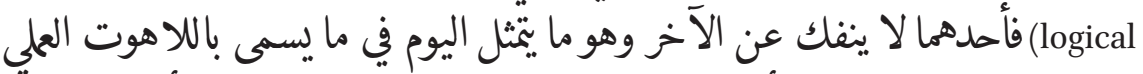
(practical theology)

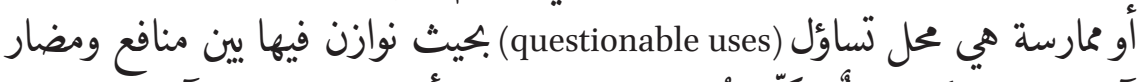

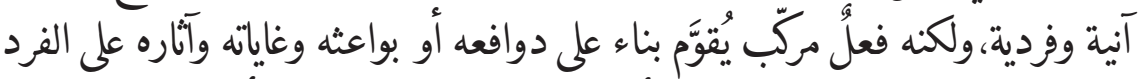

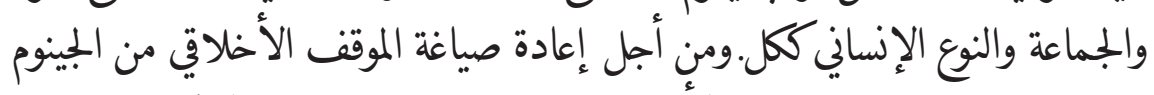

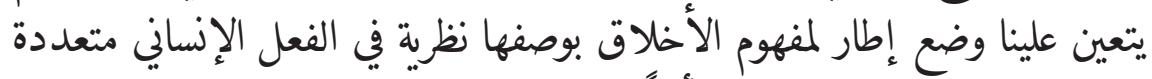

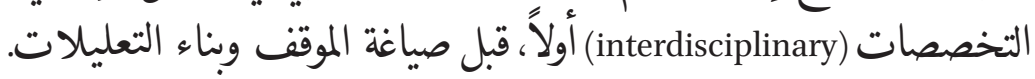

$$
\text { الأخلاق الإسلامية: المفهوم والإطار النظري }
$$

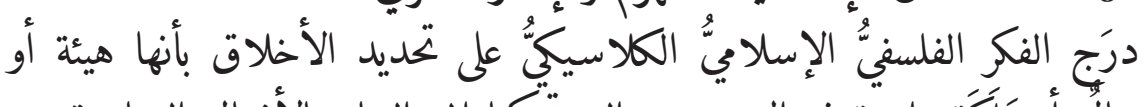

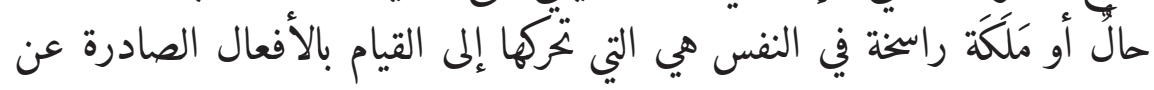

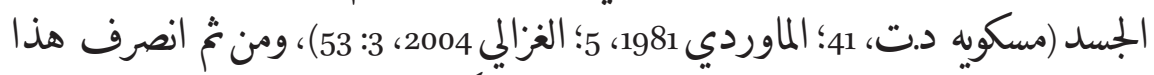
النوع من الكّابات إلى وصف طبيعة النفس وملَكاتها وتعريف الفضيلة وتقسيماتها

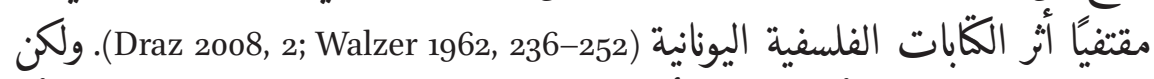

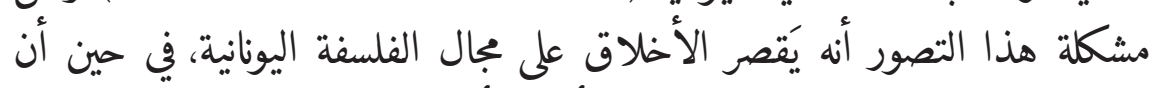

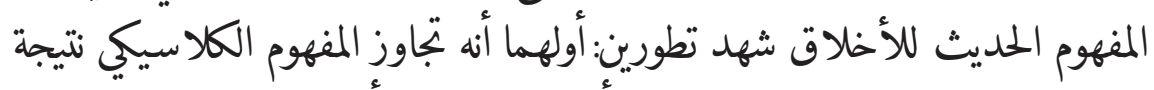

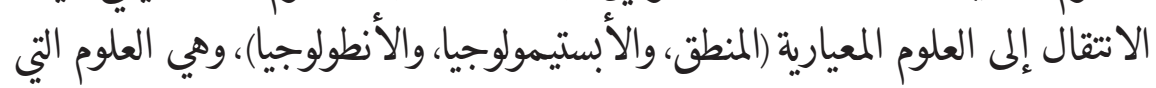

(أ))، ومحاولة اكتشاف الأبعاد الأخلاقية للفقه كقل تخصصي وأوجه الاتصال والانفصال

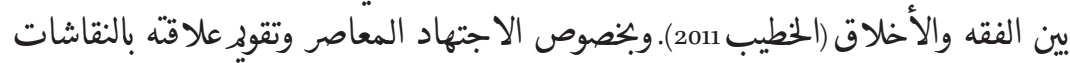
الأخلاقية والفلسفية (الخطيب 2019 (أ))، وتقويم الاجتهاد المعاصر في حقل الطب الطبه (الخطيب 


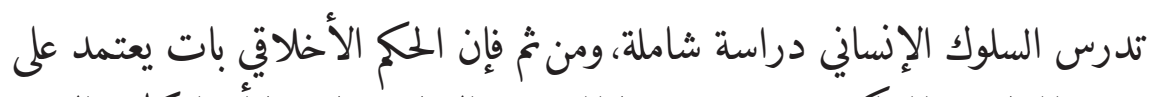

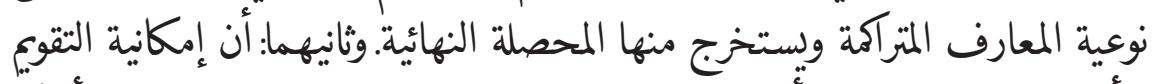

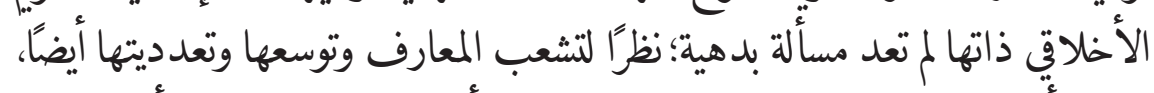

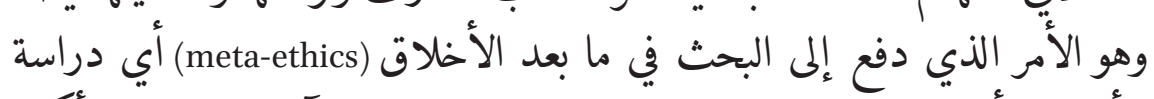

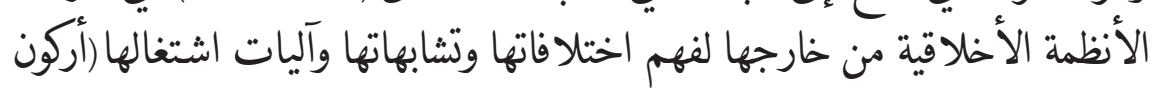
2007،

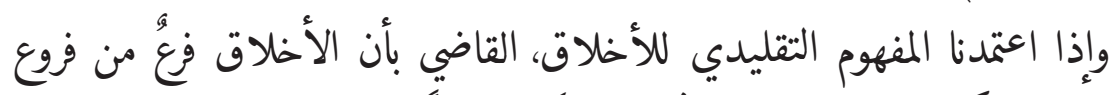

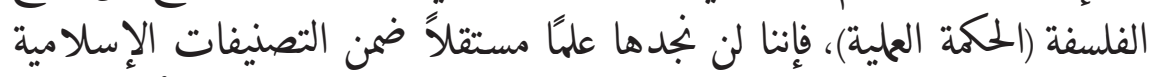

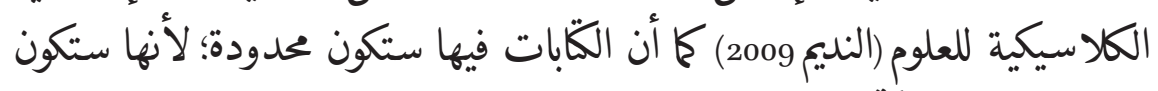

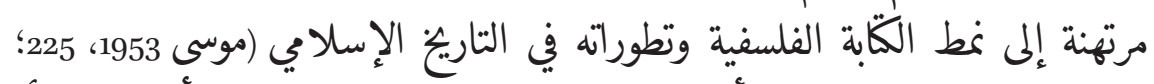

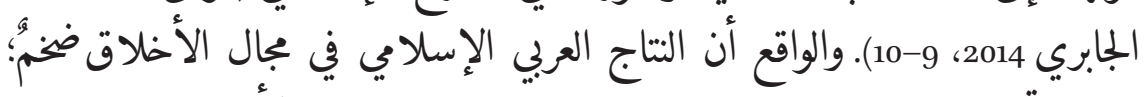

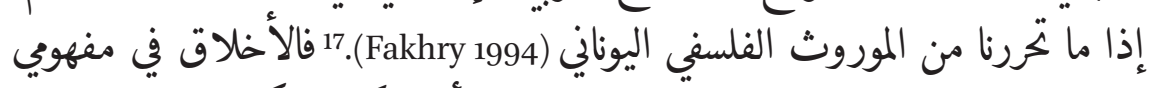

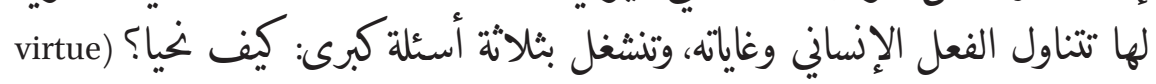

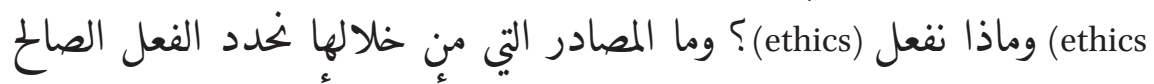

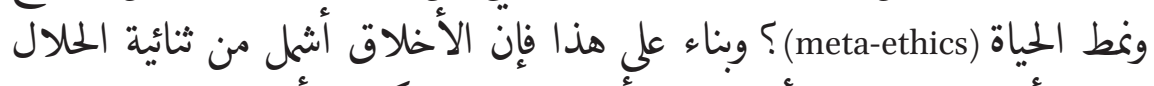

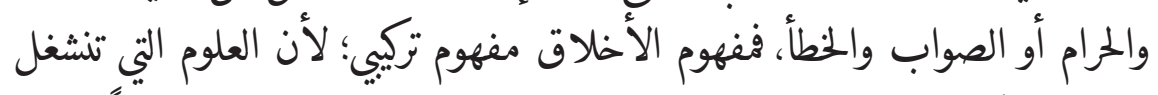

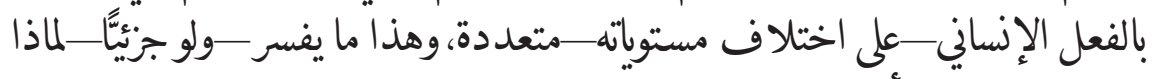

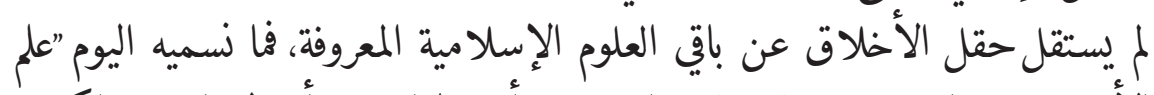

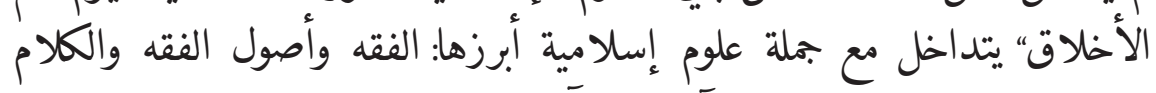

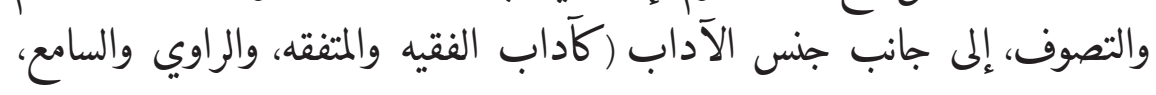
والطبيب، ...) إلى غير ذلك. و"الفعل الصالح" له مستويان: أنطولوبي (وجودي) وأبستيمولوبي (معريف)، ويسعيان

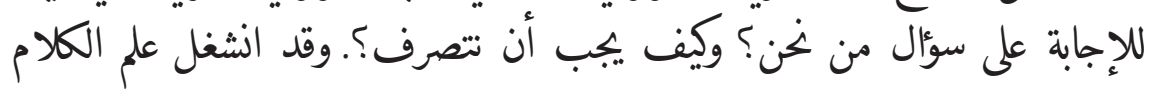
17

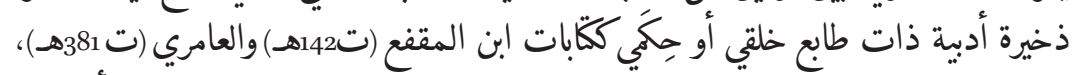

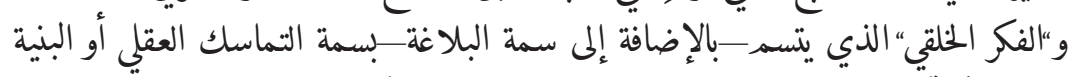
المنطقية كتّابتات المتكلمين والنصوص الخلقية الفلسفية (خُري، 1: 9-10). 
الإسلامي بهذا من خلال مناقشة محورين رئيسين: أولهما: الموقف من الفعل الإلهي

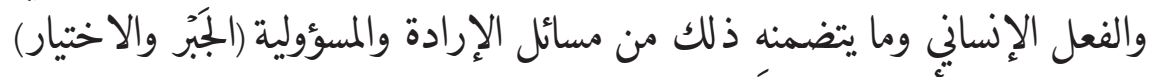

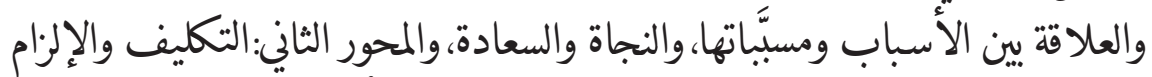

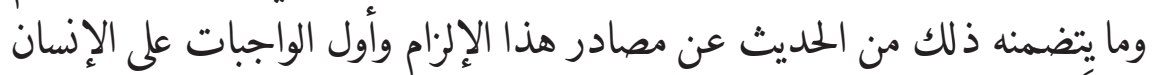

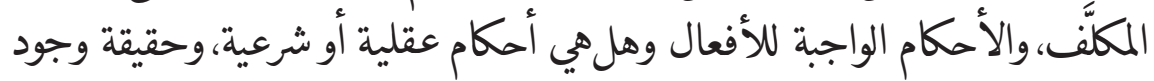

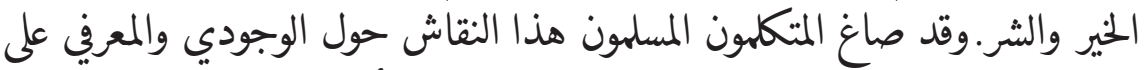

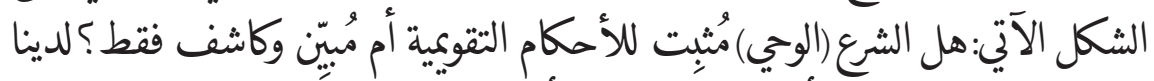
هنا نظريتان رئيستان: الأولى الموضوعية الأخلاقِية (ethical objectivism) ومُفْادها

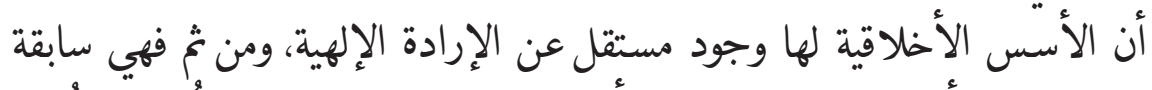

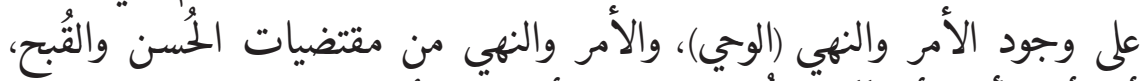

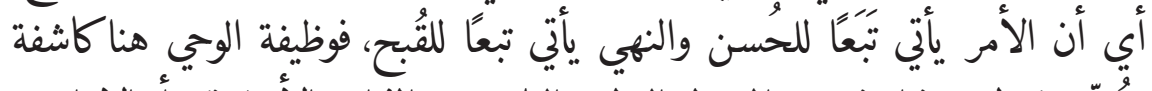

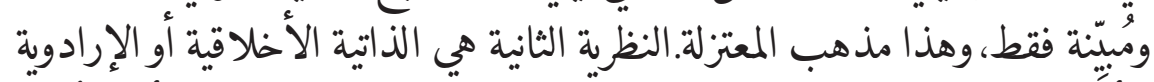

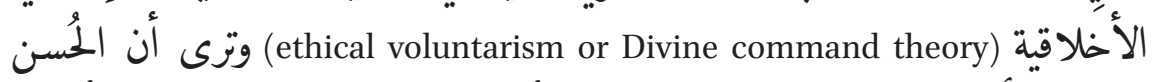

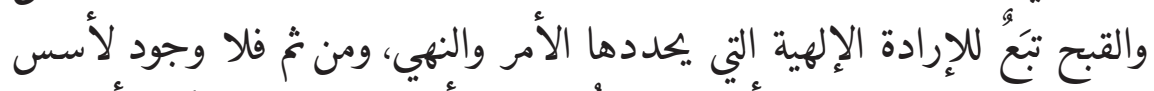

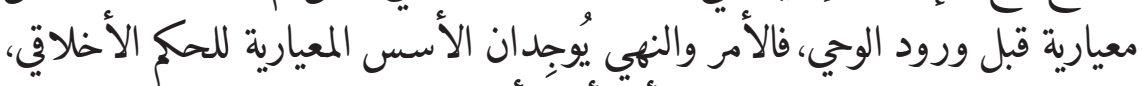

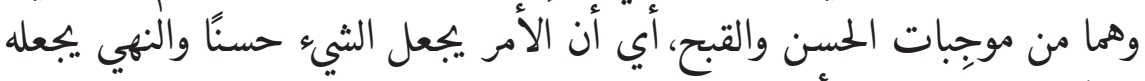

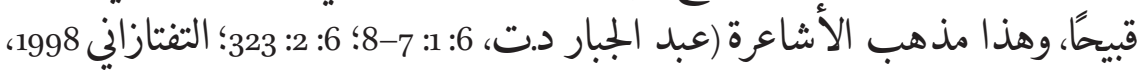

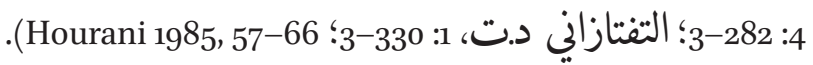

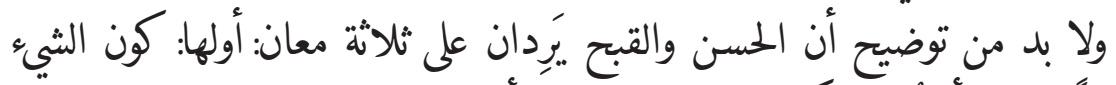

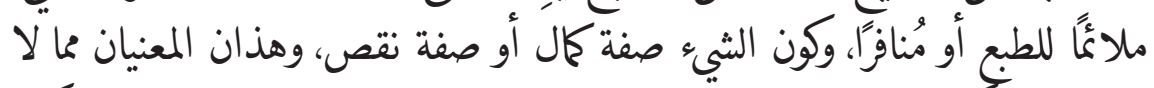

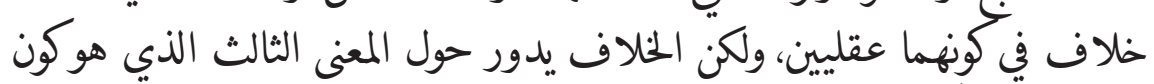

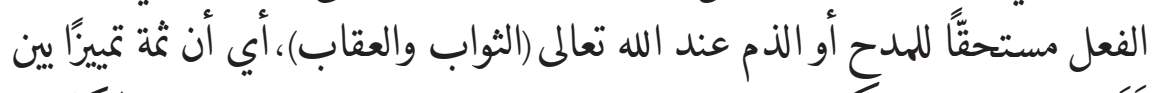

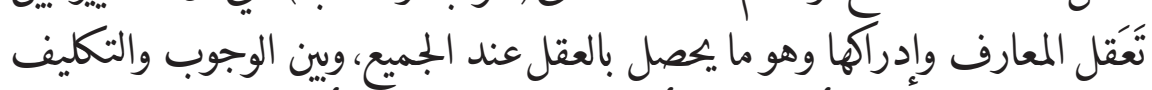

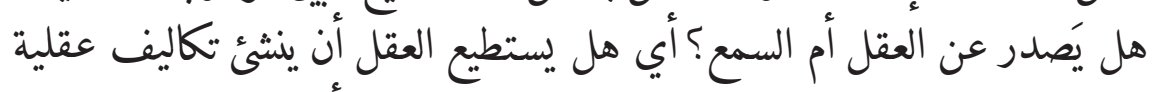

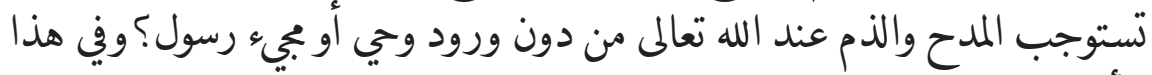

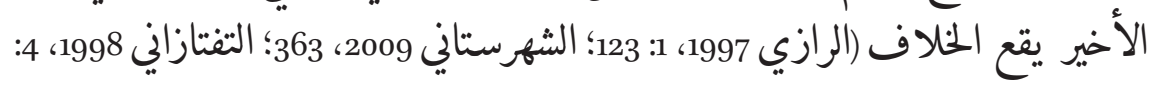

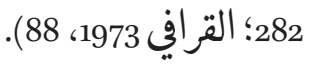


يندرج النقاش السابت ضمن ما بعد الأخلاق (meta-ethics) ومصادر الأحكام

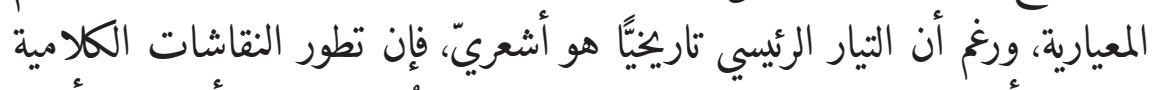

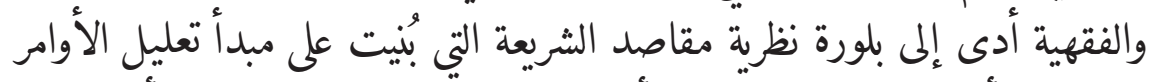

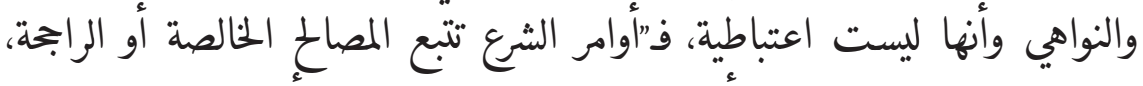

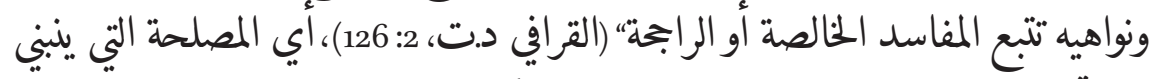

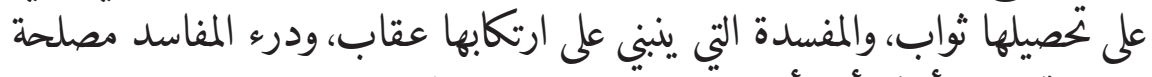

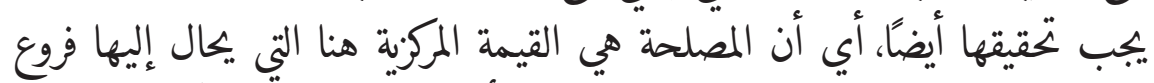

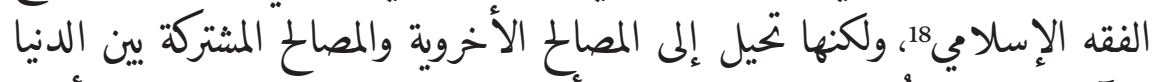

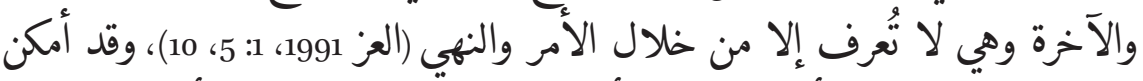

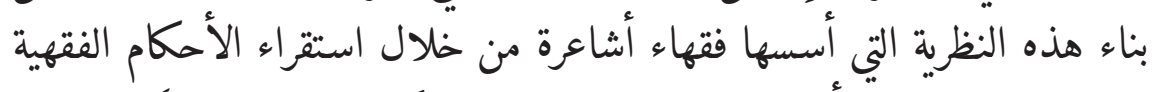

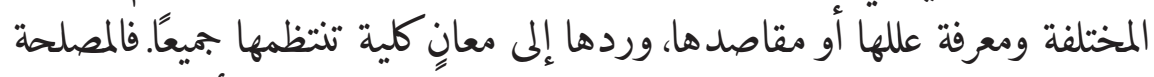

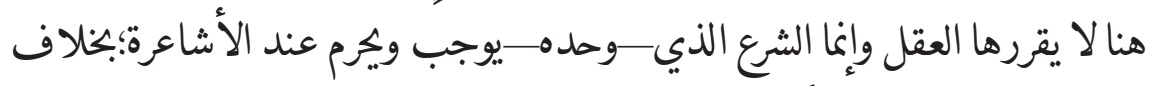

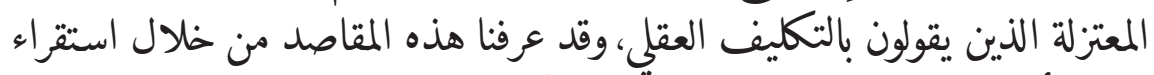

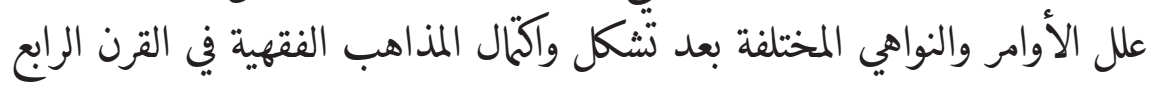
الهجري/العاشر الميلادي.

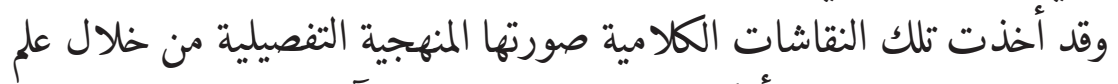
أصول الفقه الذي يعاجج الأحكام المعيارية، ومصادرها، وآليات استنباطها، وهو علم"

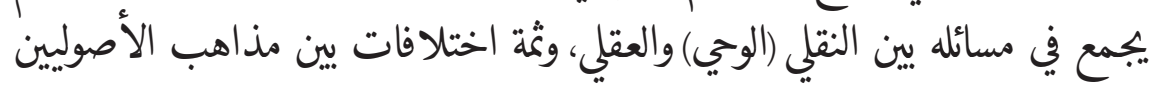

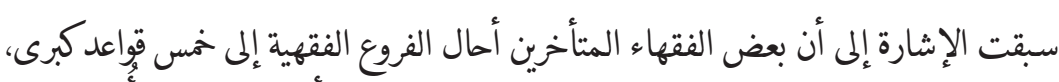

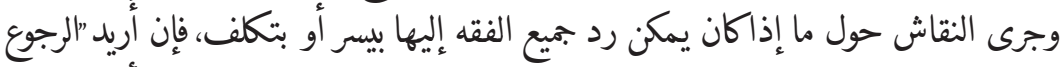

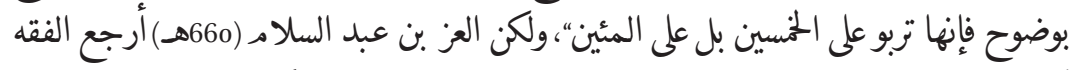

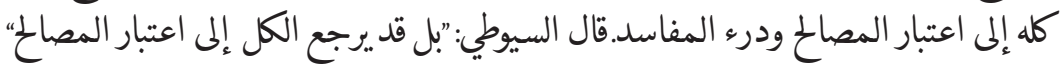
(السيوطي 1983، 8). أي أن المقاصد هي نظرية تعبر عن آكمال منظومة المذاهب الفقهية؛ فإنما أمكن التأسيس 19

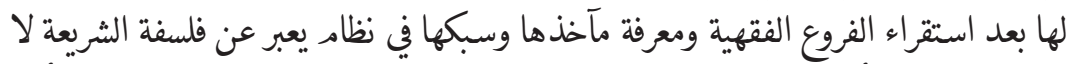

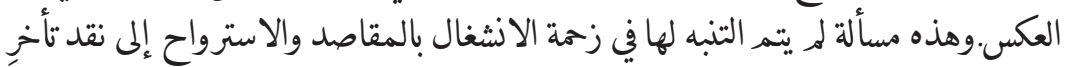

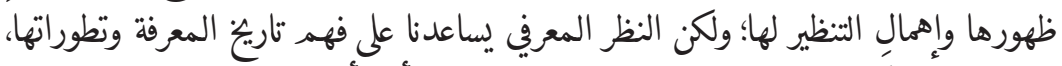

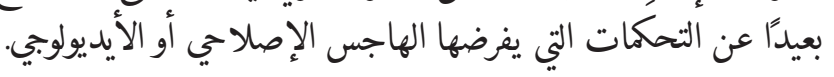


بين موسّع ومضيّق، ولكن نظرية مقاصد الشريعة جاءت لتبرز الفلسفة الكلية

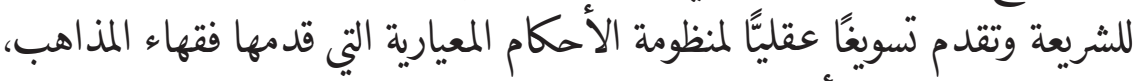

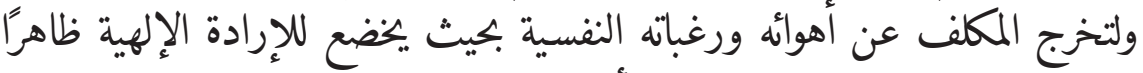

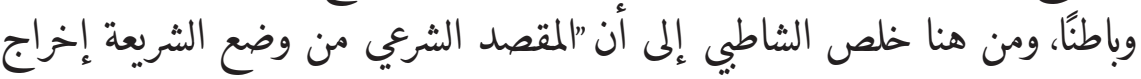

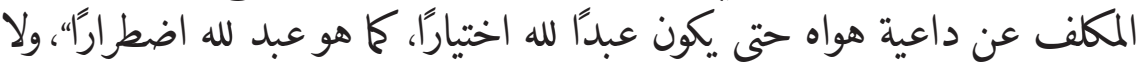

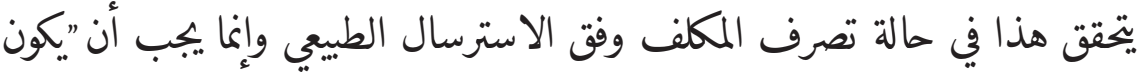

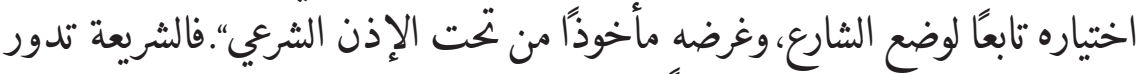

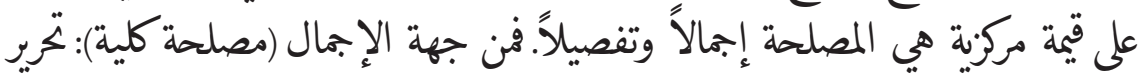

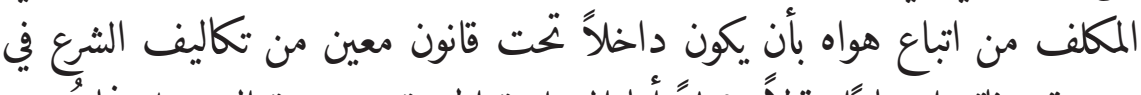

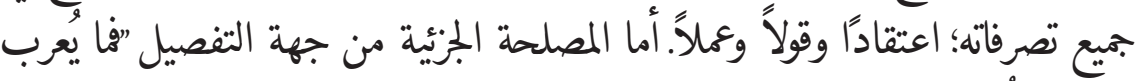

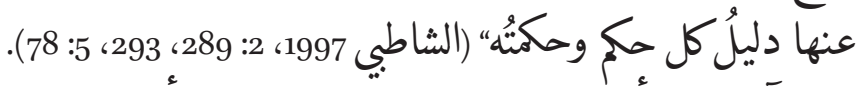

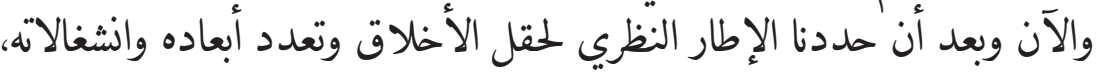
سنحاول إعادة صياغة الموقف الأخلاقي من الجينوم بناء عليه.

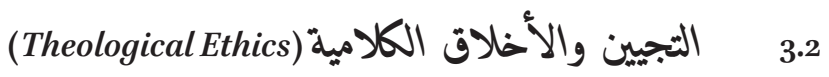

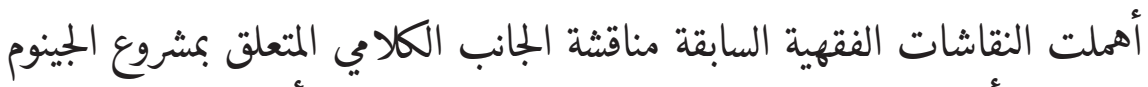

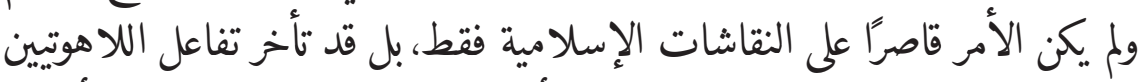

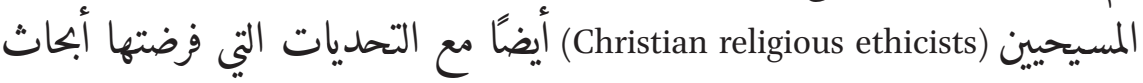

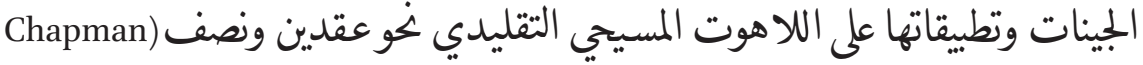

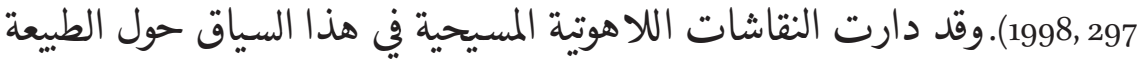

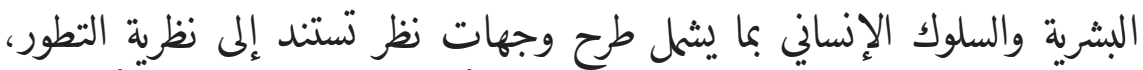

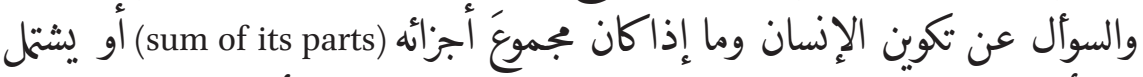

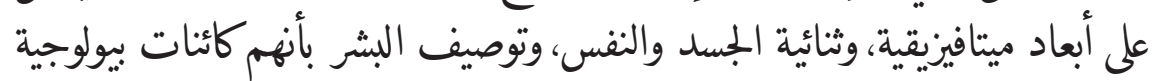

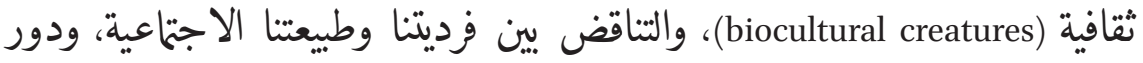

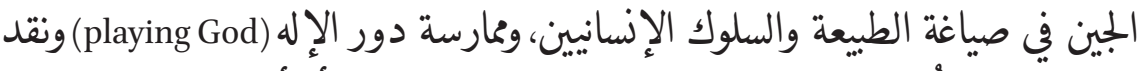

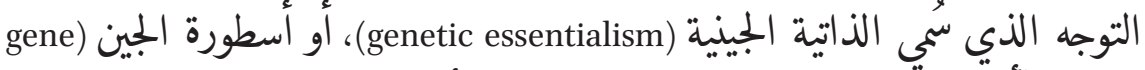
Chapman 1998,(تلأكيد فكرة الإبداع الإنساني، والمسؤولية الأخلاقية، والحينة (myth .(296-299; Peters 1997; Peters 1998 
ومن منظور علم الكلام الإسلامي يمكن لنا أن نتاقش التجيين من مدخلين رئيسين

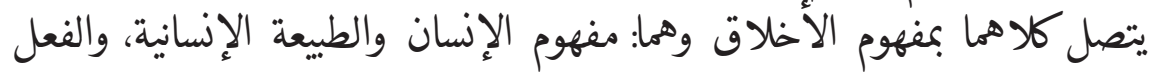
الإنساني وعلاقته بالفعل الإلهي.

\section{مفهوم الإنسان والطبيعة الإنسانية}

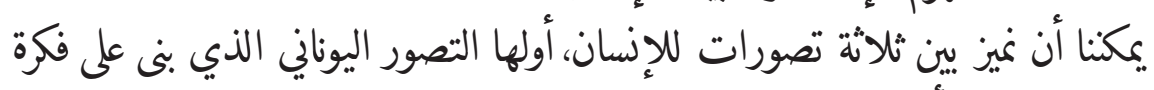

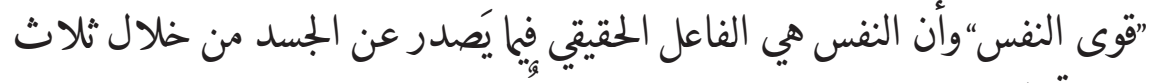

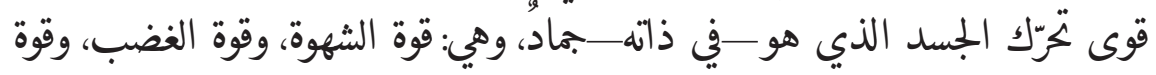

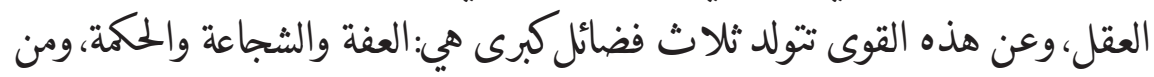

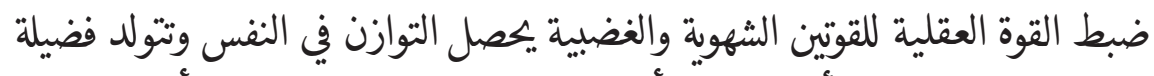

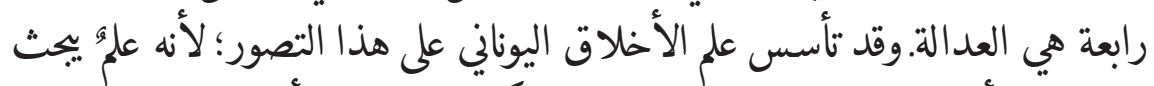

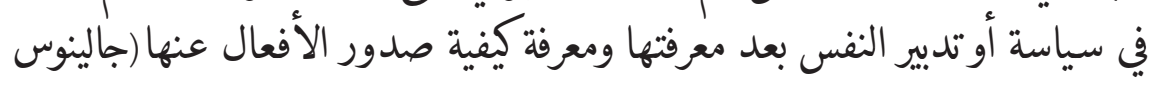

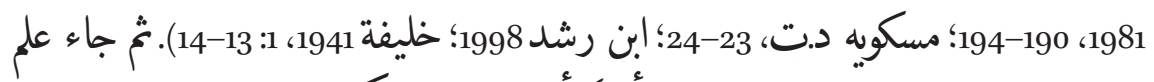
التصوف الإسلامي وبنى على النفس أيضًا أطروحته في تزيكة النفس وترقيتها. التصور

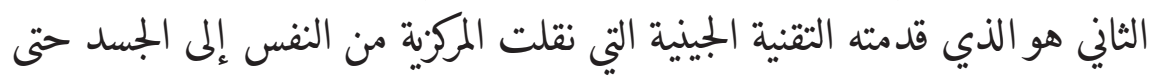

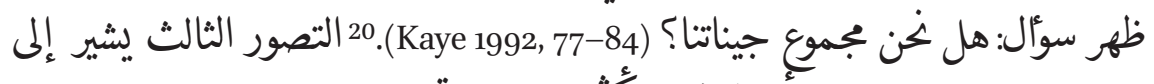

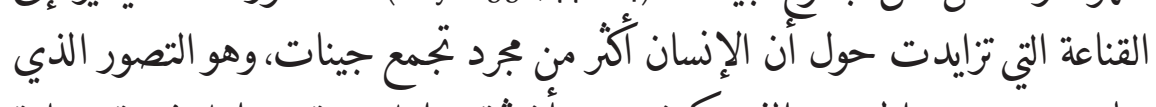
ساد بعد مشروع الجينوم والذي كثف عن أن ثمة عوامل بيئية وعوامل فردية متحدية متعلقة

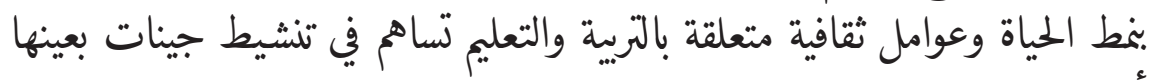
أو علده.

20 قد يجد بعضهم أساسًا لهذا التصور في نظرية الأخلاط التي سادت في الفلسفة اليونانية

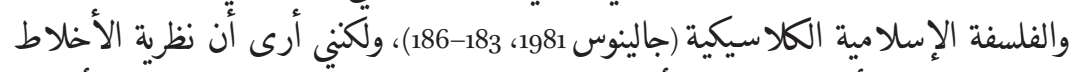

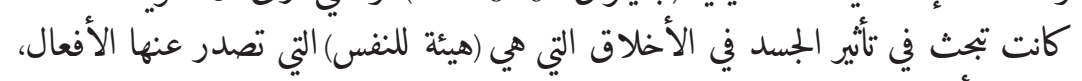

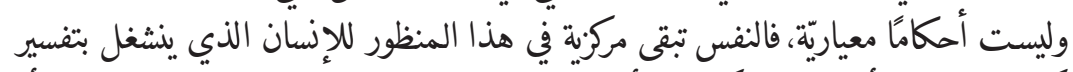

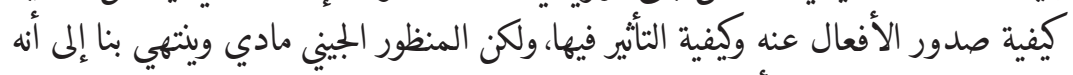

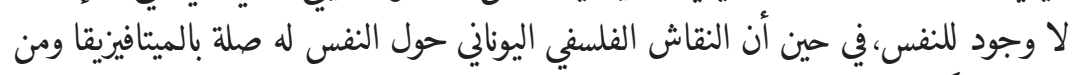

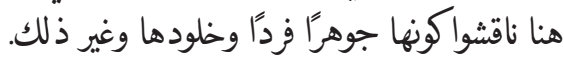


لا يمكن للاهوت عامة والإسلائ خاصة أن يُسقط الأبعاد الروحية والميتافيزيقية

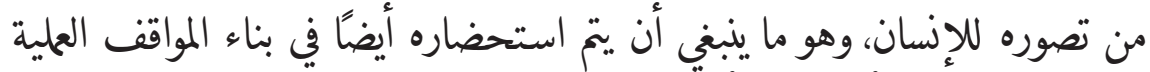

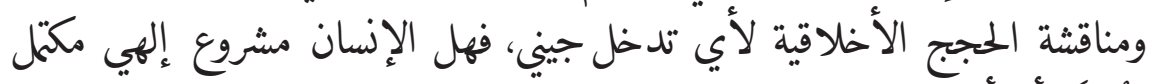

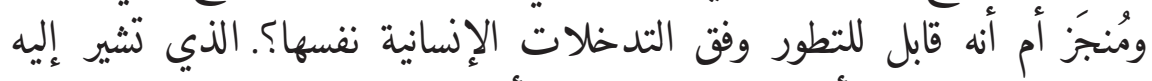

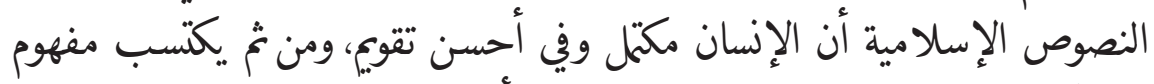

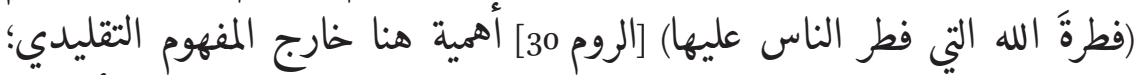

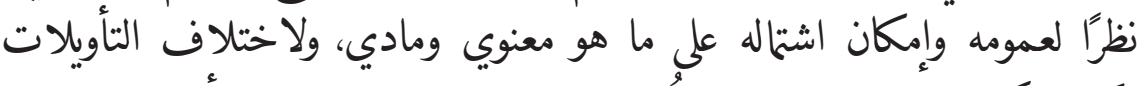

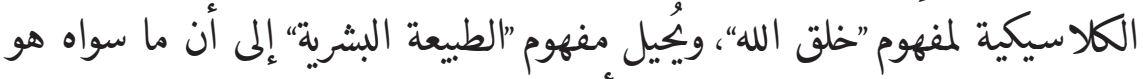
المصنّع، فالطبيعة التي خلقها الله هي الأساس المعبر عنه بالفطرة.

$$
\text { الفعل الإلمي والفعل الإنساني }
$$

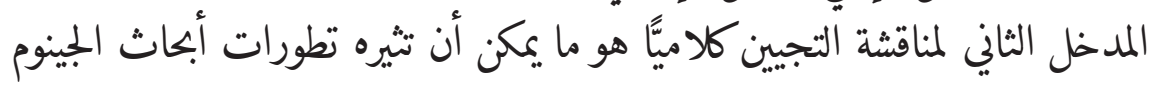

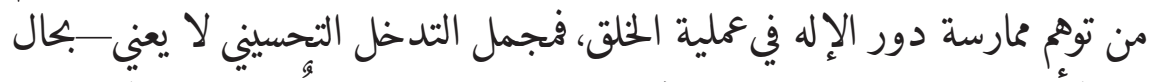

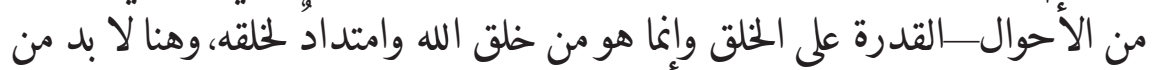

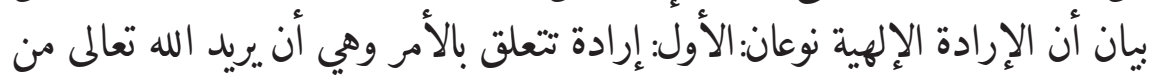

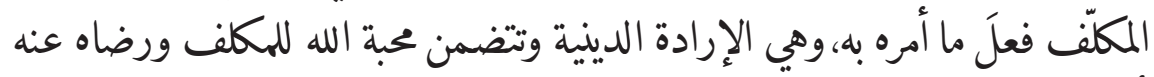

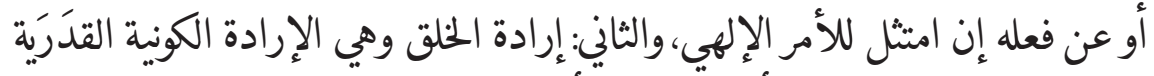

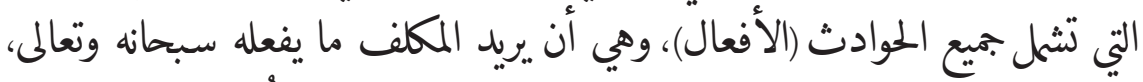

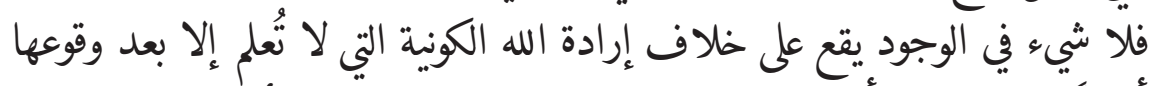

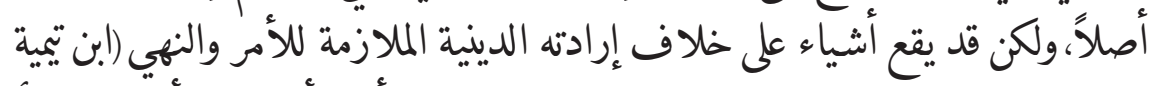

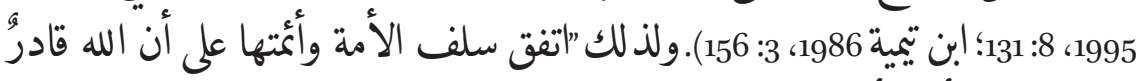

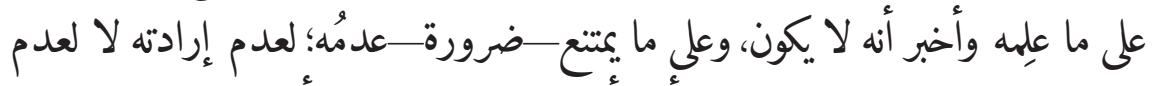

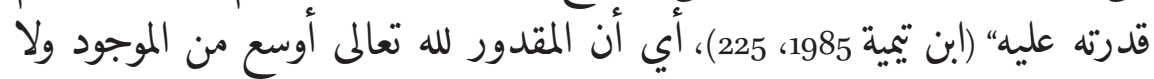

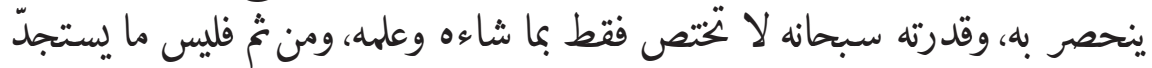

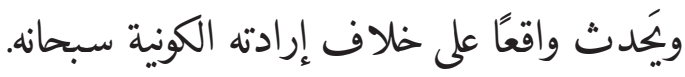

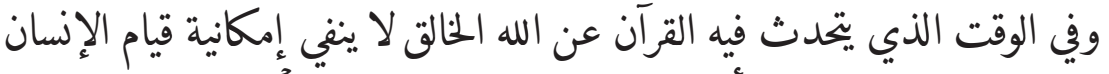

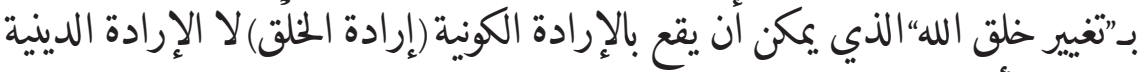

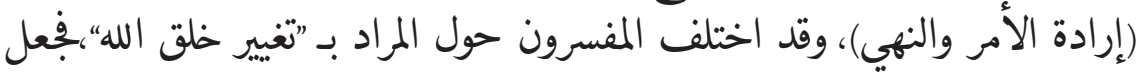


بعضهم معيار التغيير هو النفع والضرر؛ فالتغيي النافع حسن؛، والتغيير الضار قبيحُ

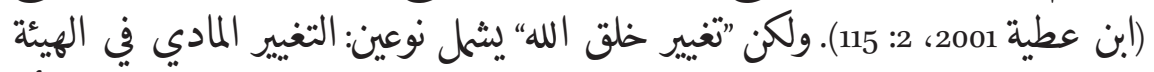

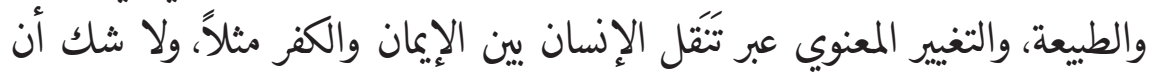

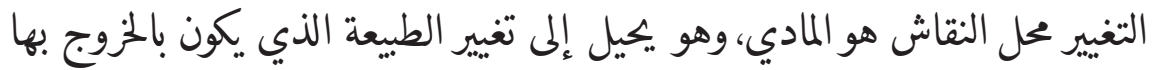

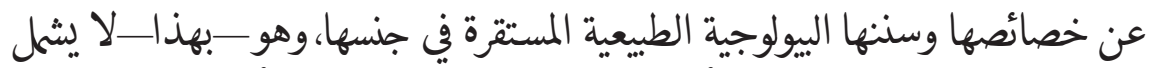

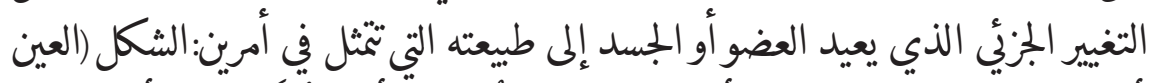

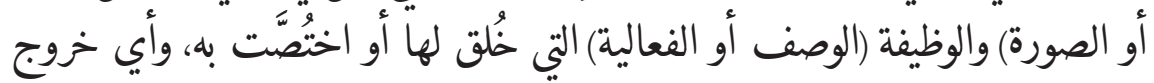

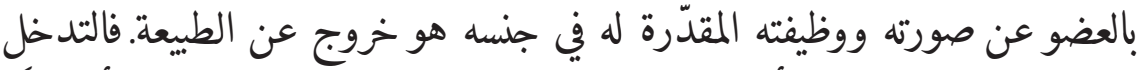

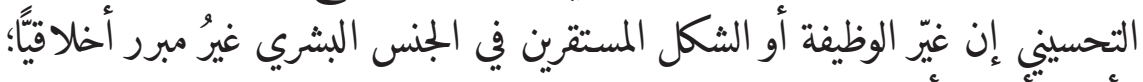

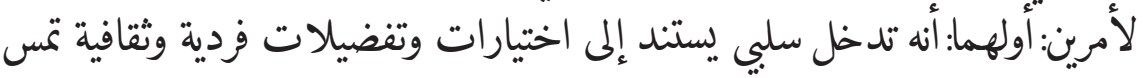
النوع الإنساني وتوازنه (الهندسة الطبيعية)؛ فقرار التغيير لا يستند إلى مرجعية عقلية

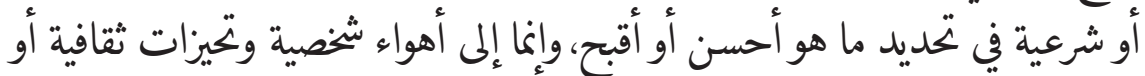

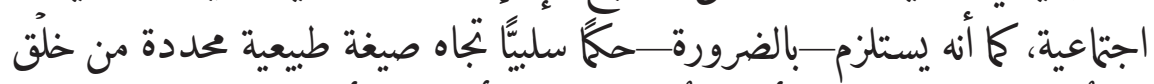

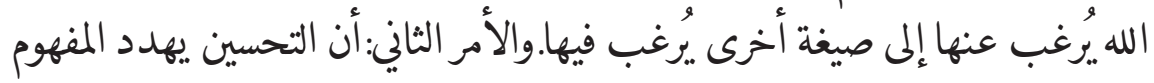

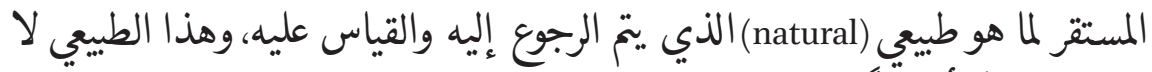

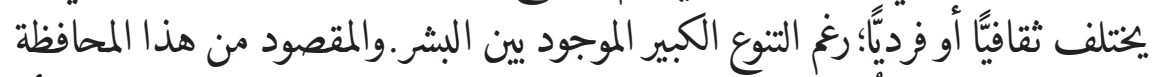

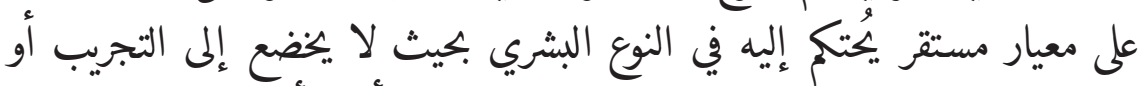

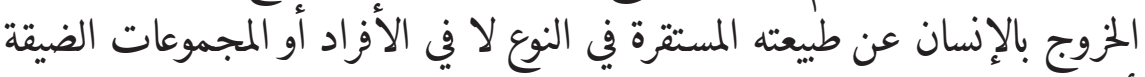

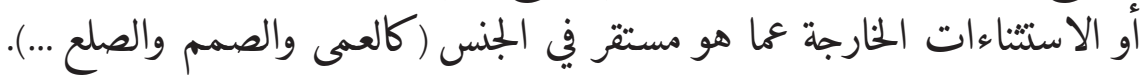

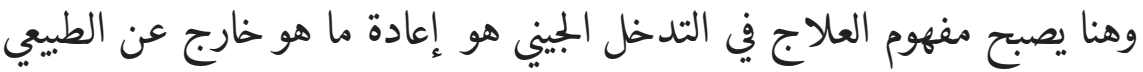

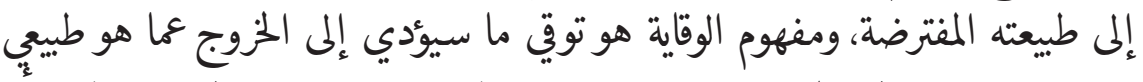

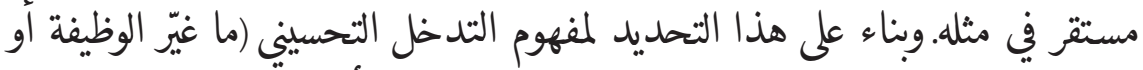

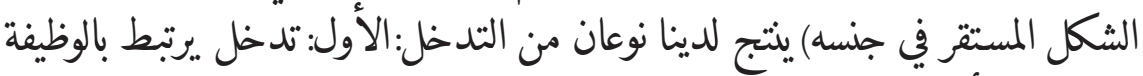

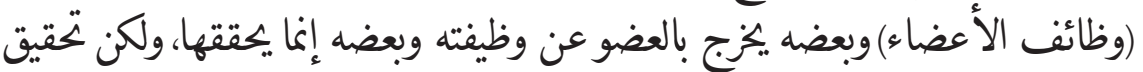

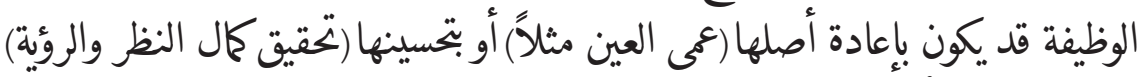

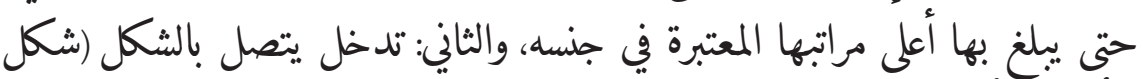

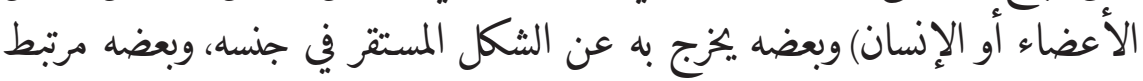


بالتفضيلات التي يسمح بها ما هو مألوف في جنسه مما يحقق مصالح معتبرة شرعًا ولا يخل بالمعيار المستقر في جنسه.

\section{التجيين والنظر الفقهي المنظوي}

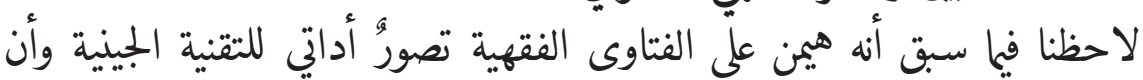

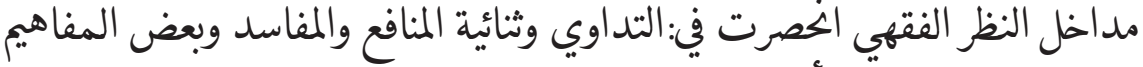

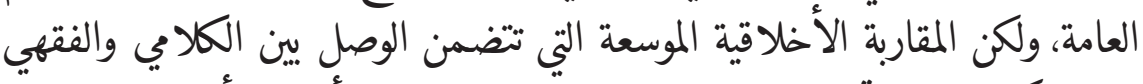

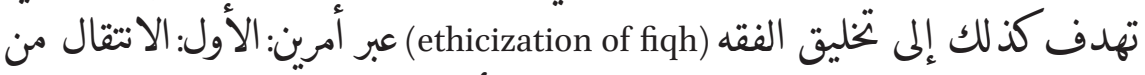

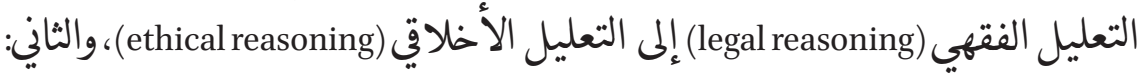
الوصل بين التراث الفقهي الضخم مع إدراك سياقاته التاريخية (historical settings)

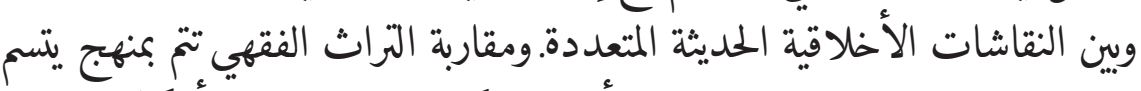

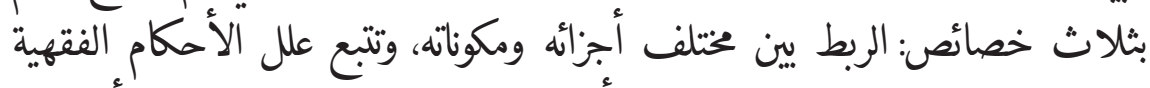

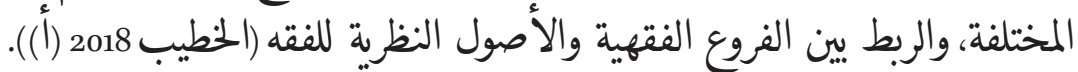

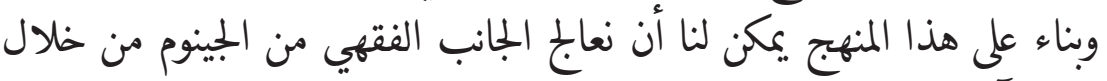

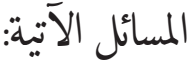

\section{التدخل الجيني ومنظومة المفاهيم الفقهية المركزية}

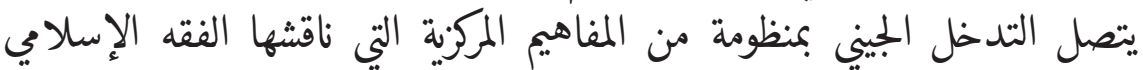

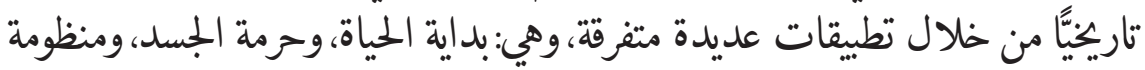

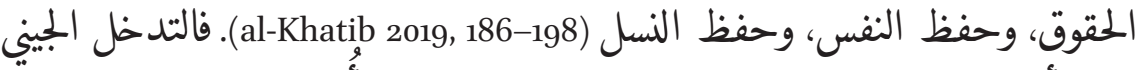

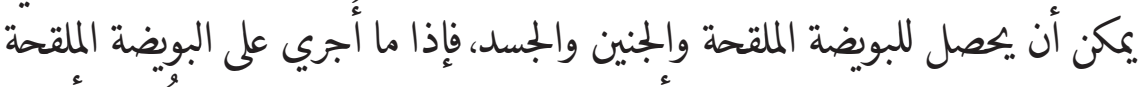

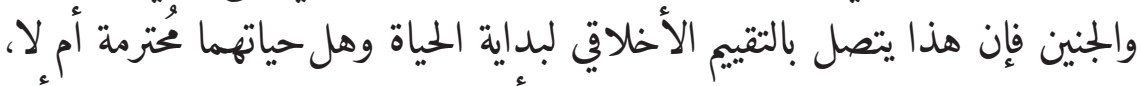
وقد ذهب عدد من المفتين المعاصرين إلى أن البويضة الملقحة لا حرمة لها؛ لأنها

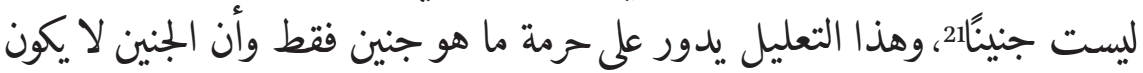

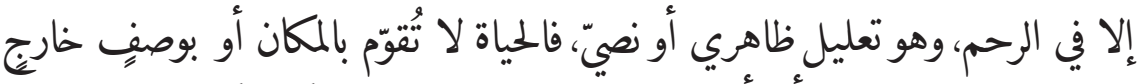

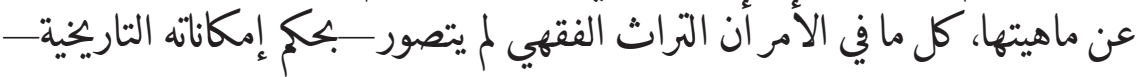

21 المنظمة الإسلامية للعلوه الطبية في الكوت، الندوة الثالثة، بتاريخ 18 (الأشقر 2001، 1: 305-310). 
وجود بويضة ملقحة خارج الرحم، ولكن المعرفة الحديثة تخبرنا بأن الحياة تبدأ من

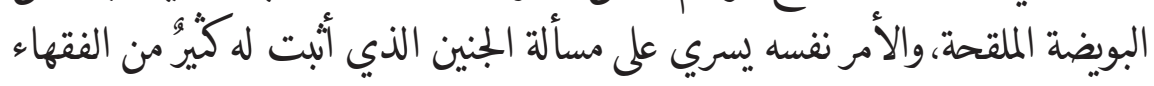

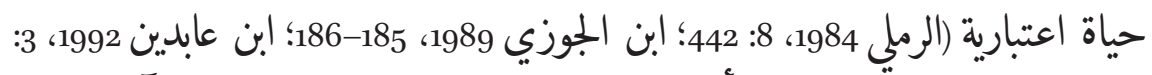
176؛ الشبراملسي 1984، 6: 182). أما التدخل في الجسد فيثيثي سؤال حرمة "الآدمية“، التي

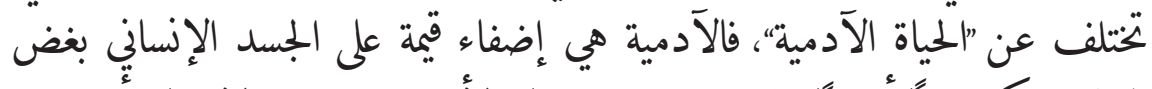

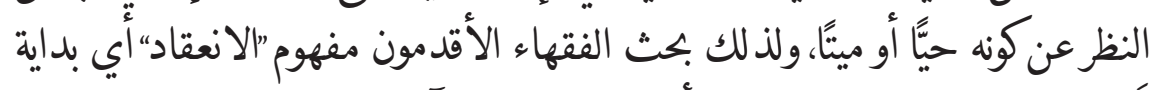

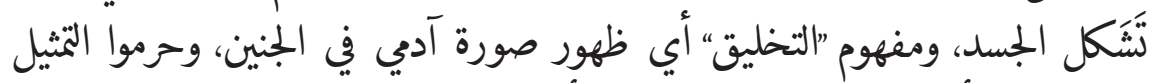

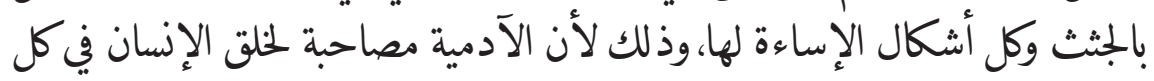

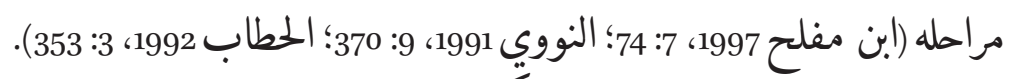
والتدخل الجيني يمس مقصدين كيرين من مقاصد الشريعة وهما: حفظ النفس النس

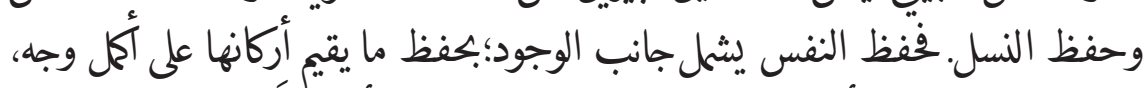

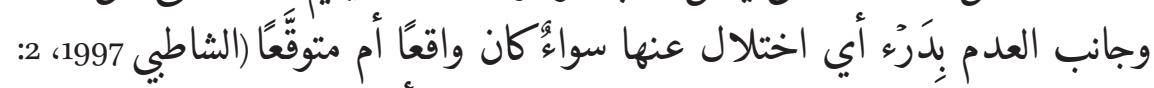

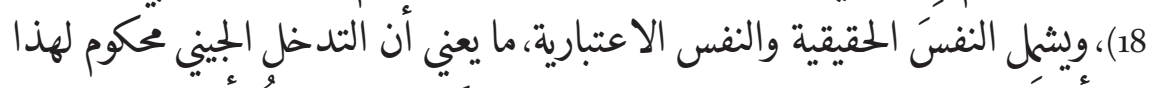

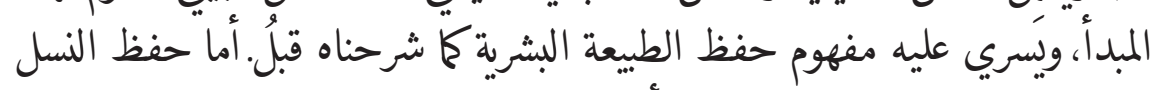
فيتداخل مع حفظ النفس من جهة أنها تشتمل على الحفظ من جانب الجزّئي؛ بما يشل إنهل

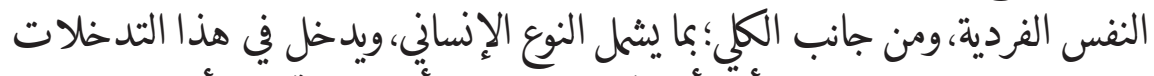

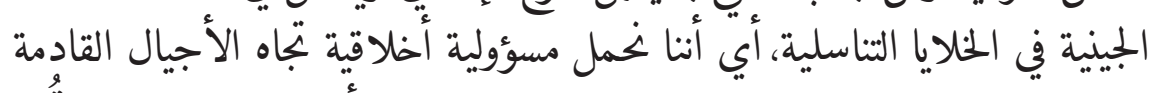

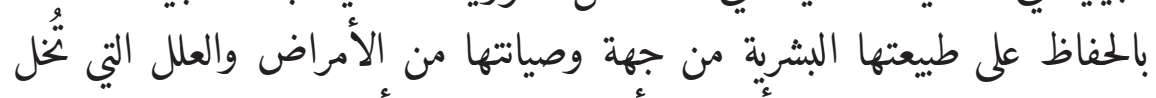

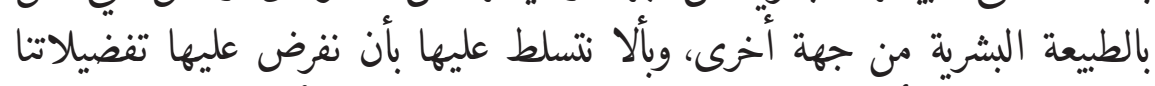
وخياراتنا الثقافية أو الفردية من جهة ثنالثة. يضاف إلى هذا هذا مسألة مركزية في الإسلام

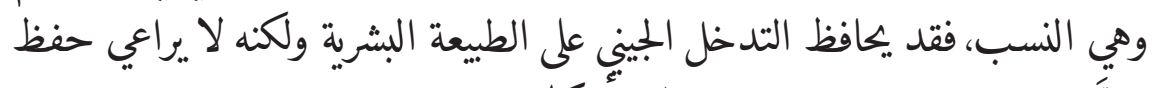

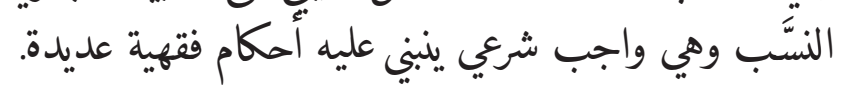

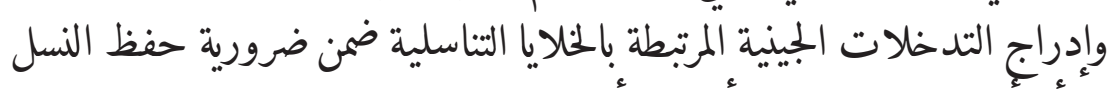

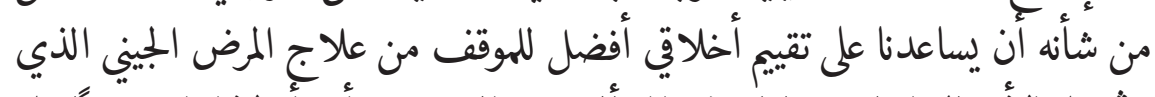

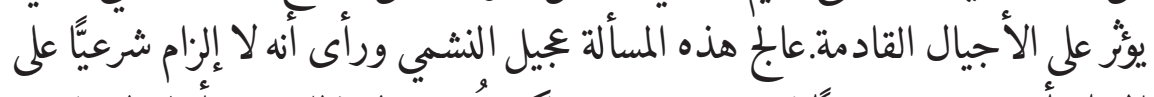

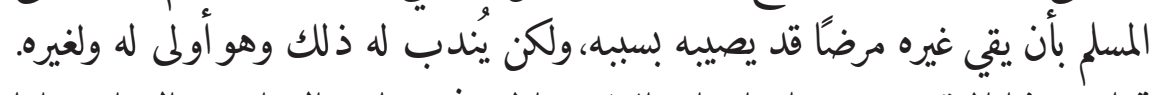

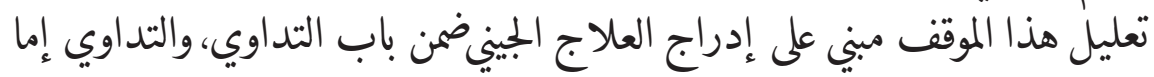


مباح أو مندوب ولا يمكن أن نؤسس لواجب على المندوب أو المباح. وبناء على هذا

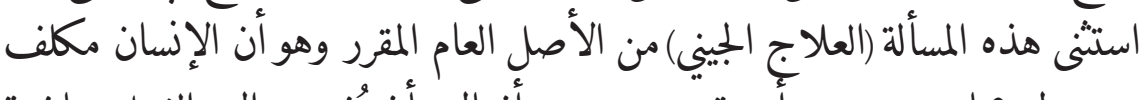

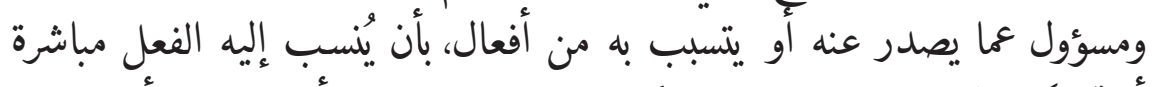

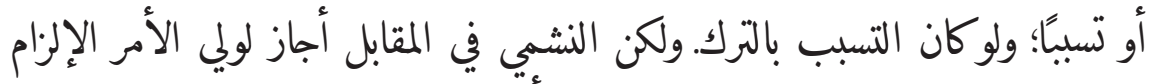

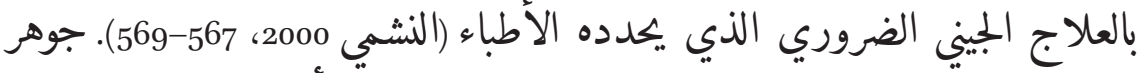

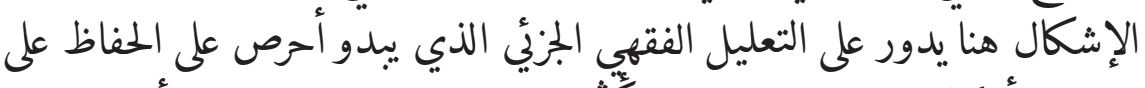

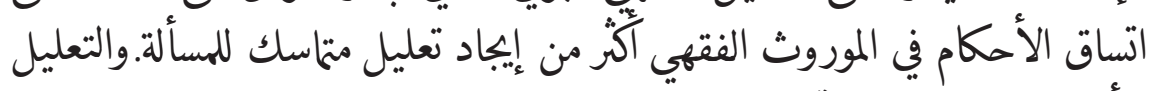

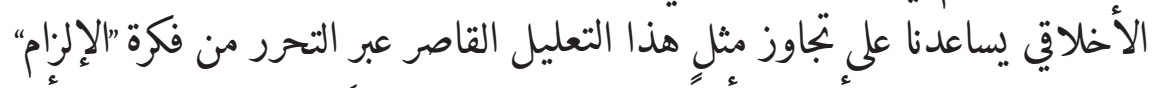

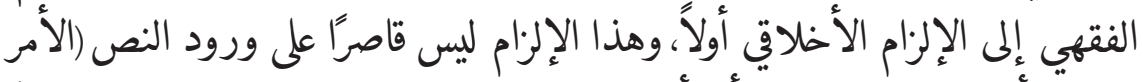

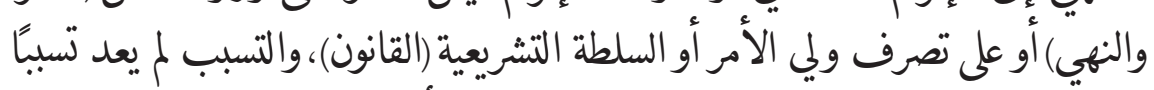

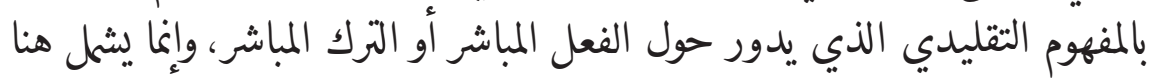

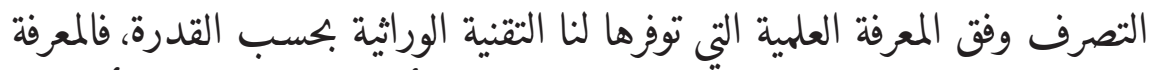

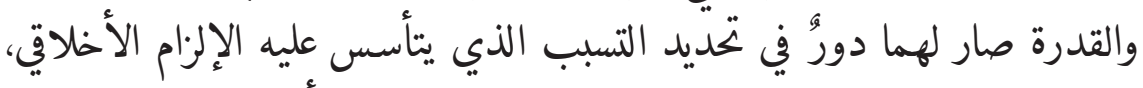

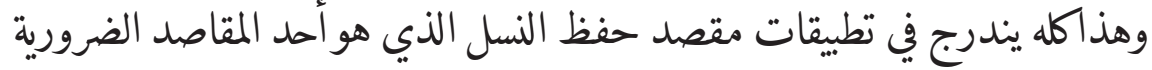
في الشربعة.

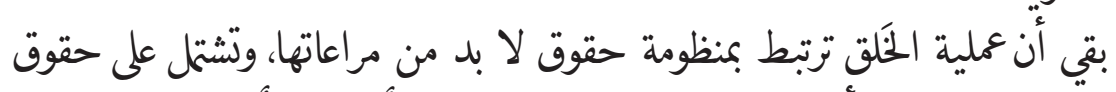

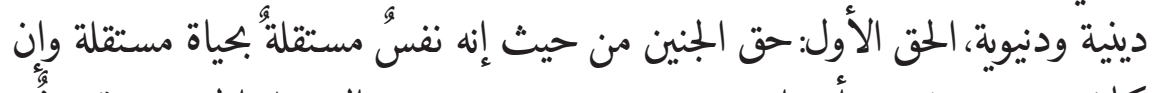

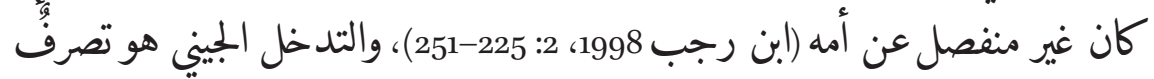

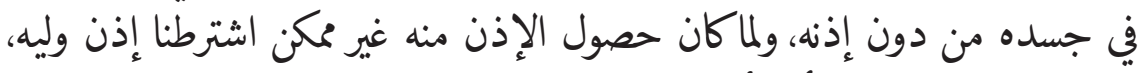

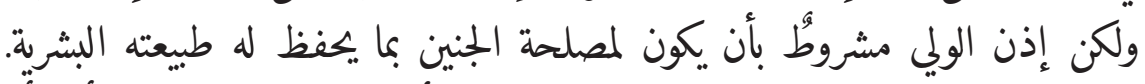

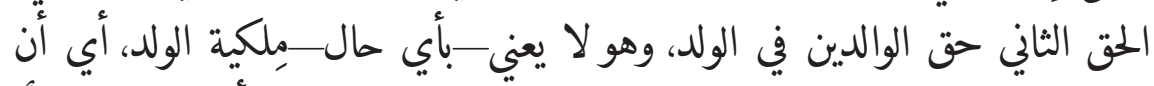

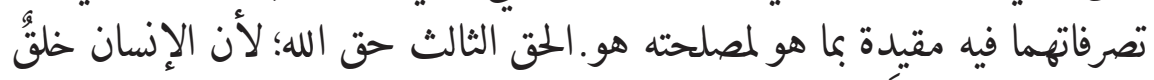

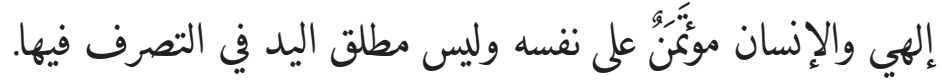

\section{القياس: التغيير العضوي والتغيير الجيني}

$3 \cdot 3 \cdot 2$

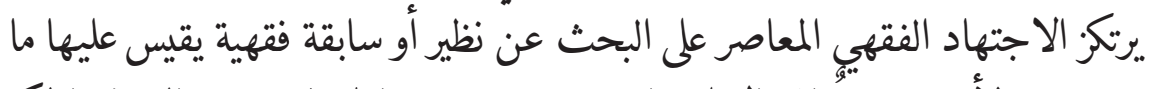

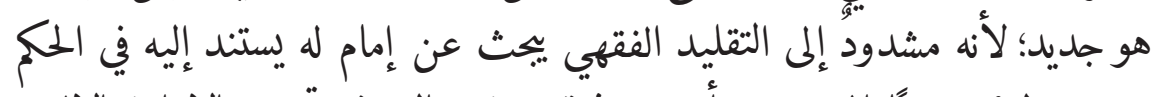

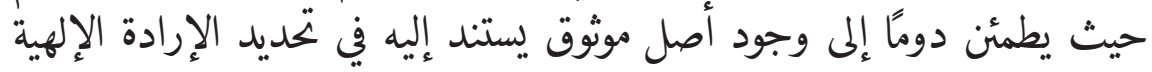




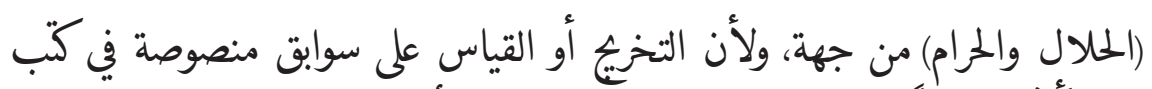

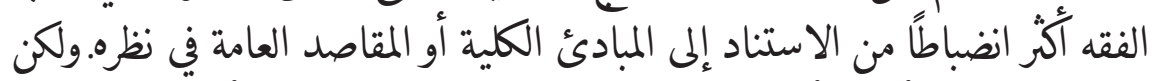

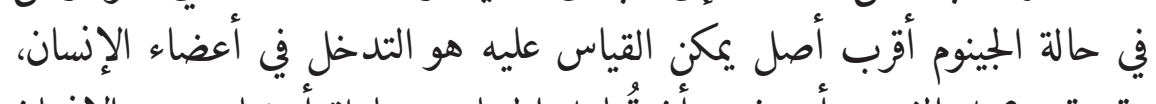

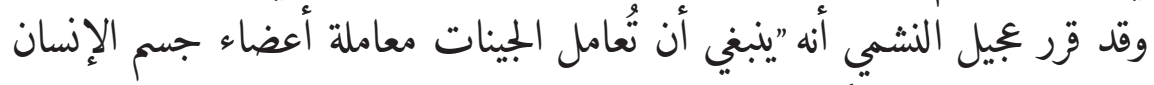
من حيث الجملة، ... لكن الجينات لها خصوصية ينيني مراعاتها،، ووزّق بين الحلايا

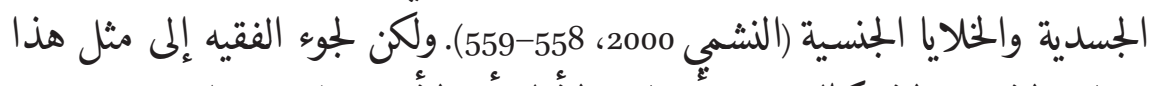

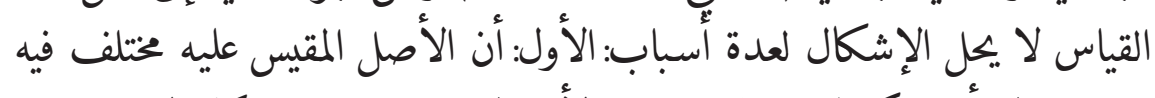

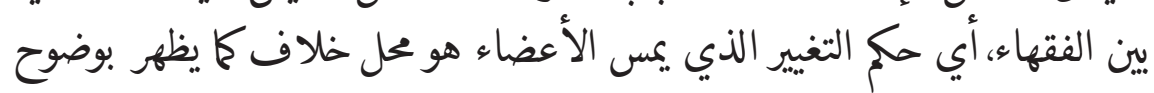

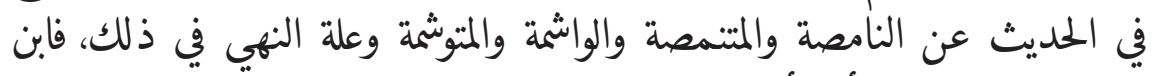

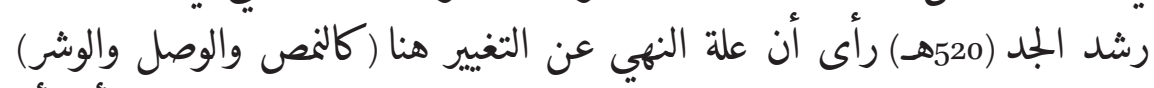

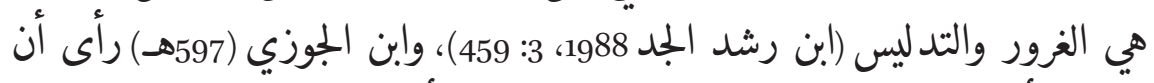

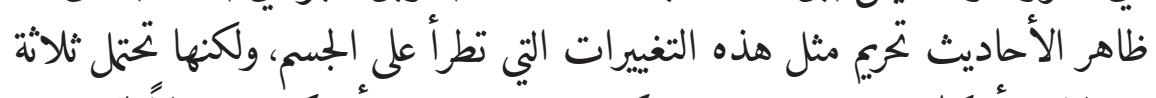

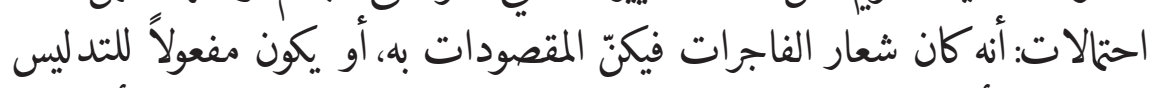

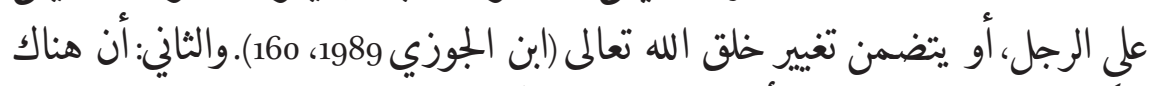

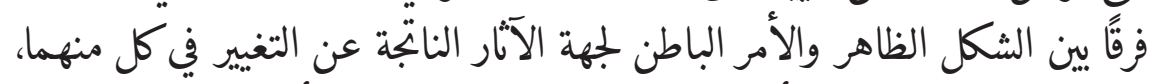

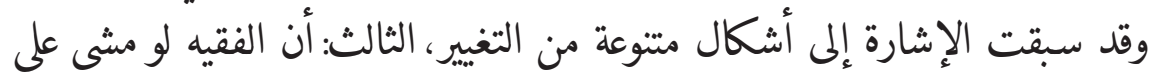

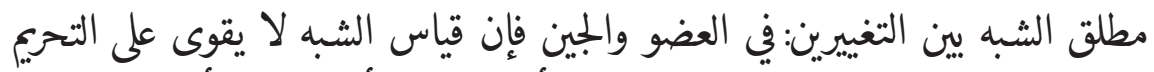

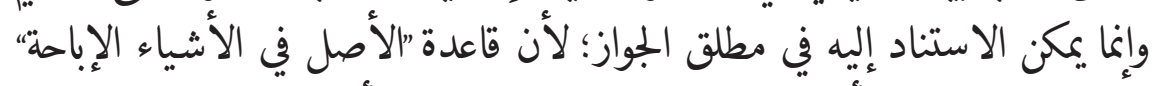

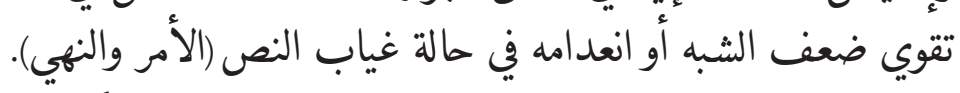

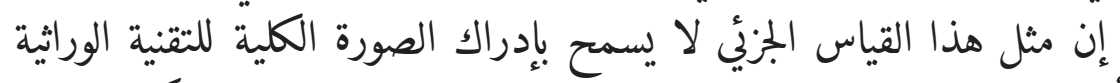

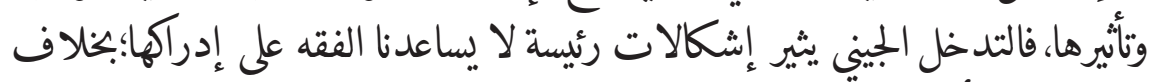

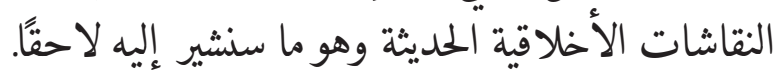

$$
\text { المعالح والمغاسد }
$$

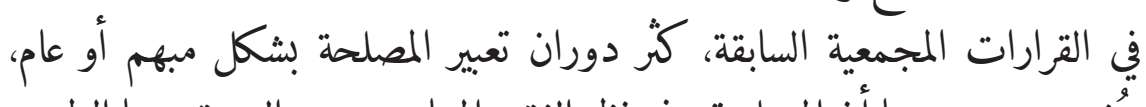

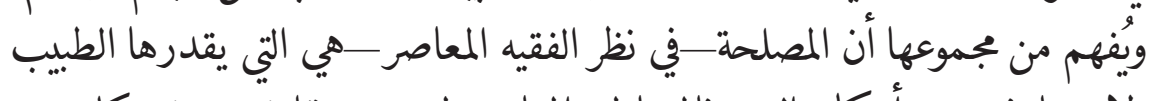

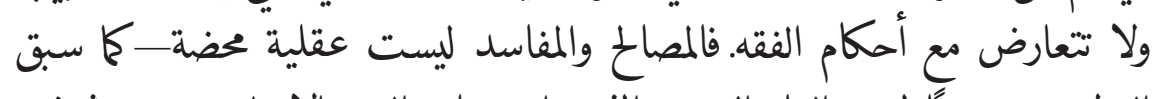

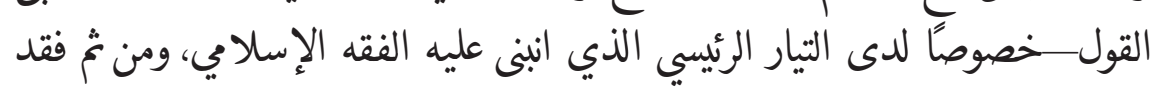


توجد منفعة دنيوية ولا تكون معتبرة شرعًا؛ لأن مدار الاعتبار والإلغاء على الوحي

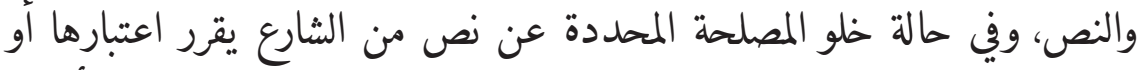

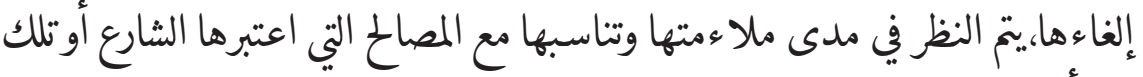

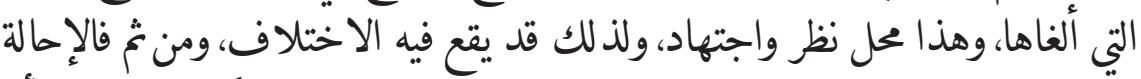

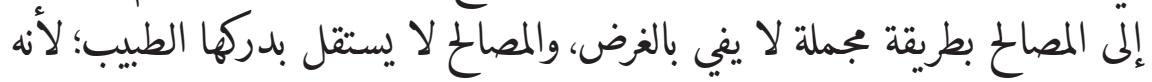

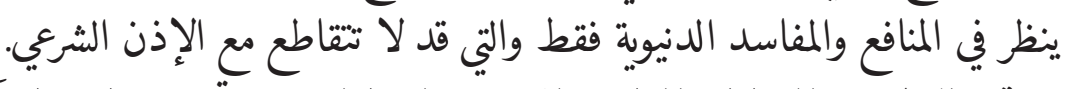

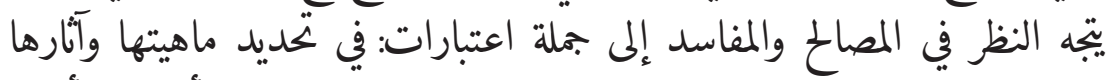

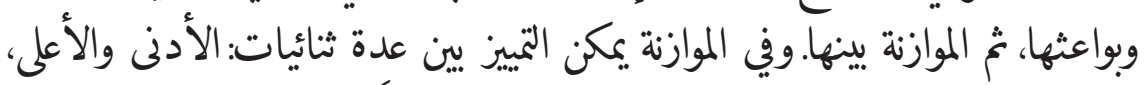

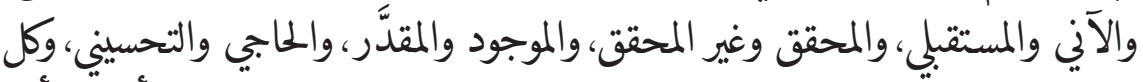

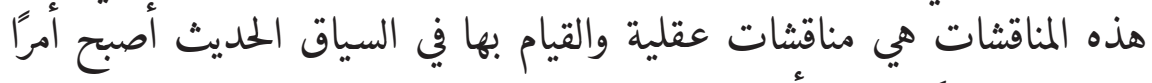

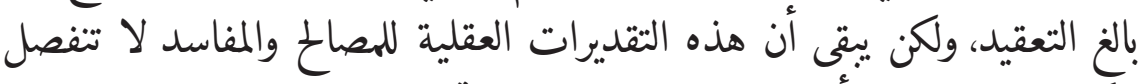

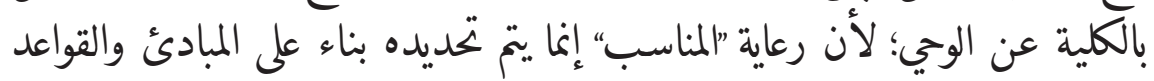

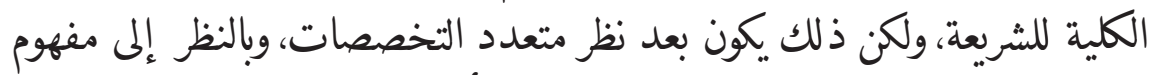

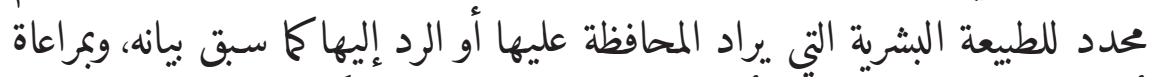

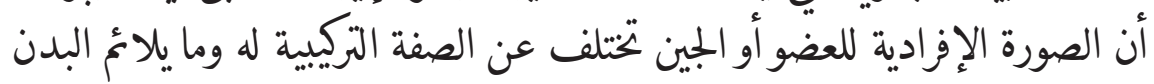

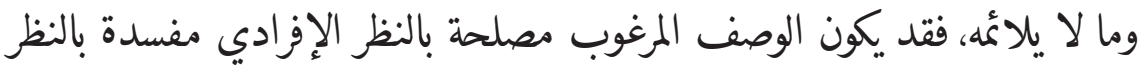

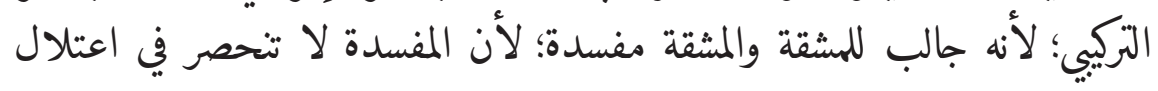

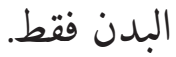

\section{البيولوجيا وسلطة الطب}

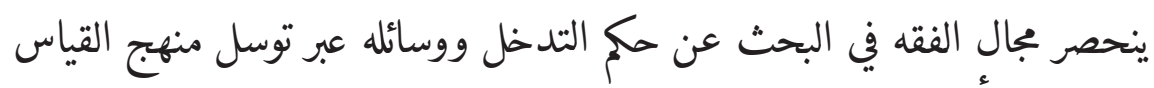

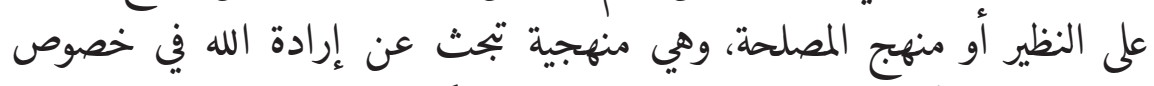

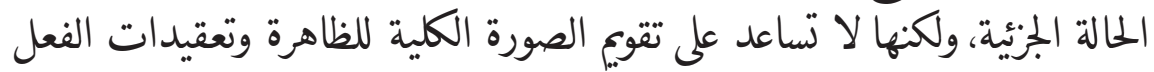

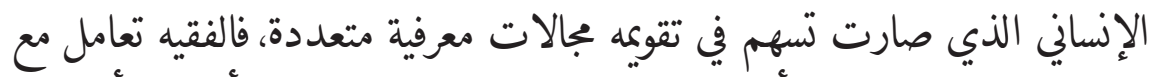

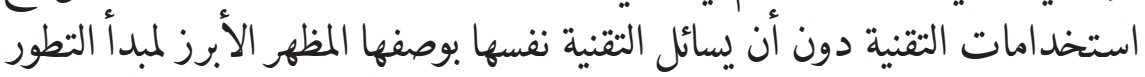

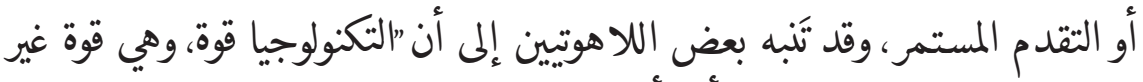

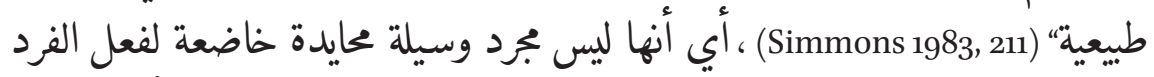

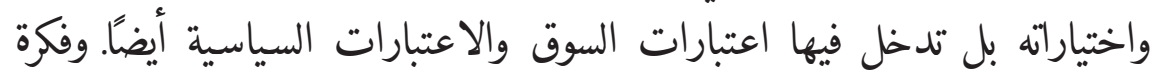


التطور المستمر تفرض إشكالات عديدة أوسع من مجرد سوأل المنافع والمفاسد ألمات

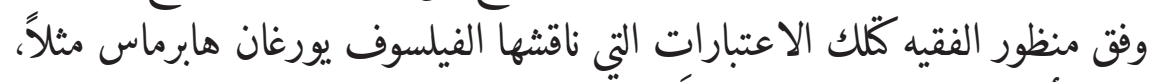

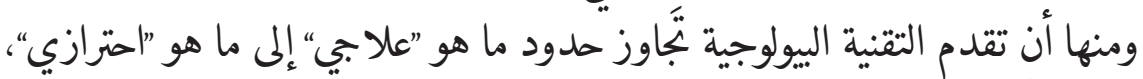

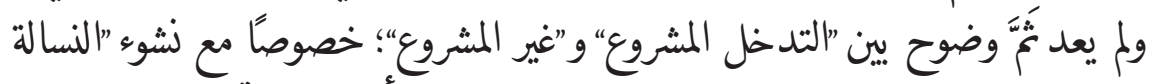

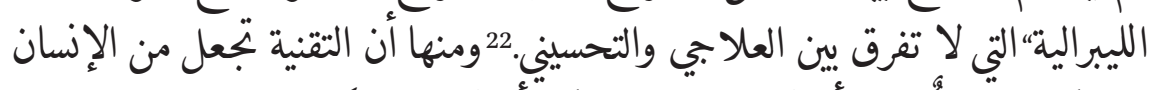

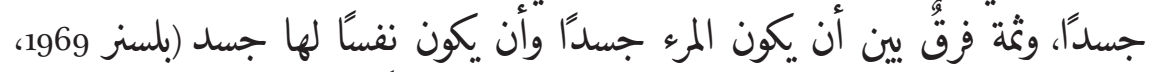

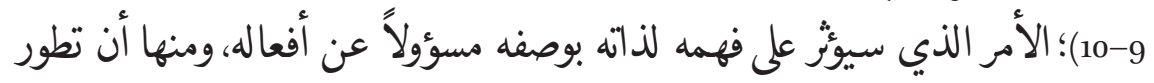
التقنيات البيولوجية قد يهدد الوضوح الذي اتسمت به الطبيعة البشرية (النوعية)

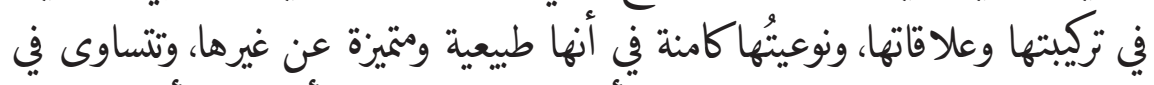
ظروف تناسلها من دون تدخلات أو تحيزات اقتصادية أو ثقافية أو بيولوجية.

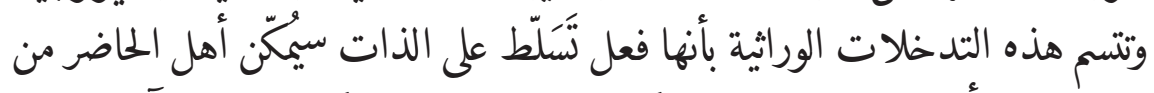

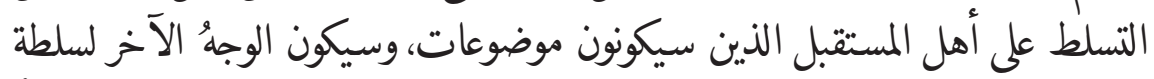

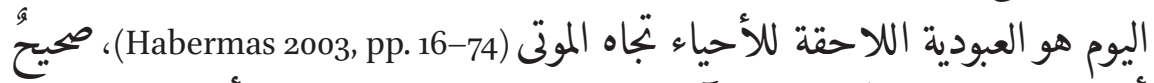

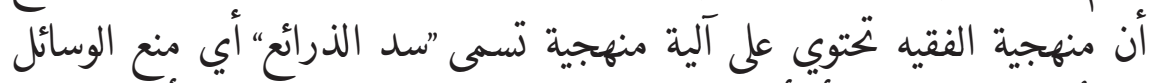

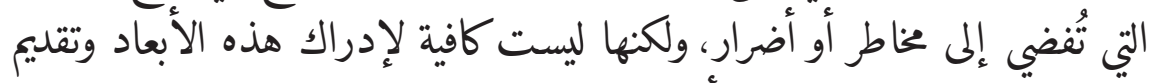

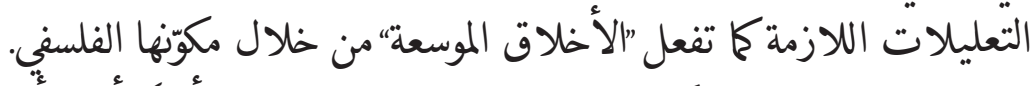

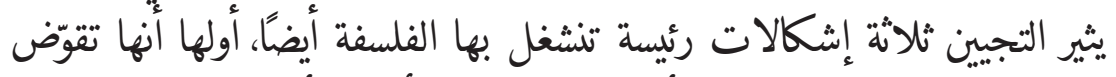

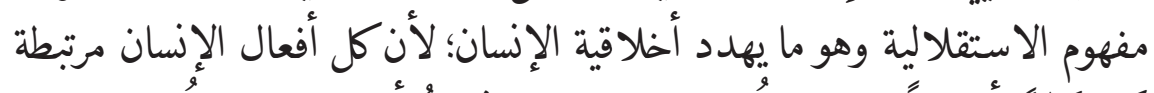

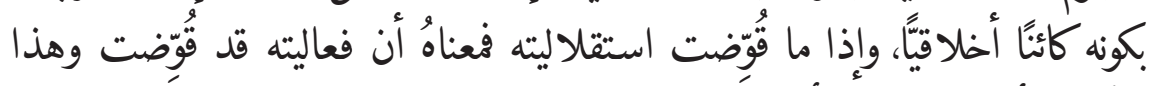

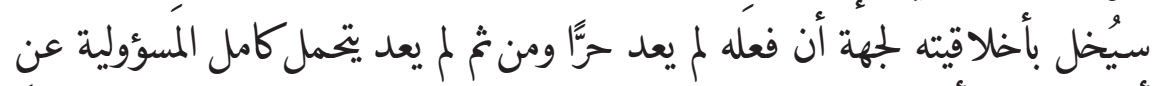

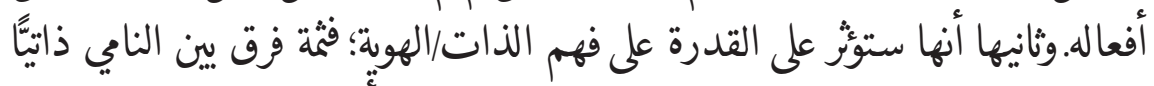

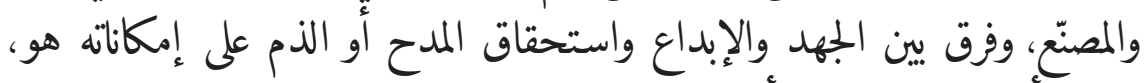

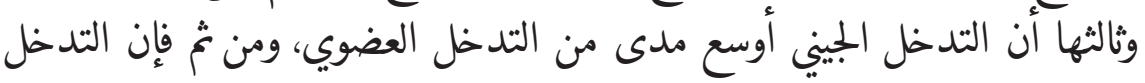
في البويضة الملقحة قبل الزرع يثير إشكالات تتعلق بالموقف من الطبيعة ما قبل

22 يحيل مفهوم النسالة الليبرالية إلى مسألة تحسين النسل؛ الممارسة التي تعطي الأبوين الحق في اتخاذ قرار التدخل في جينوه الجنين حسب مالي الميرونه مناسبًا. 
الشخصية (pre personal life) والكرامة الإنسانية لما سيكونه هذا الكائن مستقبلاً،

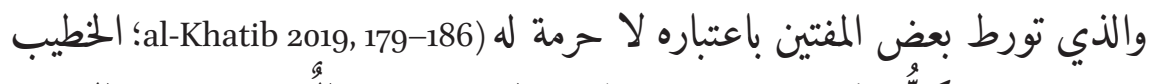

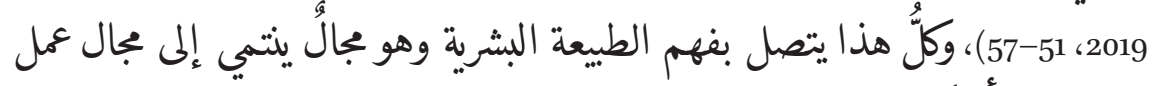
الفيلسوف أيضًا.

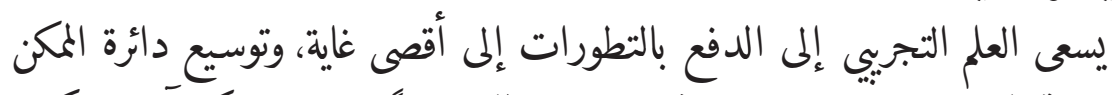

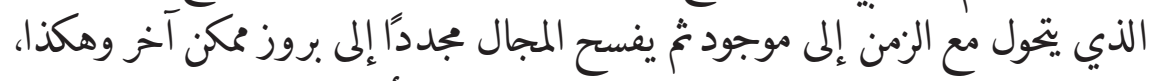

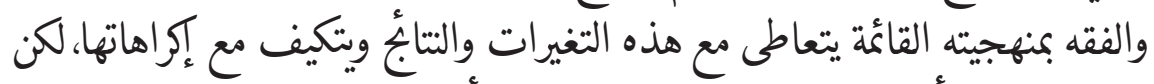

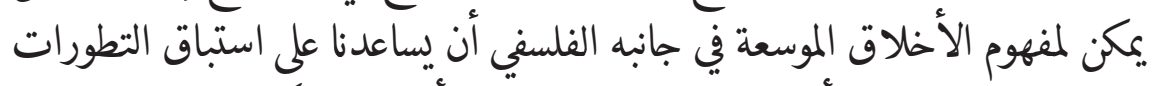

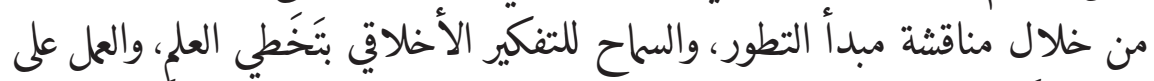

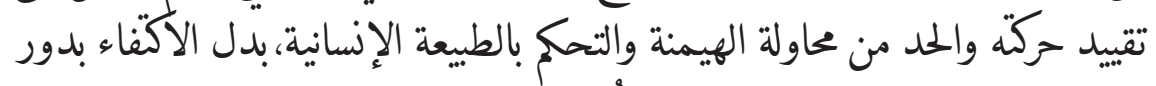

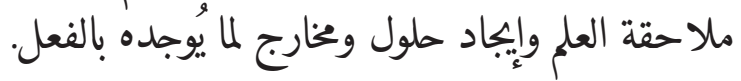

خاتمة

تساعدنا هذه المقاربة الأخلاقية الموسعة على إدراك مفهوم مركب للدين هو تتاج

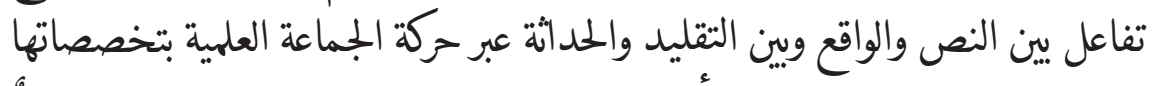

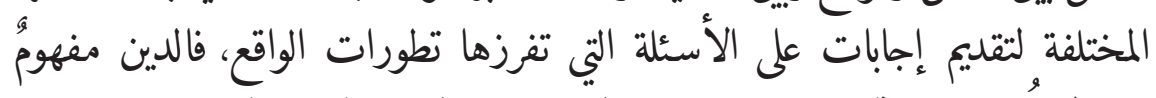

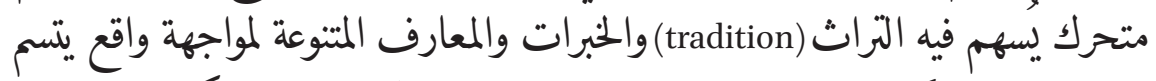

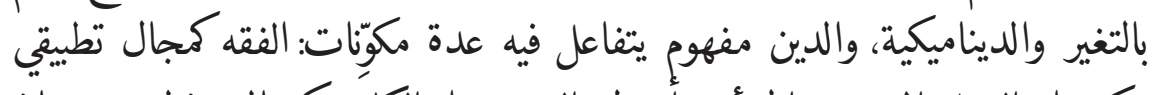

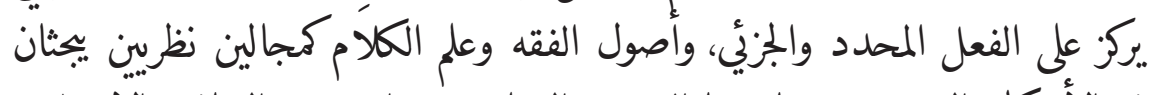

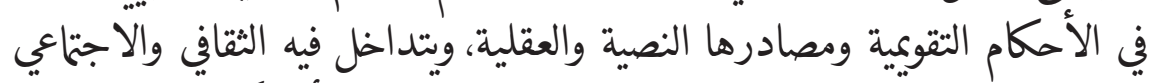

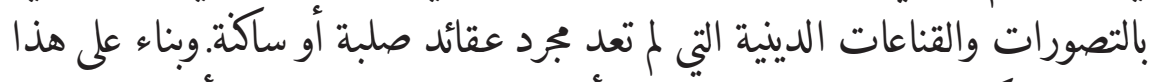

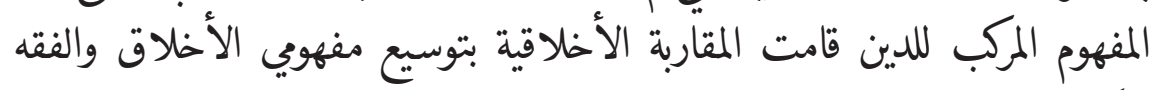

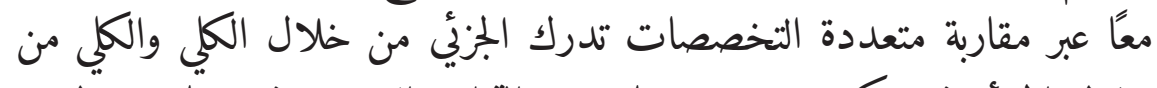

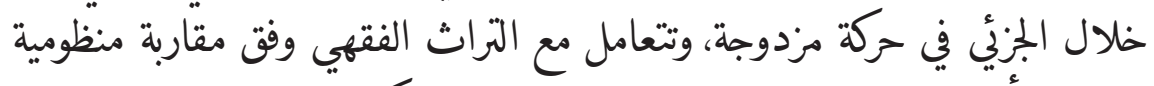

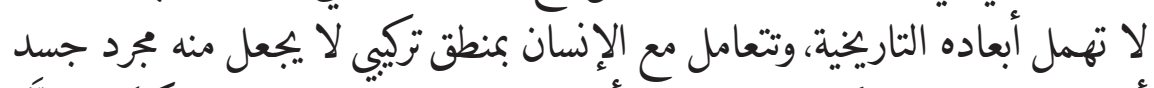

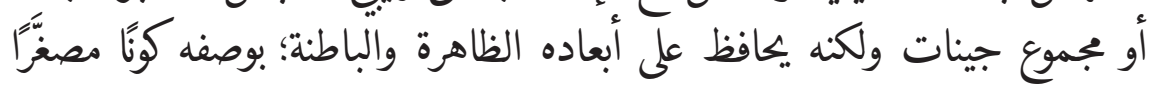


تنعكس فيه الإرادة الإلهية، ووفق هذا المنظور فإن الإنسان مؤعنَ على جسده لا

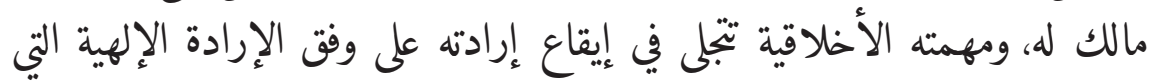

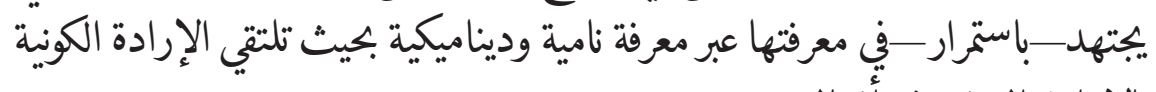
بالإرادة الدينية في أفعاله.

المصادر

ابن تيمهة، تقي الدين. 1986. منهاج السنة النبوية في نقض كلام الشيعة القدرية. تحقيق محد رشاد سالم، الرياض: جامعة الإمام محمد بن سعود.

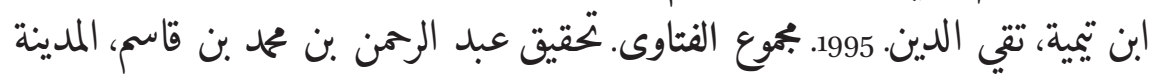

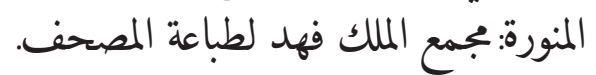
ابن رجب. 1998. تقرير القواعد وتحريز الفوائد، تحقيق مشهور آل سلمان.السعودية:دار ابن عفان.

ابن عابدين، محمد أمين. 1992. رد المحتار على الدر المختارك بيروت:دار الفكر.

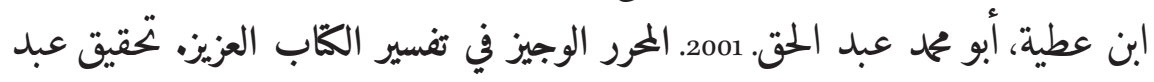
السلام عبد الشافي، بيروت: دار الكتب العلهية.

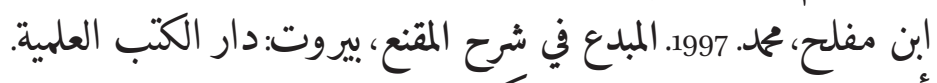

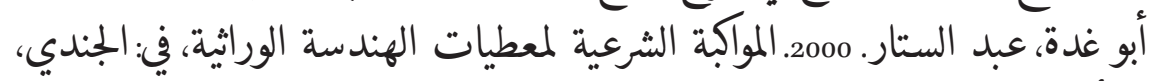

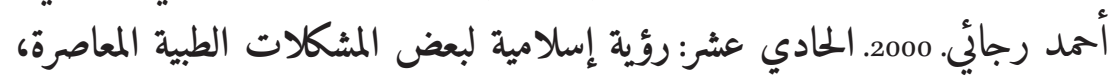

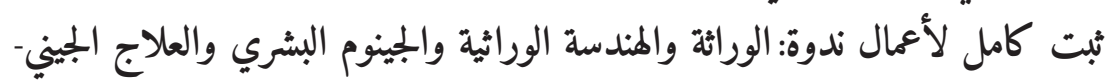

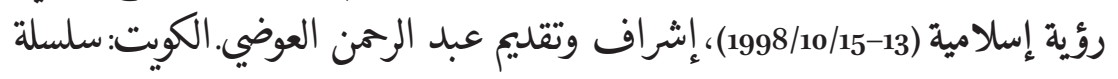
مطبوعات المنظمة الإسلامية للعلوم الطبية. الأشقر، عمر، وآخرون. 2001. دراسات فقهية في قضايا طبية معاصرة. عمان: دار النفائس.

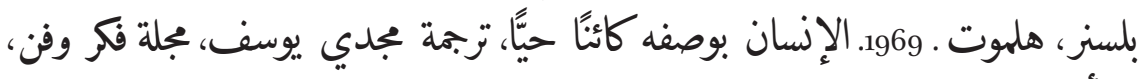
ألمانيا، عدد13. التفتازاني، سعد الدين. 1998. شرح المقاصد.تحقيق عبد الرحمن عميرة، تصدير صالح موسى شرف، بيروت: عالم الكتب. ستبع 
التفتازاني، سعد الدين. ـد.ت. شرح التلويح على التوضيح. مصر:مطبعة صبيح.

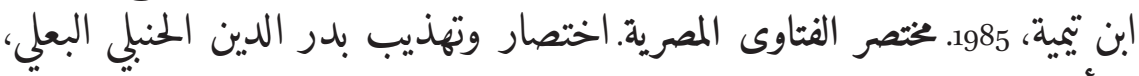
أشرف على تصحيحه عبد المجيد سليم، بيروت:دار الكتب العلمهية. ابن الجوزي، 1989. أحكام النساء.تحقيق زياد حمدان، بيروت:دار دار الفكر.

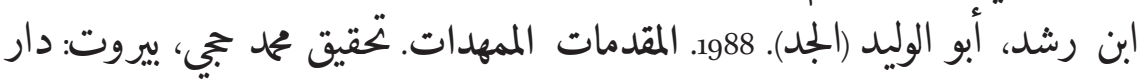

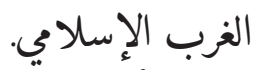
ابن رشد، أبو الويد. 1998. تلخيص الإياسة لأفلاطون (محاورة الجمهورية). بيروت:دار الطليعة. الجابري، محمد عابد. 2014. العقل الأخلافي العربي.بيروت: مركز دراسات الوحدة العربية.

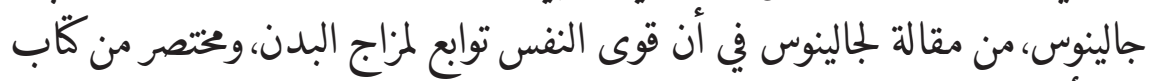

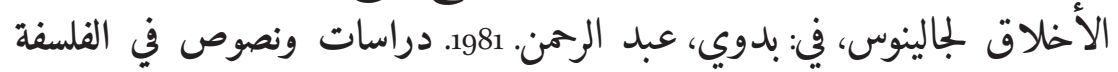

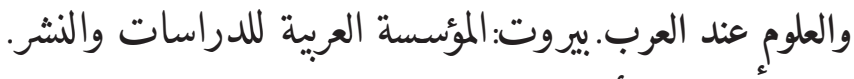
الجندي، أحمد رجائي. 2000. الحادي عشر: رؤية إسلامية لبعض المؤسية المشكلات المربة الطبية

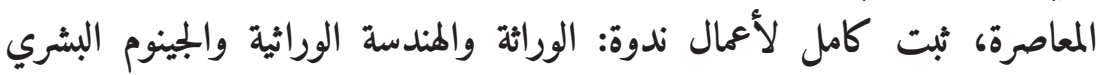

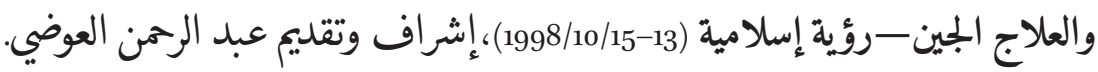
الكويت: سلسلة مطبوعات المنظمة الإسلامية للعلوم الطبية.

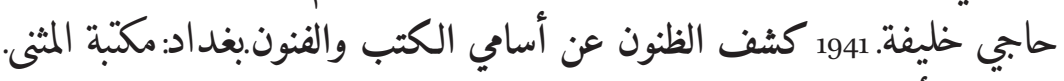

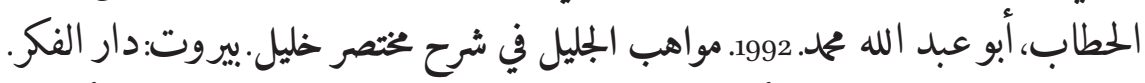

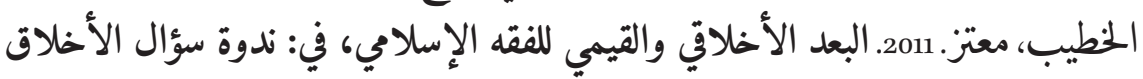

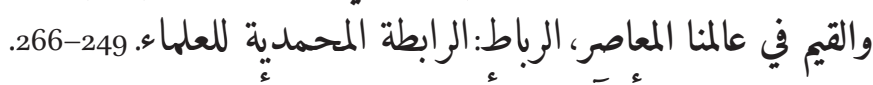

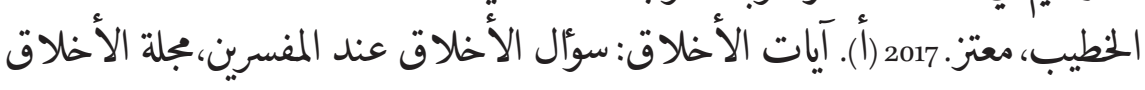

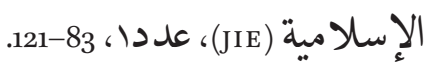

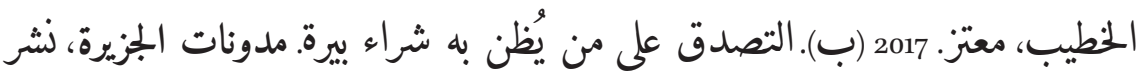

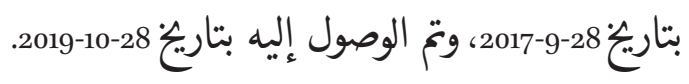

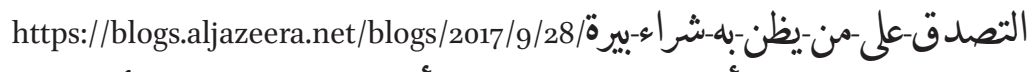
الخطيب، معتز. 2018 (أ). نهو قراءة منظومية أخلاقية للفقه، مجلة الأخلاق الإسلامية )(JIE) عدد 2، 1-27. 


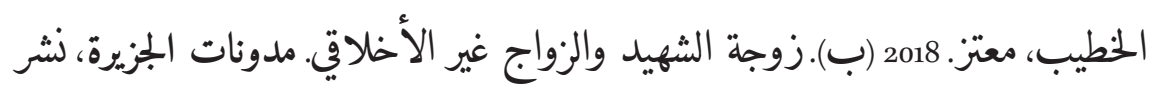

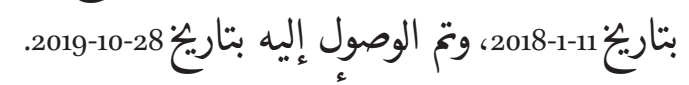

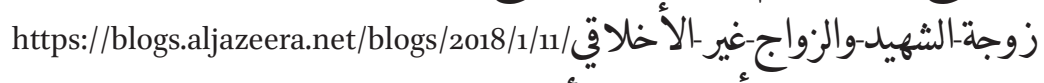
الحطيب، معتز. 2019 (أ). الحدود الأخيلاقية للتدخل الجينين: النقاش الفلسفي والفقهي

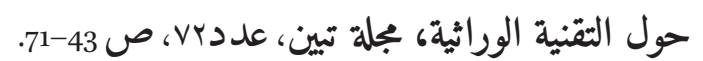

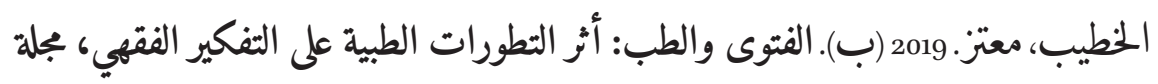

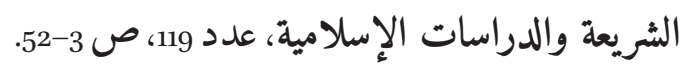

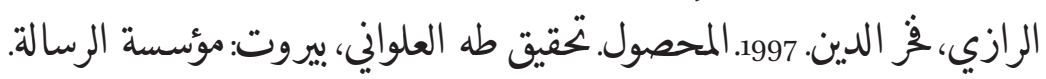

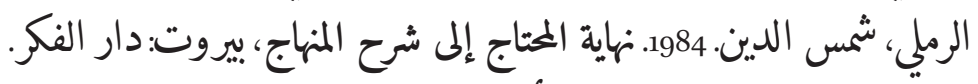

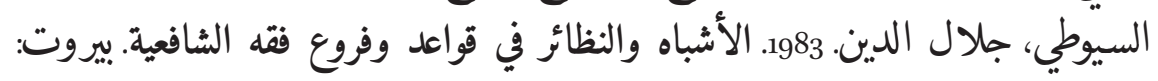
دار الكنب العلهية.

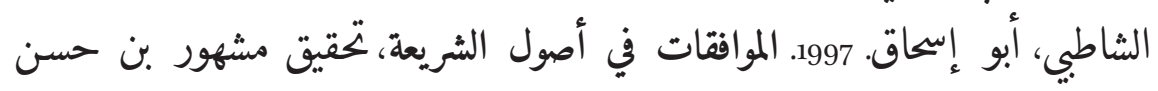
سلهان، (السعودية: دار ابن عفان. الشبراملسي، نور الدين. 1984. حاشية على نهاية المحتاج إلى شرح المنهاج للرملي. بيروت: دار الفكر.

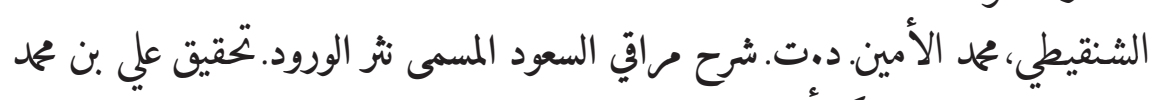
العمران، إشراف بكر أبو زيد، الرياض: اضئ دار عالم الفوائد. الشهرستاني، عبد الكريع. 2009. نهاية الإقدام في علم الكلام. شتحقيق ألفريد جيوم، القاهرة: مكتبة الثقافة الدينية.

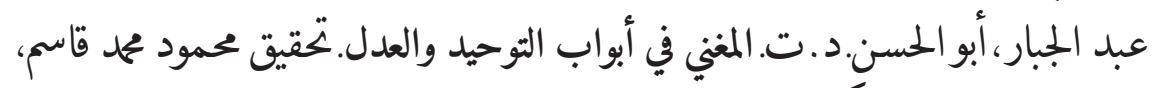

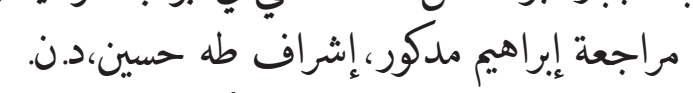

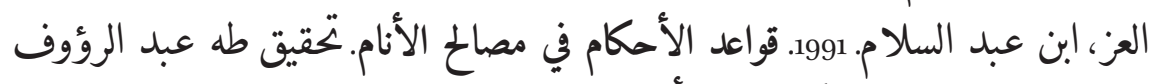
سعد. القاهرة: مكتبة الكليات الأزهرية.

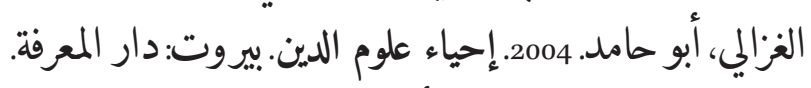

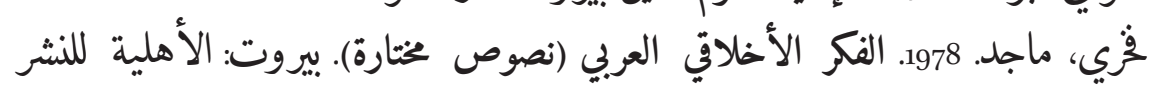
والتوزيع. 


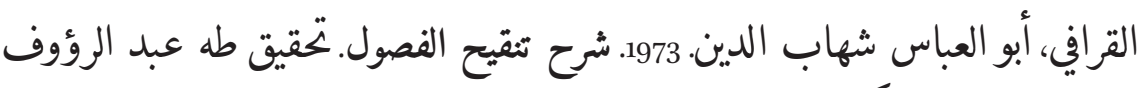
سعد.بيروت: شركة الطباعة الفنية المتحدة.

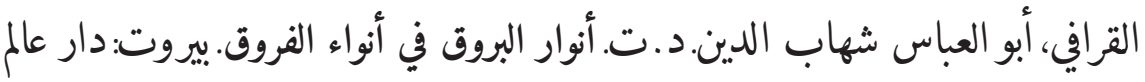

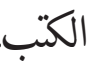

اللحجي، عبد الله بن سعيد. 188هـ. إيضاح القواعد الفقهية لطلاب المدارس الصولتية. القاهرة: مطبعة المدني. الماوردي، أبو الحسن. 1986.أدب الدنيا والدين. بيروت: دار مكتبة الحياة.

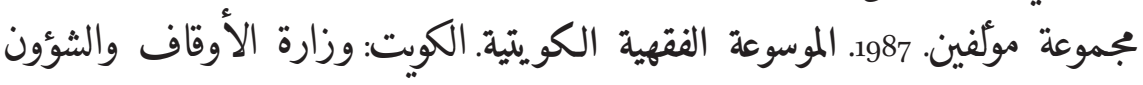
الإسلا مية، طباعة ذات السلاسل سل.

مسكويه، أحمد بن محم.د ت. تهذيب الأخلاق وتطهير الأعراق. تحقيق ابن الخطيب. القاهرة: مكتبة الثقافة الدينية. موسى، محم يوسف. 1953. تاريخ الأخلاق. القاهرة: دار الكّاب العربي.

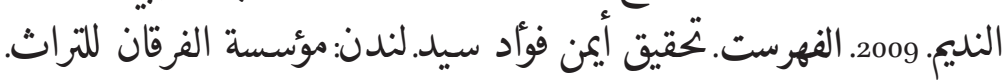
النشي، عجيل جاسم. 2000. الوصف الشئي للجينوم البشري والعلاج الجيني، في:

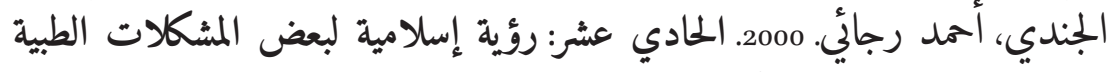

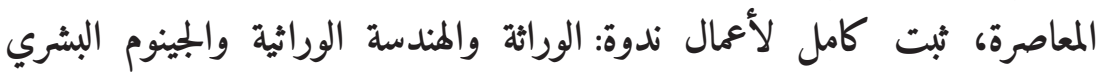

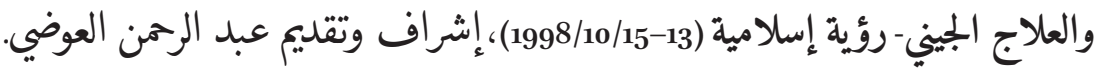
الكويت: سلسلة مطبوعات المنظمة الإسلامية للعلوم الطية الطبية.

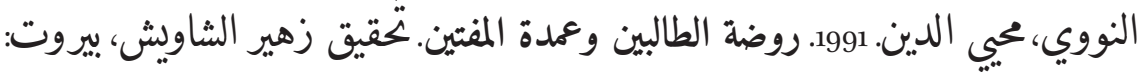
المكتب الإسلامي.

Al-Khatib, Mutaz. 2019. "The Ethical Limits of Genetic Intervention: Genethics in Philosophical and Fiqhi Discourses," in Islamic Ethics and the Genome Question, ed. Mohammad Ghaly, Leiden: Brill.

Chapman, Audrey. 1998. "Ethics and Human Genetics," Society of Christian Ethics, 18: pp. 293-303.

Draz, M. A. 2008. The Moral World of the Quran, trans. by Danielle Robinson and Rebecca Masterton, London: New York: I.B. Tauris \& Co Ltd.

Habermas, Jurgen. 2003. The Future of Human Nature. UK: Polity Press.

Kaye, Howard L. 1992. "Are We the Sum of Our Genes?" Wilson Quarterly, 16: 2, pp. $77^{-84}$ 
Peters, Ted. 1997. Playing God? Genetic Determinism and Human Freedom. New York: Routledge.

Peters, Ted. ed. 1998. Genetics: Genes, Religion, and Society. Cleveland:The Pilgrim Press. Schofield, Malcolm. 2013. "Cardinal Virtues: a contested Socratic inheritance," in Plato and the Stoics. ed. A. G. Long. Cambridge: Cambridge University Press.

Simmons, Paul D. 1983. Birth and Death: Bioethical Decision Making. Westminster Press.

Walzer, Richard. 1962. Greek into Arabic: Essays on Islamic Philosophy. Cambridge, Massachusetts: Harvard University Press. 